\title{
HUMAN ACTIVITIES AND FLOOD HAZARDS AND RISKS IN THE SOUTH WEST PACIFIC: A CASE STUDY OF THE NAVUA CATCHMENT AREA, FIJI ISLANDS
}

\author{
Katalaine Duaibe \\ A thesis \\ submitted to Victoria University of Wellington \\ in partial fulfillment of the requirements for the degree of \\ Master in Science in \\ Physical Geography
}

School of Geography, Environment and Earth Science

Victoria University of Wellington

2008 


\section{Abstract}

Human activity is increasingly becoming a factor contributing to 'disasters' that occur worldwide. As evident in the Asian Tsunami of 2004, the high levels of loss of life and livelihood, and damage to property were largely due to the population density and human development of the physical landscape of the stricken region. The magnitude of natural hazards coupled with the high population density and low levels of development can have disastrous or catastrophic impacts on a nation as a whole, especially in small island states. Furthermore, the lack of governance structures, legislative compliance, and regulatory land use and planning coupled with the perception of risk of the general public, can all contribute to the magnitude of disasters. The flood plains of Navua, a small rural town outside of Fiji's capital and prone to all types of flooding, are explored to determine the extent to which human activities impact on the magnitude of flooding and flood damage. Human activities such as land degradation, deforestation of catchment areas, increased population density along the Navua riverbanks inadequate land use planning, zoning, and control of flood plain development; and inadequate drainage, and management of discharges are examined when determining the factors that have contributed to the increased incidence of flooding of the past 100 years until 2004. The evolution of different governmental approaches to hazard and risk management in Fiji is also explored. It is observed that while considerable progress has been made to address the factors causing high risk, there is still an emphasis on hazard mitigation rather than risk reduction. A model framework for flood risk management is referred to, where the elements at risk are the land-use characteristics of the Navua Catchment. As such, part of the treatment of risks is seen as requiring adequate risk management standards that fit into the broader 'all-hazards management’ approach adopted by the Pacific Island Nations including Fiji. 


\section{Acknowledgements}

There are a number of people I would like to thank who have been instrumental throughout the process of this thesis. My gratitude and thanks to my supervisor Professor Michael Crozier for offering to be my supervisor on the very first day I set foot into the School of Geography, Environment and Earth Science to enroll in the Master in Science programme. Michael's insights, guidance and experiences were a rich resource to draw from and consult throughout this whole process.

In the Fiji Islands, my sincere gratitude goes in particular to:

a) The Pacific Islands Applied Geoscience Commission (SOPAC) for hosting me in the two month period of research in Suva as well as for access to their resource and data. Particular thanks to Mosese Sikivou, Michael Bonte and the staff of the Community Risk Programme

b) The Director, Mr Joeli Rokovada and Research officer Mr. Vuliame Tuimani of the Fiji National Disaster Management Office.

c) Mr. Melchior Mataki of the University of the South Pacific's, Pacific Centre for Sustainable Development; Mr. Atu Kaloumaira and Mr. Luke Ratukalou for sharing their knowledge and allowing me to draw from their rich experiences with the agriculture sector and watershed management programme in the Fiji Islands.

d) The technical agencies of the Fiji Mineral Resources Department, the Fiji Meteorology Services, the GIS specialists of the Fiji Department of Forestry and SOPAC and the many specialists of various fields who contributed in some way to the thought process.

In New Zealand, I acknowledge my colleagues from in the Physical Geography and Environmental Studies programme, whose different backgrounds and perspectives created a rich environment for interaction and learning. Particular thanks to Fa'asalele Malo for his feedback on my first draft. My sincerest thanks and appreciation to my New Zealand 'family' (you know who you are) who were constantly on the look out for my progress and wellbeing during my period of study; and to NZAID for their scholarship funding to complete this Post graduate Masters degree. 


\section{Contents}

Abstract

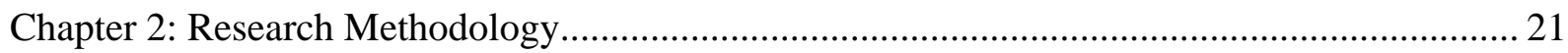

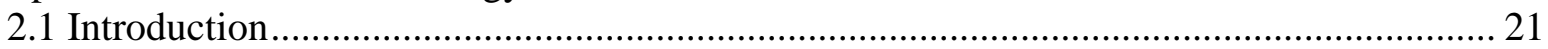

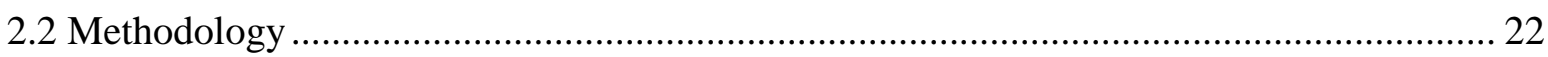

2.2.1 Objective 1: To establish the wider hazard context within Fiji ................................. 22

2.2.2 Objective 2: Evolution of flood hazard and risk management in the course of

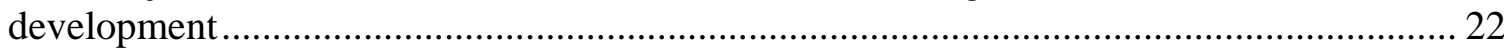
2.2.3 Objective 3: To analyse a recent case study (2004 Navua Flood) to determine the role of elements at risk, vulnerability and management in explaining flood losses .................... 24 2.2.4 Objective 4: To examine critically the governance structure for hazard management in

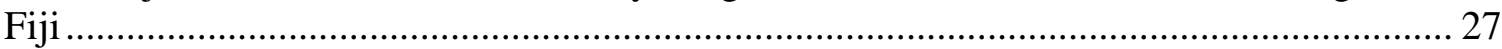

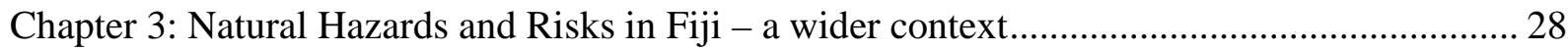

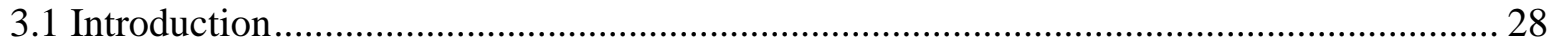

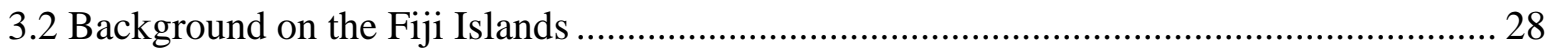

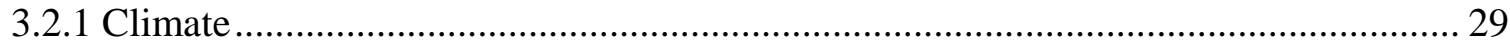

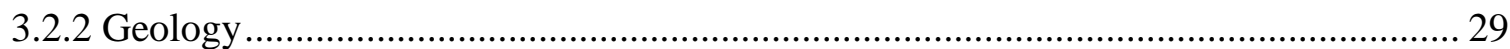

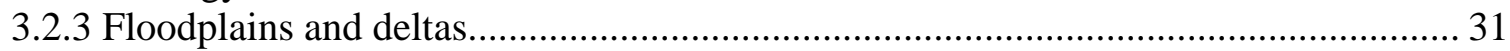

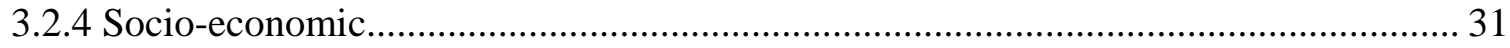

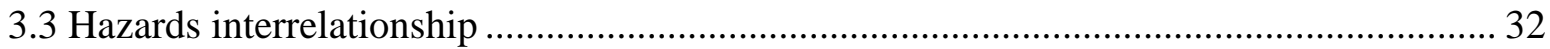

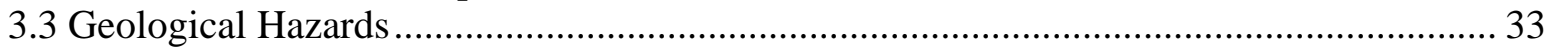

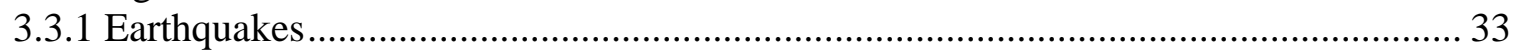

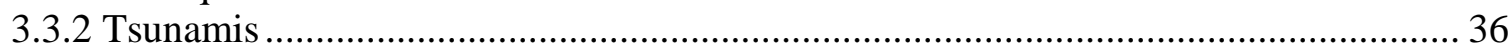

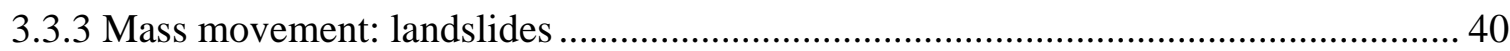

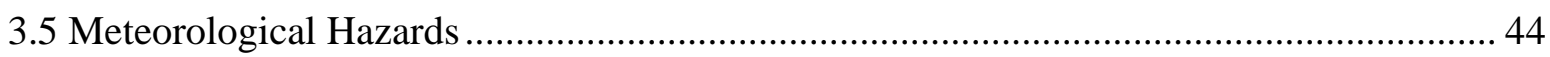

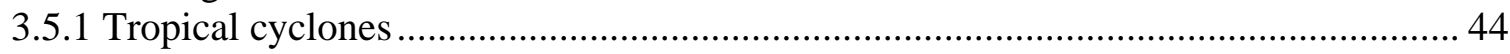

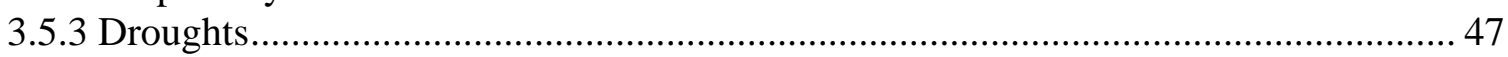

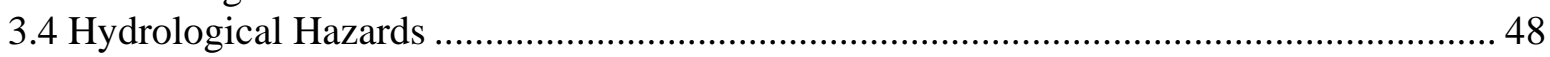




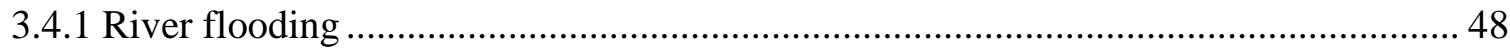

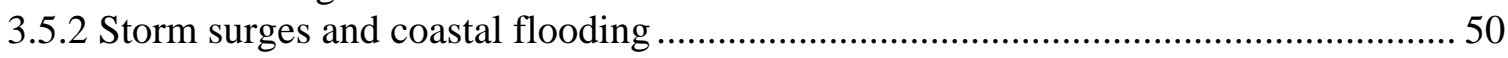

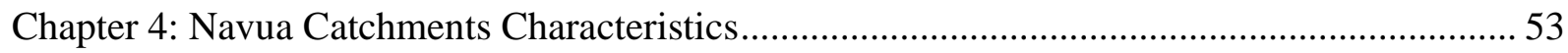

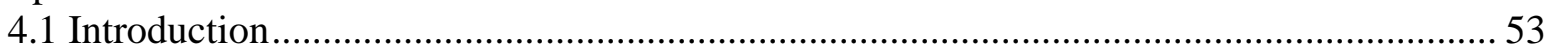

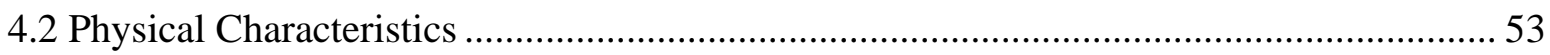

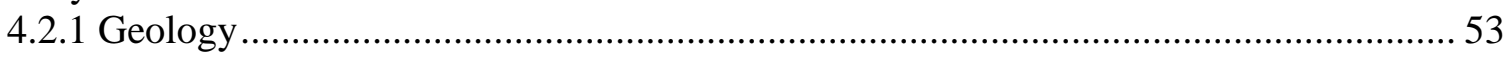

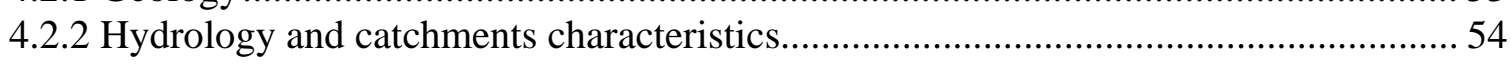

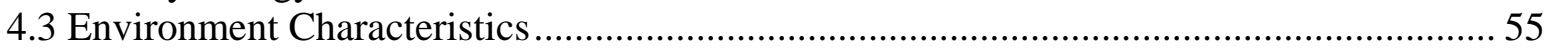

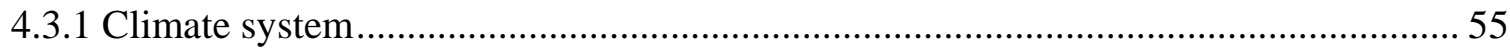

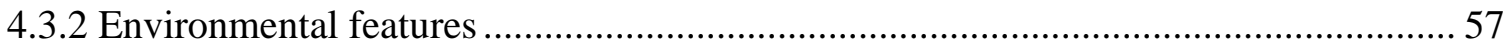

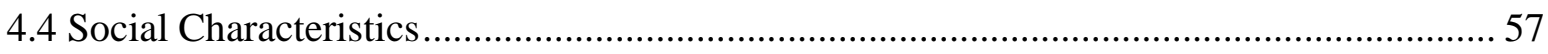

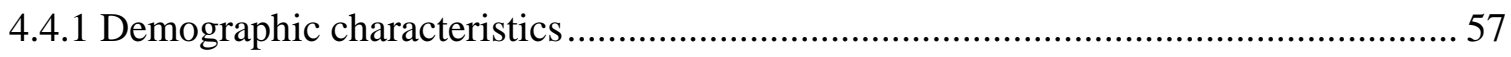

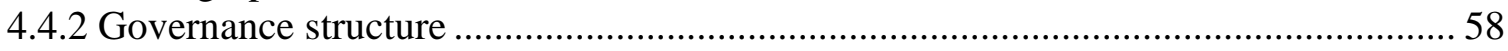

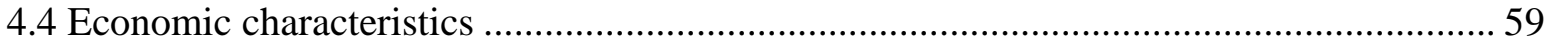

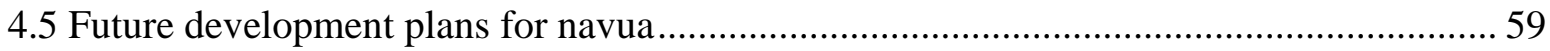

Chapter 5: Navua Catchment's Evolution of Flood Hazards and Risk Management................... 60

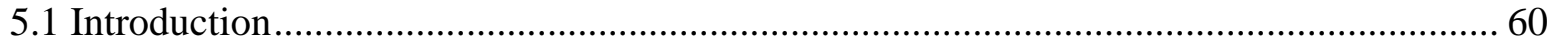

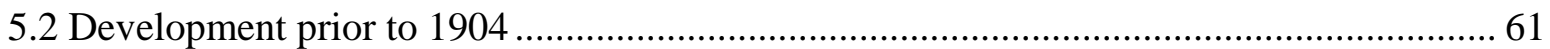

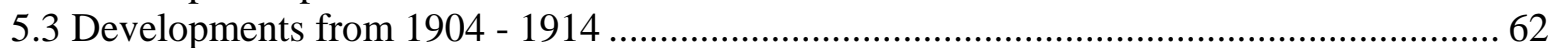

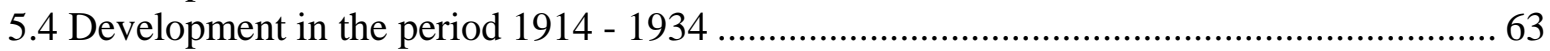

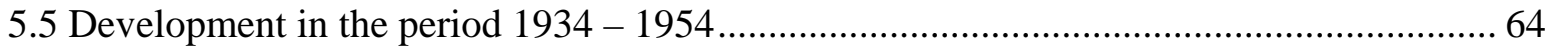

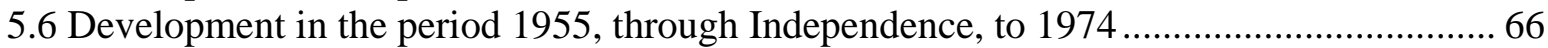

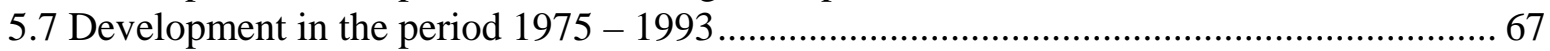

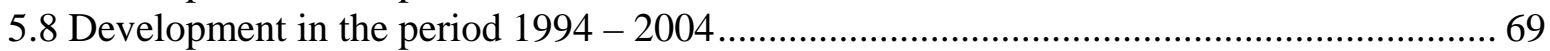

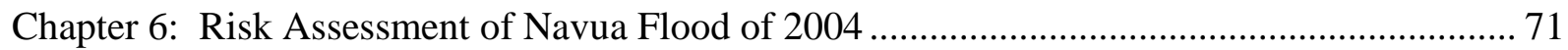

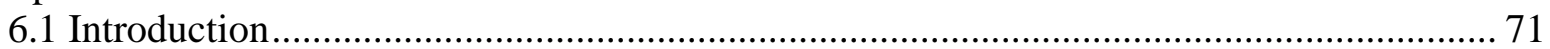

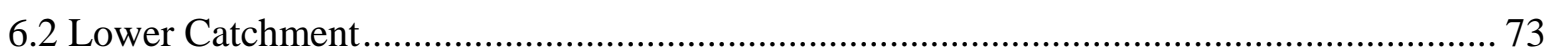

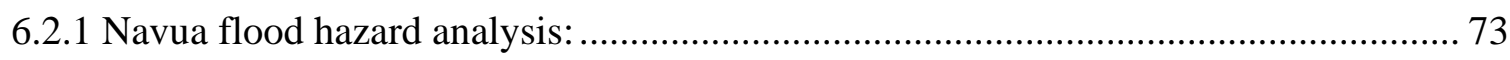

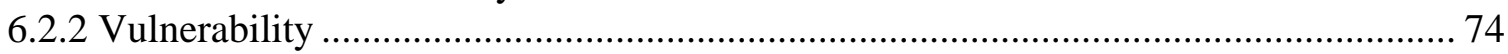

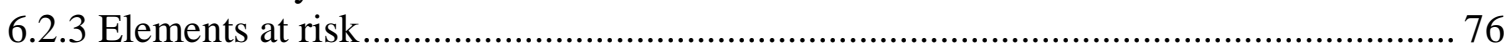

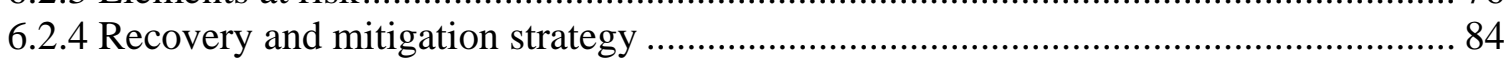

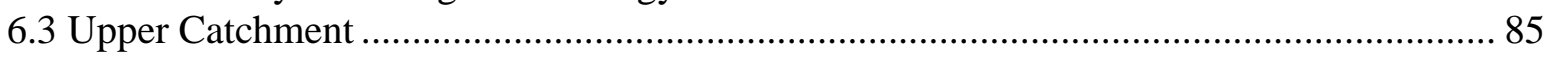

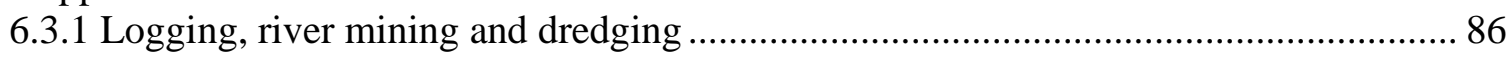

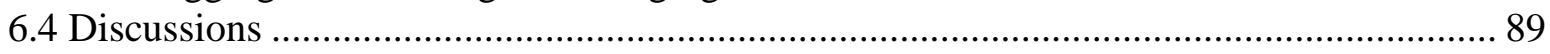

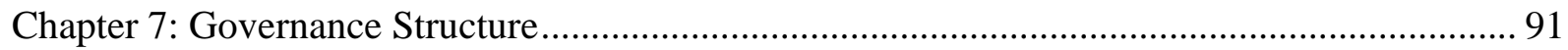

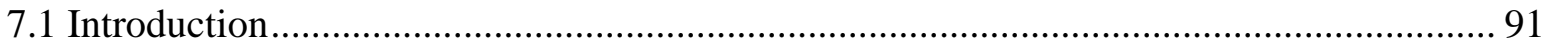

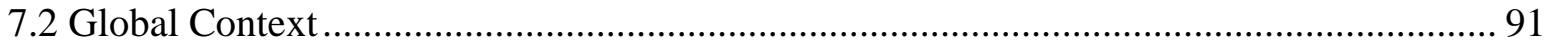

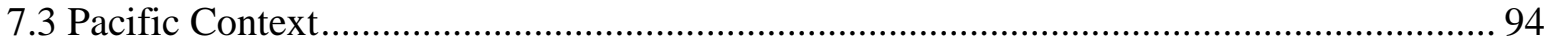

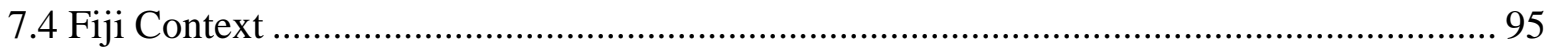

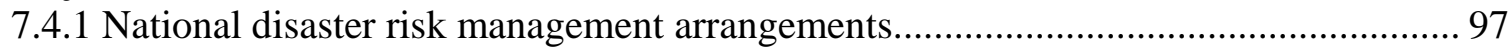

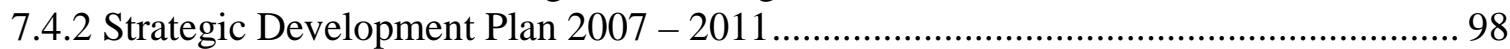

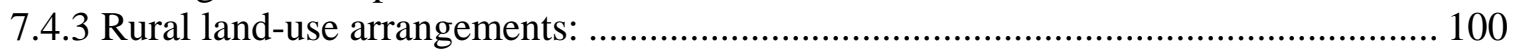




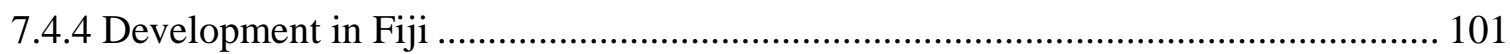

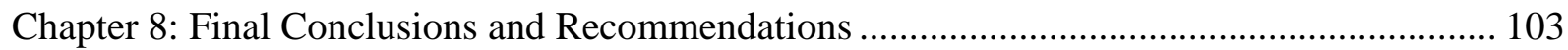

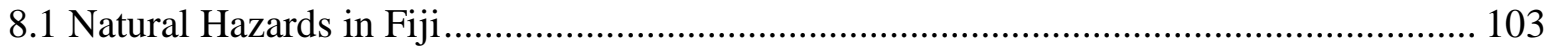

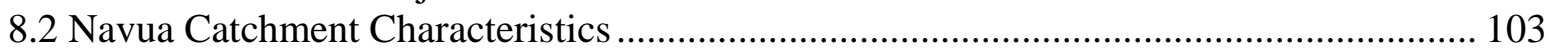

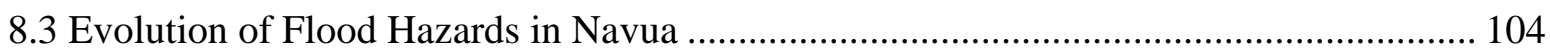

8.4 Flood Risk Assessment of Navua Flood ....................................................................... 104

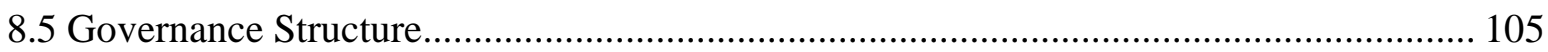

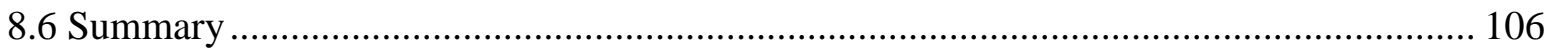

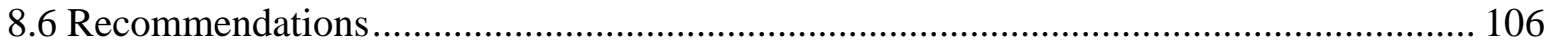

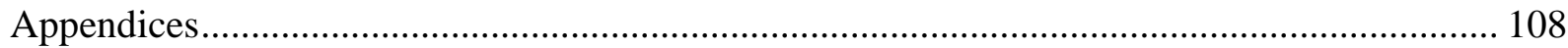

Appendix 1: List of Surveys Conducted for the Navua Region ............................................. 108

Appendix 2: List of Participants of Navua Flood Response Planning Workshop................... 109

Appendix 3: Participant Information Sheet and Consent Form for the Data Gathering On

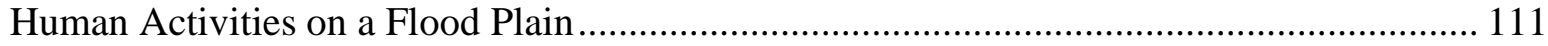

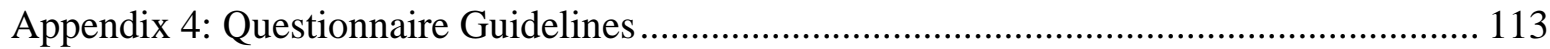

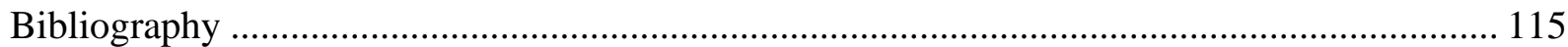




\section{List of Figures}

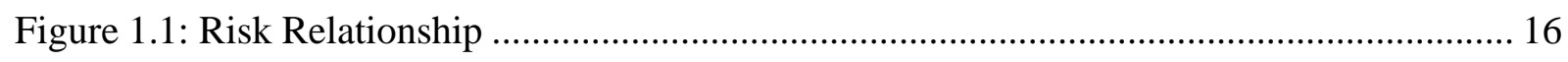

Figure 2.1: Flood Risk Management Model .............................................................................. 24

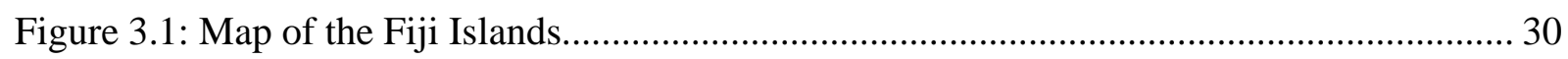

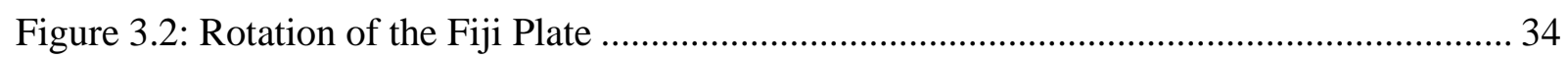

Figure 3.3: Seismic Activity in the Fiji Islands from 1881 - 2001_........................................... 35

Figure 3.4: The extent of impact of the tsunami waves in 1953................................................ 38

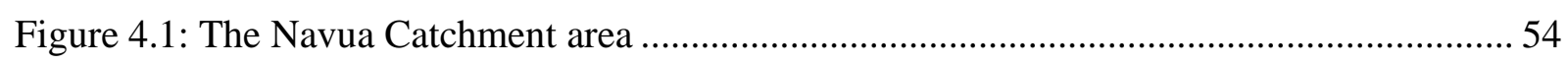

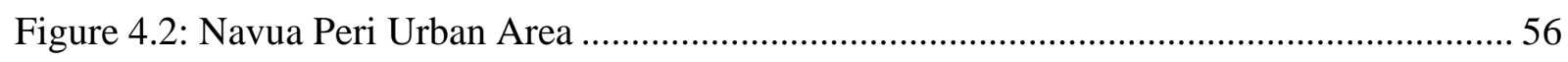

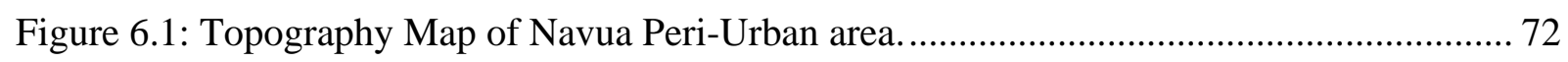




\section{List of Tables}

Table 3.1: Primary and Secondary Natural Hazards of the Fiji Islands (Adapted from Gregg and

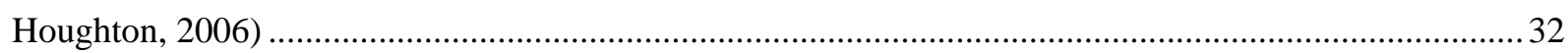

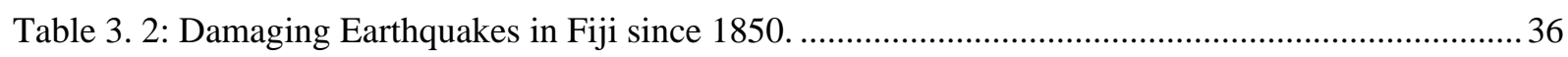

Table 3.3: Loss of Lives due to Tropical Cyclones and Relative Damage of Event ...................................46

Table 3.4: Storm Surges that have occurred during a tropical cyclone in Fiji........................................... 51

Table 4.1: Population Statistics of the Provinces and Peri-urban area.......................................................... 58

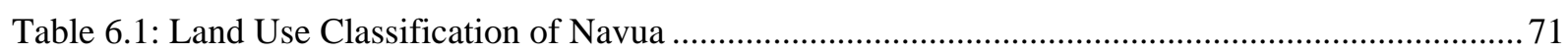

Table 6.2: Vulnerability factors identified by six groups of Navua community leaders in Aug 2007 ....... 74

Table 6.3: Estimated Damage of Losses to Households from 2004 Flood .................................................. 76

Table 6.4: Civic and Community Estimate Loss / Damage from 2004 flood............................................... 78

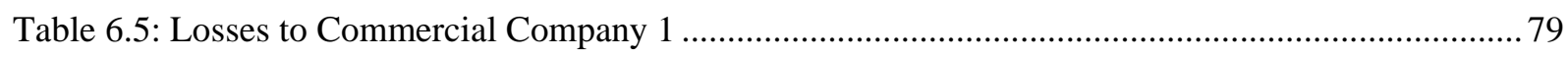

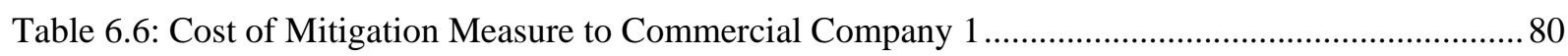

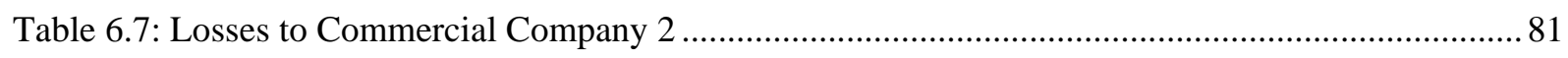

Table 6.8: Total Losses to Commercial Agricultural Land Use in 2004 Flood ........................................... 81

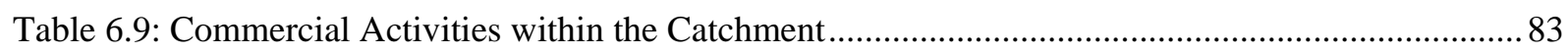

Table 6.10: Cost and Benefits of Upper Catchment activities over flood losses of Navua ........................ 89

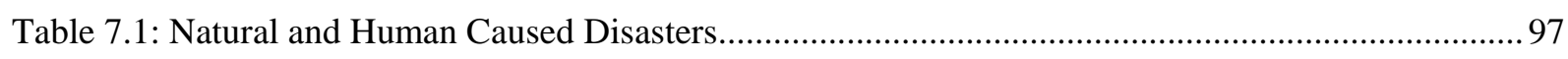

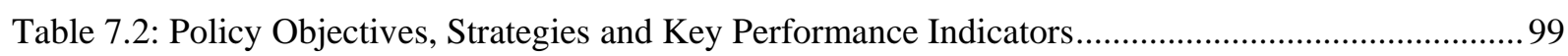




\section{List of Plates}

Plate 3.1: The displacement of the Suva wharf due to the earthquake in Suva in 1953............... 39

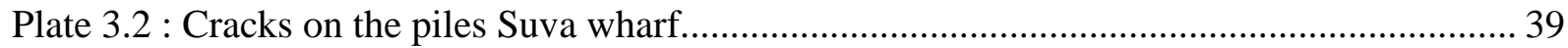

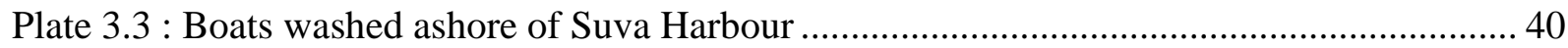

Plate 3.4 : Landslide on vegetation cover for subsistence plantations ........................................... 43

Plate 3.5 : Debri flow into the lowland floodplain....................................................................... 43

Plate 3.6: Extent of landslide in Navua Catchment area in reference to height of a human being43

Plate 3.7 : Steep topography coupled with weather system makes the upper catchment of high

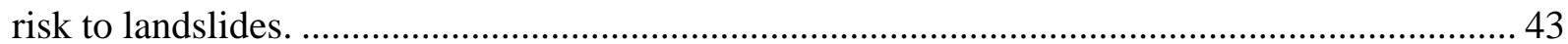

Plate 3.8 : Debri deposition downstream of the Navua River.................................................... 44 


\section{Chapter 1: Introduction and Central Question of thesis}

\subsection{Introduction}

Human activities are diverse and a key component in influencing the level of hazard ${ }^{1}$ and risk ${ }^{2}$ presented by the physical environment. The relationship between human activities, flood hazards and risks is an area of particular interest given the arguments surrounding climate change, and the increasing productivity of human populations and stresses on the physical environment that such developments initiate. In fact, the alteration of the physical environment, be it through natural processes or through human activities will always have some sort of impact, whether negative or otherwise. The impact of natural hazards is no longer considered a function of geological processes or climatic factors alone. There are numerous examples of human activities and modification of the natural and physical environment that have increased the risks of natural hazards. For instance in Italy, the impact of landslides is greater in the residential areas on hill tops than in less populated areas of the Italian landscape (Guzzetti et al., 2005). The increased risks of damage from earthquakes and volcanoes, loss of life and livelihood in Indonesia is higher than ever before because of the density of population and increase in the built environment (Boer and Sanders, 2002; Thornton, 1996). In small island states, predominantly in the Pacific, tropical cyclones alone have the potential to dent an entire economy particularly where natural resources are the mainstay of the economy (McKenzie et al., 2005) ${ }^{3}$. In places like New Orleans, its structural measures such as the levees designed for a 100 year return period flood in magnitude, failed in the face of Hurricane Katrina, a category 3 hurricane. The failure of the structural measures has been attributed to the engineering of the levees and the sociopolitical influences at the time of their construction which failed to address its weaknesses and implement measures beyond the 40 year life span of the levees (van Heerden, 2007).

\footnotetext{
1 'Hazard' is the probability of occurrence of a damaging event. (Crozier and Glade, 2004).

2 'Risk' is the probability of adverse consequences occurring as a result of the hazard (Crozier and Glade, 2004).

3 The case of Cyclone Heta in Niue in 2004, is a good example of vulnerable economies. McKenzie (2005), report in their cost benefit analysis of the impact of natural disasters on development in the Pacific, that the cost of damage and losses wrought by Cyclone Heta on Niue’s Public Sector amounted to NZ\$25.7million, which was more than double the Gross Domestic Product (GDP) of Niue for 2002. (McKenzie, 2005)
} 
Flooding, whether by natural causes or induced and/or aggravated as a result of human activities is one of the most threatening hazards for human societies. It is also one of the most obvious hazards that is not restricted to catchments and coastal areas but also within cities due to the failure of damns, levees or burst pipes and improper and/or irregular maintenance of drainage systems. Unlike some hazards, flooding is not limited by the geology or other physical characteristics of an area nor is it solely due to climate and atmospheric conditions. Rather it is an event that any country can be subject to through natural causes or induced by human activities (Haque, 2005).

Flooding is threatening in a number of ways: in terms of the financial losses to a nation and individuals within it, loss of lives, and, in some societies, their livelihoods. In addition, the occurrence of water-borne diseases are often associated with this hazard. Problems may arise if mitigation measures taken by a local area to protect its property are uncoordinated, as my research results will show. In addition, flooding may also cause the loss of aesthetic values or environmental values ${ }^{4}$. The two main types of natural flood hazards are river flooding and coastal flooding, although intense rainfall may produce localized 'flash' or surface flooding. River flooding is when a river overflows its banks and coastal flooding is when the sea inundates a stretch of coastline (McGuine et al., 2002). Human induced flooding may include the bursting of damns or the failure of dykes, and the bursting of drainage pipes and so forth (Guzzetti et al., 2005; Wheater, 2006) .

Structural measures on rivers and coasts such as bridges, damns and levees are conventionally designed to cope with all floods up to the 100 year return period flood in magnitude. This has been a common approach to flood hazard and risk management in the past 100 years. This approach is applied by Fiji towards the management of flood hazard and risk through the implementation of its watershed management programme for its major rivers (Yachiyo Engineering Co., 1998). However, the validity of this approach has been increasingly disputed

\footnotetext{
${ }^{4}$ Aesthetic or environmental values are basically values of people that directly involve features of the natural environment such as trees, views, animals or plant species as opposed to values that are a result of the economic benefits that could be derived from the use of the environment such as tourism. Such environmental values have resulted in the rise in environmental legislation, policies and international agreements of the past 30 or so years (Gregory, 1998).
} 
with the recognition of climate change and the increasing human activity along rivers and within the catchment (McGuine et al., 2002). Historical river discharge records alone are not enough to determine flood trends because of factors such as human modification including the rechanneling and other changes to river hydraulics as well as increasing sedimentation of riverbeds from deforestation, agricultural activities and other non-climatic factors such as river dredging. All these activities have an effect on the flow regime and river levels (McGuine et al., 2002).

\subsection{Human activities and flood hazard}

The human influence on river behavior and flooding has been extensively described from many parts of the world. In the Mississippi River for example, increasing flood stages have been attributed to engineering works (Criss and Shock, 2001). Criss and Shock (2001), state in their study that channeling and levee construction are primarily responsible for the trend of steadily increasing floods (Criss and Shock, 2001). Their findings were based on observing river discharge data over a 140 year period and showed that the most severe effects are found along the stretches with wing dams and levees where as stretches with dams are less severely affected. They conclude that human engineering rather than natural forces have deepened and narrowed the major rivers of North America and that impacts such as the loss of islands, wetland habitat, and flood storage capacity resulting from major river engineering projects are well documented (Criss and Shock, 2001).

Rivers in Brahmaputra-Barak and Ganga basins of India are another example. Severe erosion in this area is governed by the discharge in the river, bed slope, sediment flow and composition of bed and bank materials. Deforestation of upper catchments and hills lead to increased sediment load in these rivers. River erosion in turn causes a loss to the land resources (Mohapatra and Singh, 2003). Other causes of natural and anthropogenic flooding in India include:

- Transport of sediments by rivers during floods;

- Damn break;

- Encroachment of floodplain areas;

- Presence of several structures and absence of proper regulations for maintenance which creates artificial floods; 
- Flash floods particularly in hilly regions where the bed slope is very steep;

- Snowmelt through glaciers that hold large quantity of bound water which when released suddenly causes severe flooding;

- Cyclones and passage of storm over river basin leads to severe flooding (Mohapatra and Singh, 2003).

Similarly, in Nepal, it's been discovered that anthropogenic activities such as mining and road building have aggravated mass wasting and interventions such as weirs and barrages lead to aggradations, exacerbating the impact of flooding due to a congestion of the drainage (Dixit, 2003). In Italy, on the other hand, it is the failure of structural measures that have caused the flooding. These measures include the failure of levees, check dams and dams (Guzzetti et al., 2005).

Other examples of how human activities have aggravated flood hazards and risks are through urbanization and agricultural activities. Canada's city of London in Ontario has had an increase in risk from river flooding in urban areas between 1974 to 2000 due to heavy urbanization in the watershed area of its upper Thames River . To mitigate flooding of the City, structural measures have been installed upstream. These structural measures include the dyked areas which have been reinforced, raised in elevation and extended (Nirupama and Simonovic, 2006). Other ways in which urbanization can aggravate flooding is through urban storm water runoff that when combined with burst sewers, as pressure builds up under extreme conditions, causing manholes to blow open and flooding to take place (Nirupama and Simonovic, 2006). In the United Kingdom, to mitigate the local scale efforts of urban development, engineering solutions have been routinely adopted to reduce flood peaks through the provision of detention storage (Wheater, 2006).

A final example of human activities impacting on flood hazards is through agricultural and forestry practices on soil structure (Dull, 2007; Wheater, 2006). Debris flow and sedimentation from deforestation activities are quickly initiated during heavy rainfall, often blocking river channels or hindering the flow regime (Dull, 2007; Papankova et al., 2006; Wheater, 2006). Sometimes, the high sediment loading of river channels causes a bigger portion of the 
catchments to be inundated than it would with water discharges alone. Consequences include blocked water channels and/or pollution of water sources (Tokalauvere and Biukoto, 2003). Surface run-off from farmland is another matter often causing pollution of natural water storage such as lakes, rivers and streams (Papankova et al., 2006; Wheater, 2006). Reclamation of wetlands and alteration of floodplains by private property owners, particularly where regulations are absent, also alter the flow regime of floodwaters with repercussions felt in other areas of the community or the catchment (Mohapatra and Singh, 2003).

\subsection{Competing paradigms}

The discipline of geography has evolved over the years in the way different paradigms frame its approach (Castree et al., 2005). In the early days, geography was largely explored through time, by tracing the succession of major paradigms; to the latter where given the context of nature, history or philosophy, the focus was on human geography (Castree et al., 2005). Now, the discipline is one that is hotly contested and can no longer be addressed as a single discipline but rather one which is holistic, integrative and broad. However across the stripes of Geography (human and physical), are fundamental issues which underlie and cut across it. Such issues include the use of 'models' which vary from physical analogues and scale models to conceptual, box and arrow schematic diagrams and various forms of mathematical modeling (Demeritt and Wainwright, 2005). A few of these paradigms that underlie this thesis are addressed below.

The reductionism methodology is one whereby understanding is at a small scale and is extrapolated upwards to provide explanations at the large scale. Emergent theorists reject this fundamental notion by reductionists and argue that explanations are not entirely dependant on scale, but that a plurality of theories may provide the deepest understanding (Curry, 2005). Therefore in this situation, a physical geographer employing principles of emergence would therefore recognize that the relations between objects play a special role in the landscape and that the landscape form is contingent upon a number of influences which may not be amenable to reductionist explanations (Curry, 2005; Harrison, 2005). To some extent, this thesis will draw its approach from emergent theories. 
Using a different perspective, some geographers draw on the theory of Marxism for explaining spatial organizations. One such argument is that the uneven geographical development is an essential part of capitalism. "Urbanisation is thus the most visible manifestation of this process, which they argue arises as the profit seeking proclivities of producers lead to the dense spatial massing of units of capital and as a corollary of labour (Graham, 2005)”. To some extent this theory applies to this thesis in terms of what drives people to settle on floodplains. Explanations of risk based on the underlying notions such as Marxism is referred to as the 'structuralist' approach. In other words, it is the fundamental 'structures' of society that determines the opportunities and risks faced by an individual or community (Smith, 2004).

Historically, physical geography is the study of natural elements that constitute landscapes and is concerned with landforms, soils and biological elements and the effects of climate and weather (Castree et al., 2005; Harrison, 2005). Today it typically involves detailed processes often on a small scale and allied to sophisticated laboratory and field experiments, statistical treatment of the results and the application of computer modeling (Harrison, 2005). Acknowledging that the landscape is shaped by physical and human actions or processes, Rhoads (2005), argues that the relationship between process and forms is fundamental to geography (Rhoads, 2005). This thesis, in recognizing that the inter-relationships between human and physical processes strongly influence the level of hazard and risks, adopts a Rhoads approach.

Previously, the paradigm that underpinned flood risk management was a 'behaviouralist' paradigm (Smith, 2004). This paradigm can be seen where flood risk management relates to a set of decisions and actions for flood protection based on an understanding of the hazard, which is essentially the behaviouralist approach (Schanze et al., 2006; Smith, 2004). Actions undertaken would involve design standards that would provide flood protection, assessed by scientific investigation. The behaviouralist approach is commonly equated with the 'technical fix approach' (Smith, 2004). It has been argued that while such solutions are achievable, they are unsustainable (Schanze et al., 2006). A good example is the flood levees of New Orleans which burst its capacity during Hurricane Katrina in 2005 (van Heerden, 2007) 
The United Nations International Strategy for Disaster Reduction (UNISDR) has taken an integrated multi-hazard approach to disaster risk reduction. The approach was adopted as a pragmatic response to the different disaster risk reduction capabilities of the various nations, advocated for in the lead up to the Second World Conference on Disaster Reduction (UNISDR, 2005). The outcome of the conference, a framework of guiding principles for risk reduction and management at national country level, underscores the generic concept of risk. "Disaster risk arises when hazards interact with the physical, social, economic and environmental vulnerabilities (UNISDR, 2005)”. UNISDR defines hazards as “a potentially damaging physical event, phenomenon or human activity that may cause the loss of life or injury, property damage, social and economic disruption or environmental degradation. Hazards can include latent conditions that may represent future threats and can have different origins: natural (geological, hydro-meteorological and biological) or induced by human processes (environmental degradation and technological hazards) (UNISDR, 2005)” and best conceptualized in the diagram below which is adapted from Crozier and Glade (2004).

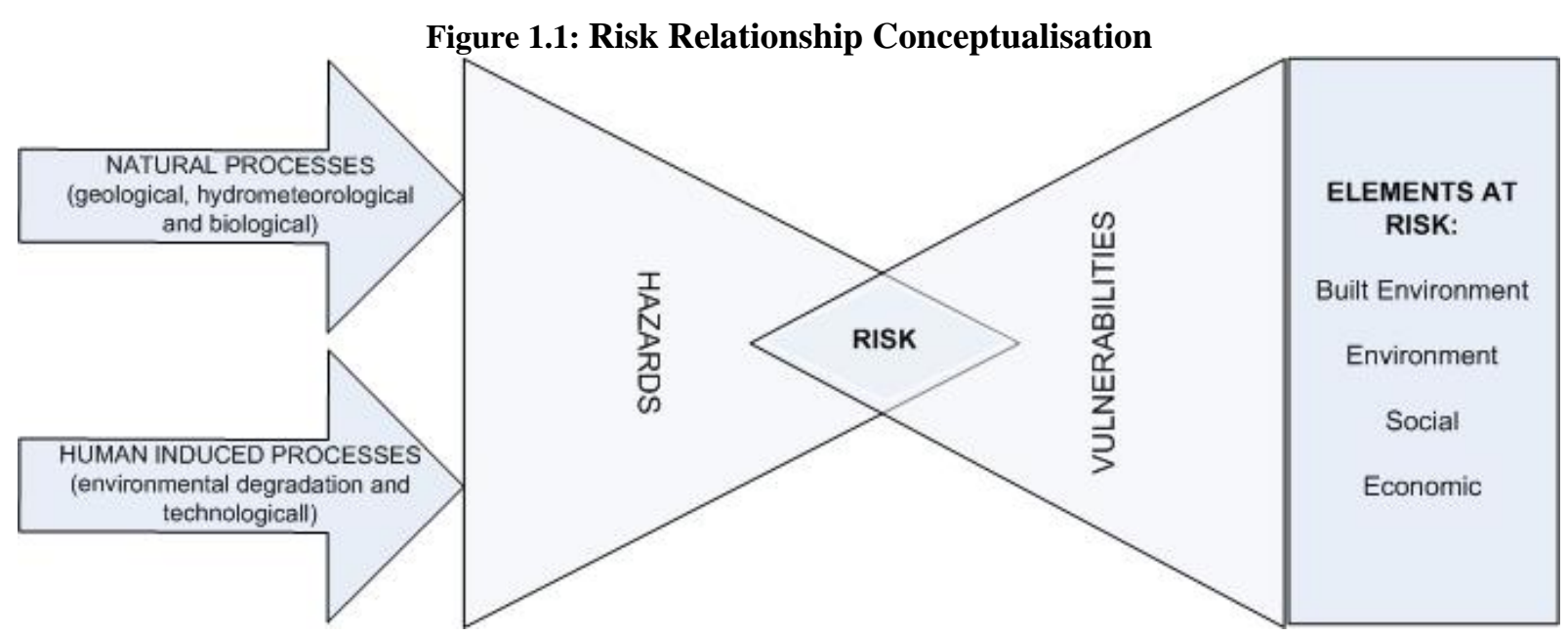

Source: Adapted from Crozier and Glade (2004) and using the UNISDR definition of disaster risks, diagram showing that the input of both natural and human induced processes posses' risks on the physical, social, economic and the environment of humanity. 
The Hyogo Framework for Action 2005 - $2015^{5}$ states that in order for risk reduction to be integrated and holistically approached; there needs to be an understanding of the generic risk equation including the principal factors that contribute to risks (UNISDR, 2005). Risks (R) = Hazards (H) + Vulnerability (V) + Elements at Risk (E)

This thesis is largely driven from a pragmatic point of view or; in that for policy to be effective, a compromise between both the structuralist and behaviouralist paradigms are both integral in formulating policy (Smith, 2004). To achieve such, the consideration of components of the generic risk equation above will be the underlying basis of this thesis.

\subsection{Research concept and focus}

Lonergran (2005) in her thesis investigates how the modeling of land use change in Navua, Fiji can improve vulnerability and adaptation to climate change impacts within Pacific Communities. Significantly for the current study, she identifies some areas of future research for Navua, one being the 'investigation of how flood hazard has been managed over the course of development' (Lonergan, 2005). As mentioned previously, flood hazard management in the past has been addressed from the behaviouralist paradigm. Mitigating measures for flood hazards have in turn reflected this paradigm through a 'technological fix' approach (Smith, 2004). This approach is claimed by some to be unsustainable (Schanze et al., 2006) and as clearly demonstrated in literature in the previous section, has also led to the initiation of flood hazards. 'Hazard', as clearly articulated by Crozier and Glade (2004), in a broad non-technical sense, is defined as those processes and situations actions or non-actions that have the potential to bring about damage, loss or other adverse effects to those attributes valued by mankind (Crozier and Glade, 2004). Risks on the other hand is the likelihood of adverse consequences occurring (Bogardi, 2006; Crozier and Glade, 2004; Penning-Rowsell et al., 2005).

\footnotetext{
${ }^{5}$ The Hyogo Framework for Action 2005 - 2015 Building the Resilience of Nations and Communities to Disaster is a strategic and systematic framework for reducing the vulnerabilities from risks to hazards of nations and communities. This framework is the outcome of the Second World Conference on Disaster Reduction and a strategy driven by the United Nations International Strategy for Disaster Reduction (UNISDR, 2005).
} 
The history of hazard and risk in Fiji need to be viewed in the context of development. Development is a broad term which denotes progress in a range of areas and has often been equated with economic growth (Kambhampati, 2004). This is however inadequate. While it encompasses economic growth, it also involves social and political progress as well as the fulfillment of basic human needs (Kambhampati, 2004). For the purposes of this thesis, this broader definition of 'development' will be treated in reference to temporal and spatial changes. Land use activities are examined within the context of flood hazard and risks. Land-use is a 'dynamic process, changing over time because of a number of factors, including increasing population, income changes, technologies, the general structure of the overall economy and political policies (Leslie \& Ratukalou, 2002)'. Hietel et al (2006), state that landscape history, which is unique to each landscape, is an important basis for understanding land-use / cover changes, as Lonergan (2005) also demonstrated in her thesis when she investigated how land use of the Navua peri-urban area has changed over time (Lonergan, 2005).

\subsection{Aim and objectives}

The aim of this thesis is to identify the inter-relationships between human activity, flood hazard and risks. This will be achieved by examining the record of flooding and its impact alongside the history of development in one region of Fiji, the Navua Catchment. A national context will also be established by characterizing the extent to which the country is subjected to hazards and the way in which governance structures have evolved to cope with the situation. There are four objectives to be met.

Objective 1: To establish the wider hazard context within Fiji;

Objective 2: To trace the evolution of flood hazards and risk management in the context of development within the Navua Catchment;

Objective 3: To analyse a recent case study (2004 Navua Flood) to determine the role of elements at risk, vulnerability and management in explaining flood losses; and

Objective 4: To examine critically the development of a governance structure for hazard management in Fiji. 


\subsection{Thesis structure}

This thesis is structured into eight chapters. Chapter 1 is essentially the introduction whereby the relationship between human activities and natural hazards is introduced and then further narrowed down to the relationships between human activities and flood hazards specifically. This is done by highlighting examples from around the globe whereby the human activities of 'modification' or 'mitigation' to protect from flood hazards have resulted in an increased risk of flooding. In doing so, the different paradigms and theories that exist within geography are explored and models of hazard and risk management highlighted to arrive at the theoretical position of this thesis. The chapter concludes with the central focus of this thesis.

Sequentially, Chapter 2 outlines the methodology utilized in this thesis and the reasons behind this methodology. To do so, each objective is outlined and the methodology explained. The methodology is both quantitative and qualitative and stated accordingly under each objective.

Chapter 3 specifically addresses the first objective of this thesis, which is the wider context of natural hazards within the Fiji Islands. To do so, a brief background on the physical geography and socio-economic characteristics of the Fiji Islands is provided to set the context for the natural hazards Fiji is susceptible to. This context is critical to demonstrate that natural hazards are inter-related in that a range of secondary hazards is often the outcome of a primary hazard. The chapter draws on specific case study of events to show the relationship of the hazards as well as the impact of the hazards on development at the time of its occurrence.

Chapter 4 and 5 fulfill the second objective of this thesis. Essentially, the second objective is to trace the evolution of flood hazard and risk over the course of development. To do so, Chapter 4 describes the characteristics of the Navua catchment. These characteristics are described in terms of its physical geography to its built environment. Chapter 5 focuses on the evolution of flood hazards and risks over the course of development as far back as 1904 to 2004 and how flood hazard and risks have been managed throughout this period.

Chapter 6 analyses the risks of the Navua Community in terms of the last big flood (2004) using the generic risk management equation of “risk = hazards + vulnerability + elements at risk". In 
doing so, the data collected on adaptation, economic costs of disasters, environmental impact assessments of river mining and dredging and risk perception of the Navua community is analysed and presented in this chapter. This chapter fulfils the third objective of this thesis.

Chapter 7 focuses on the current governance structure that is relevant to flood hazards and risks of the catchment area of Navua. The thesis concludes with recommendations in Chapter 8, in which a flood risk management model that is reflective of the changing paradigms of flood risk management is proposed, as demonstrated in the previous chapters. 


\section{Chapter 2: Research Methodology}

\subsection{Introduction}

The aim of this research is to identify the inter relationship between human activity, flood hazard and risks within the Navua catchment. One possible way to achieve this is to survey individual households, businesses, and essential services within the Navua catchment to determine in what way human activity or land-use development had aggravated flooding. However, upon arrival in Fiji I became aware that Navua was a region that had been surveyed thoroughly on numerous occasions, and that another survey would not draw the same enthusiasm as previous surveys, given the size of the population and the dynamics that is often characteristic of small communities. In addition, the uncertainty of the receptivity of the people of Navua that they were unaware of what had become of the data in the previous surveys (Appendix 1) conducted by researchers, institutions, and government. Given the resistance likely to be met by carrying out a further survey, it was decided that information would need to be obtained by other means such as:

a) Utilizing flood data gathered by research institutions on previous surveys;

b) Personal Communication with former public sector workers previously involved in development projects in the Navua area and on flood mitigation works in the greater Fiji Islands;

c) Access to data and personal communication with the Fiji National Disaster Management Office;

d) Workshop on flood hazard planning for the greater Navua area;

e) Chronological search with the National Archives of Fiji; and

f) Personal Communication with technical agencies namely the Fiji Meteorology Services and the Fiji Mineral Resources Department for geological based information. 


\subsection{Methodology}

The absence of reliable river discharge and velocity data of the past 100 years for the Fiji Islands makes it impossible to gauge quantitatively how much human activity has impacted on flood hazards and risks. The methodology employed to address the objectives is listed in the following sub-sections. These objectives are:

Objective 1: To establish the wider hazard context within Fiji;

Objective 2: To trace the evolution of flood hazards and risk management in the context of development within the Navua catchment;

Objective 3: To analyse a recent case study (2004 Navua Flood) to determine the role of elements at risk, vulnerability and management in explaining flood losses; and

Objective 4: To examine critically the governance structure for flood hazard management in Fiji.

\subsubsection{Objective 1: To establish the wider hazard context within Fiji}

Damage assessments within the Fiji Islands are coordinated by the National Disaster Management Office. To fulfill this objective, damage assessment data were collected from the National Disaster Management Office for the period in which records of disaster were collated. Damage assessments are done within three days of the event taking place. Damage assessment reports and key information go as far back as 1985 . However records of other hazard events that have taken place in history are kept by the relevant technical agency. Therefore, information on the wider hazard context of the Fiji Islands data were gathered through personal communication with the National Disaster Management Office, the Fiji Meteorology Services and the Fiji Mineral Resources Department. The inter-relationships between the hazards presented are done through literature review.

\subsubsection{Objective 2: Evolution of flood hazard and risk management in the course of development}

Records in the form of Fiji Government reports, newspapers, and other materials held with the National Archives of Fiji are explored for information on flood hazards and risks, damage and losses, relief responses to flooding, weather records, river discharges, national development 
initiatives and projects, and reports on land use, going as far back as 1904. Yeo (2007), constructed the biggest flood record of any Fiji River; 100 year flood record of the Ba river, by exploring records held at the Rarawai Sugar Mill in $\mathrm{Ba}$, on flood water levels to ascertain the frequency and magnitude of flood events within this flood plain (Yeo et al., 2007). I looked into the national archives of Fiji for records of flooding of the Navua River and its impact on the current key developments in the vicinity of its flood plain beginning from 1904. Such a quantitative methodology utilized by Yeo however cannot be obtained for the Navua River as the sugar mill that was in operation in Navua ceased to exist, 22 years after it was established in 1884. Further, the absence of river discharge and velocity data for the Navua River up until the 1970s has lead to a 100 year look into other historical information in order to gather information on how flood hazards and risks have been managed over the course of development. During Fiji's pre-independence days, reports of the then Fiji Colony were compiled into one publication, “The Annual Colonial Reports”. Such reports hold accounts of economic progress, agricultural development and progress, rainfall data, damage assessment reports of the Fiji Islands for instance, as examples of the range of sectors a single report would cover. These reports were researched in order to gather evidence of flood events and risks throughout the history of Navua. Other reports such as the Cyclopedia of the Fiji Islands were also researched for excerpts of flood history and its impact in the Navua area.

To test the validity, these findings on flooding and other natural hazards were matched against records of tropical cyclones and storms obtained from the Fiji Meteorology Services (FMS), which also, in the absence of reliable instrumental records, has researched into reliable historical records of tropical cyclones and their impact to compile the history of tropical cyclones within the Fiji Islands. The Fiji Meteorology Services state that it was not until the 1970s that reliable recording was available and satellites were used to track tropical cyclones from 1970s onwards (McGree, 2002). However the lack of maintenance of river gauges of the Navua River since the 1970s resulted in an unreliable record of river flows and difficulty in matching these with the cyclone record. These findings are presented in Chapter 5 of this thesis. 


\subsubsection{Objective 3: To analyse a recent case study (2004 Navua Flood) to determine the role of elements at risk, vulnerability and management in explaining flood losses}

Schanze (2006) proposes a flood risk management framework of which flood hazards and risks are addressed in three components:
a) risk analysis;
b) risk assessment;
c) risk reduction and illustrated below.

Figure 2.1: Flood Risk Management Model

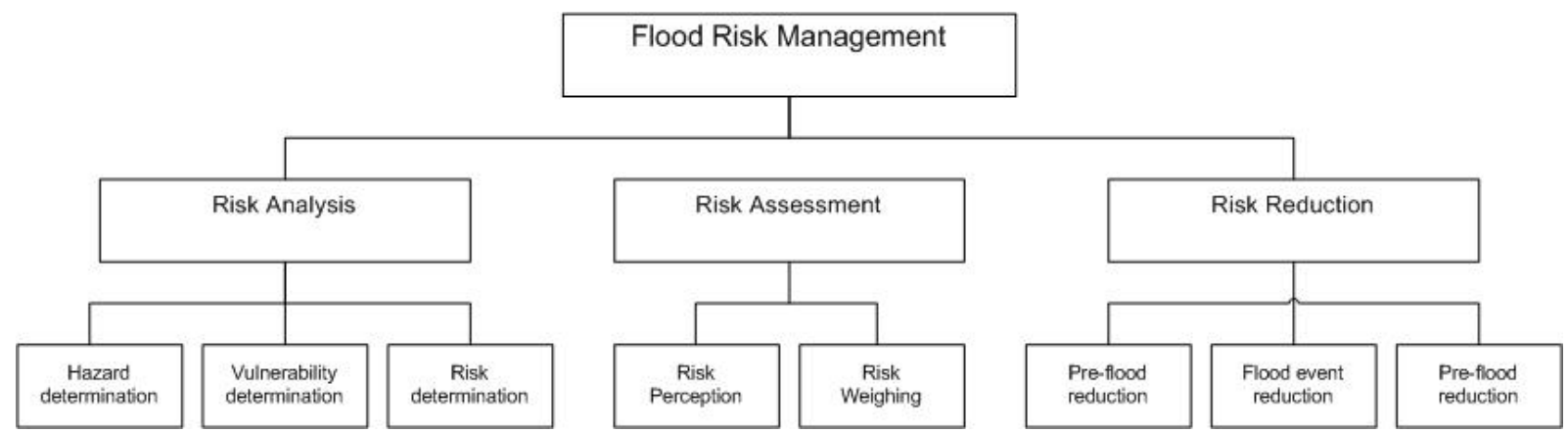

Source: Tasks and Components of flood risk management model proposed by Schanze (2006).

Schanze's (2006) proposed framework is somewhat similar to the risk management framework for landslides highlighted by Crozier and Glade (2004) where risk management includes; a) risk analysis, b) risk assessment and c) risk treatment where after the risk assessment procedure, decisions are then made about how to treat the risk (Crozier and Glade, 2004).

Risk's assessments are both qualitative (likelihood) and quantitative (probabilistic) in approach (Crozier, 2006) with differing variables depending on the context in which it is used (PenningRowsell et al., 2005). However, the basic principles apply in the various stages of risk assessment:

a) Determine the scope;

b) Determine the hazards; 
c) Estimate the risk;

d) Evaluate the risk; and

e) Treat the risk

(Crozier and Glade, 2004; Messner and Meyer, 2006; Schanze, 2006)

There are yet to be officially recognised accepted risk management standards for the Fiji Islands (personal communication with Fiji NDMO). There are however plans, to recognise the Comprehensive Hazard Assessment and Risk Management (CHARM) Framework as the official risk management framework (Fiji, 2006a) for all hazards in Fiji. The framework also underscores the basic framework of risk management (SOPAC, 2002).

The methodology utilized in this thesis for flood risk management encompasses the basic risk management framework and implies that analysing risk assessment ought to be undertaken holistically as advocated by the UNISDR, in that risks are created by both natural and human induced hazards (figure 2) and that for flood risk management to reflect this, the three components of the risk management framework proposed by Schanze (2006) above needs to be considered. Within this context flood risks are assessed using the risk equation of:

$$
\text { Risk }(\mathrm{R}) \text { = hazards }(\mathrm{H}) \text { + vulnerability }(\mathrm{V}) \text { + elements at risk }(\mathrm{E}) \text {, where; }
$$

Hazards (natural and human activities) = Flooding + alteration of the physical environment Vulnerability = built environment + social + environment + economic

Elements at Risk = built environment + social + natural environment + economic

Using the UNISDR definition of 'disaster risk', natural hazards would be flood events and human activities would be those in the catchment study site that are known to aggravate flood hazards, therefore;

Flood = magnitude and frequency

Human processes $=$ logging + river dredging + river mining + abandoned land use works Scope $=$ Navua Catchment area 
It is quite evident in flood prone areas that debri is also an initiator of increasing flood risks. While there is yet no set methodology available for quantitatively measuring debris potential in the event of a flood (Penning-Rowsell et al., 2005), as it could be a function of varying land use in the upstream catchment area, however the likelihood of the occurrence of such (qualitative approach) can be addressed through a risk/benefit analysis of these activities to the Navua Community (Crozier, 2006). While there are many arguments on how to measure vulnerability, in this thesis however, it is measured against indicators as suggested by Messner and Meyer (2006). These indicators are consistent with the holistic way in which Schanze (2006), and the UNISDR (2005), suggest for addressing risk management. For the Navua area, these indicators are extracted from the national commitments made towards the Millennium Development Goals (MDG) as outlined in the Strategic Development Plan 2007 - 2011 of the Fiji Islands. Vulnerability is measured in terms of the following variables:

Table 2. 1: Vulnerability Indicators

\begin{tabular}{|l|l|}
\hline Vulnerability & Indicators \\
\hline Social & Population, Education, Health, Cultural \\
\hline Environment & Ecological, water access, tourism \\
\hline Built Environment & Housing, roads, access to essential services \\
\hline Economic & Poverty, Employment, tourism \\
\hline
\end{tabular}

Because this thesis is primarily concerned with how flood hazards are managed concurrently with development, and in this sense, land-use development; elements at risk are identified according to the land-use characteristics identified for Navua as Lonergan (2005) uses in her model of land-use change for the Navua catchment. To do so a risk management exercise based on the last big flood of 2004 in Navua is undertaken. In the exercise, the elements at risk are the land use features identified in Table 2.2. 
Table 2.2: Elements of Land Use at Risk in the Navua catchment

\begin{tabular}{|l|l|}
\hline Land-Use Classification & Features \\
\hline Residential purpose & $\begin{array}{l}\text { Building and associated gardens, driveways, parking areas and } \\
\text { house yards }\end{array}$ \\
\hline Civic and Community & $\begin{array}{l}\text { Buildings, waste disposal sites, cemeteries, roads, sports fields and } \\
\text { parks }\end{array}$ \\
\hline Commercial Agriculture & $\begin{array}{l}\text { Large Scale Agricultural Enterprises, subsistence agriculture, low } \\
\text { value grazing and its associated buildings, sheds and infrastructure }\end{array}$ \\
\hline Natural Drainage Lines & $\begin{array}{l}\text { Estuaries, South Pacific Ocean and fragments of inland mangrove } \\
\text { forests }\end{array}$ \\
\hline Commercial non-agricultural & $\begin{array}{l}\text { Dredging and excavation activities, supermarkets, shops, tourism, } \\
\text { sites and offices, timber works and stockpiles }\end{array}$ \\
\hline
\end{tabular}

The risk to the communities in Navua is examined according to the land-use classification system outlined above. Risk for every indicator is not calculated, however, examples of risks calculation are highlighted to provide some knowledge on the level of risk that the community and types of initiatives, land use or otherwise, that are most at risk in the Navua area.

\subsubsection{Objective 4: To examine critically the governance structure for hazard management in Fiji}

One of the factors that make a group vulnerable is the lack of regulatory frameworks to address natural hazards and risks. In examining the regulatory frameworks for hazard management in Fiji, the mechanism of disaster risk management in Fiji is critically explored. This includes a look at the influences of global initiatives aimed at improving the way in which disaster risks are managed within the Pacific and subsequently in Fiji. As such the influences such as the framework of the United Nations International Strategy for Disaster Reduction (UNISDR) are examined and the Pacific Framework for Action 2005 - 2015, and the current governance structure within the Fiji Islands. These structures are:
a) the National Disaster Risk Management Arrangements;
b) Strategic Development Plan 2007 - 2011;
c) Rural Land Use Arrangements; and
a) Land use Development Legislation in Fiji 


\section{Chapter 3: Natural Hazards and Risks in Fiji - a wider context}

\subsection{Introduction}

Literature indicates that $81 \%$ of the world's largest earthquakes occur at the edge of the Pacific which is known as the Pacific Rim of Fire (Hays, 2004; SOPAC, 2006a). Fiji’s physical geography and location within this tectonic plate, makes it susceptible to a number of natural hazards. The country's tropical climate coupled with its volcanic island arc and deltas that form out into the coasts mean that it is subject to a variety of geological, hydrological and climate related hazards (Nunn, 1998; Parry, 1981; Raj, 1986; SOPAC, 2006c). These natural hazards can be classified into the following general categories of hazards: hydrological hazards, geological hazards and meteorological hazards (Paton and Johnston, 2006). Geological hazards of the Fiji Islands are: earthquakes, landslides, tsunamis and volcanic eruptions. Hydrological hazards that Fiji is susceptible to are: river flooding, of which flash floods are most recently quite frequent, and coastal flooding. Meteorological hazards are hurricanes or cyclones, storm surges and drought. Other hazards are a result of human processes and often, technological hazards tend to cause environmental degradation as well as risks to human health and wellbeing. This chapter will outline the main hazards that affect Fiji and with the use of case studies will examine the physical events, their causes and the associated impacts. However, in order to understand the susceptibility of Fiji to these hazards the physical and social context of the islands will be presented first

\subsection{Background on the Fiji Islands}

The Fiji Islands (Figure 3.1), commonly referred to as the hub of the South Pacific, is an archipelago of over 320 islands located between latitudes $15^{\circ}$ South and $22^{\circ}$ South, and between longitudes $174^{\circ}$ East and $177^{\circ}$ West. Fiji has 18,272 square kilometers of land area, surrounded by an Exclusive Economic Zone (EEZ) of 1.26 million square kilometers (Statistics, 2007a). Its two main islands; Viti Levu, comprising a land area of 10, 389 square kilometers, and Vanua Levu, 5, 556 sq. kilometers have the major river systems in Fiji. The study location, Navua, is 
located on the island of Viti Levu, on the south east central portion of the island (refer to the map). Fiji’s physical geography and location makes the country susceptible to climatic changes and various natural hazards. These natural hazards include cyclones, hurricanes, storm surge, coastal flooding, river flooding, droughts, earthquakes, landslides, tsunamis and volcanic eruptions, which may cause rapid and sometimes catastrophic landscape change (Nunn, 1998).

\subsubsection{Climate}

Fiji's climate is influenced by the south-east trade winds. It has two distinctive seasons: the wet season from November to April and the dry season from May to October. The windward sides of the larger islands are extremely wet; the average rainfall on the windward side ranges from 1,090 millimeters in the dry season to 2,497 millimeters in the wet season. The leeward sides have considerably less rainfall, with an average of 479 millimeters of rain in the dry season and 1,392 millimeters in the wet season (FMS, 2007a). Navua is said to be the wettest part as it lies beneath the mountain range that separates the wet and dry sides (Terry et al., 2001).

\subsubsection{Geology}

Fiji sits near the edge of the Indo-Australia Plate between two opposite facing sub-duction zones and forms part of the South-West Pacific island arc systems, which marks the boundary between the Indo-Australian and Pacific Tectonic Plates (Johnson, 1990). The seismic zone around this tectonic plate is known as the Pacific Rim of Fire. Fiji's tectonic history dates back to some 40 million years ago, which is reflected in the strong, faulting and folding of 12 to 7 million old rocks south west of Viti Levu (Rodd, 1993). Rodd, 1993, states that Fiji represents a portion of the old Vityaz Arc, which was split up and rotated anti-clockwise to its present position, forming a mini plate known as the Fiji Plate (Vuetibau, 2008) 
Figure 3.1: Map of the Fiji Islands

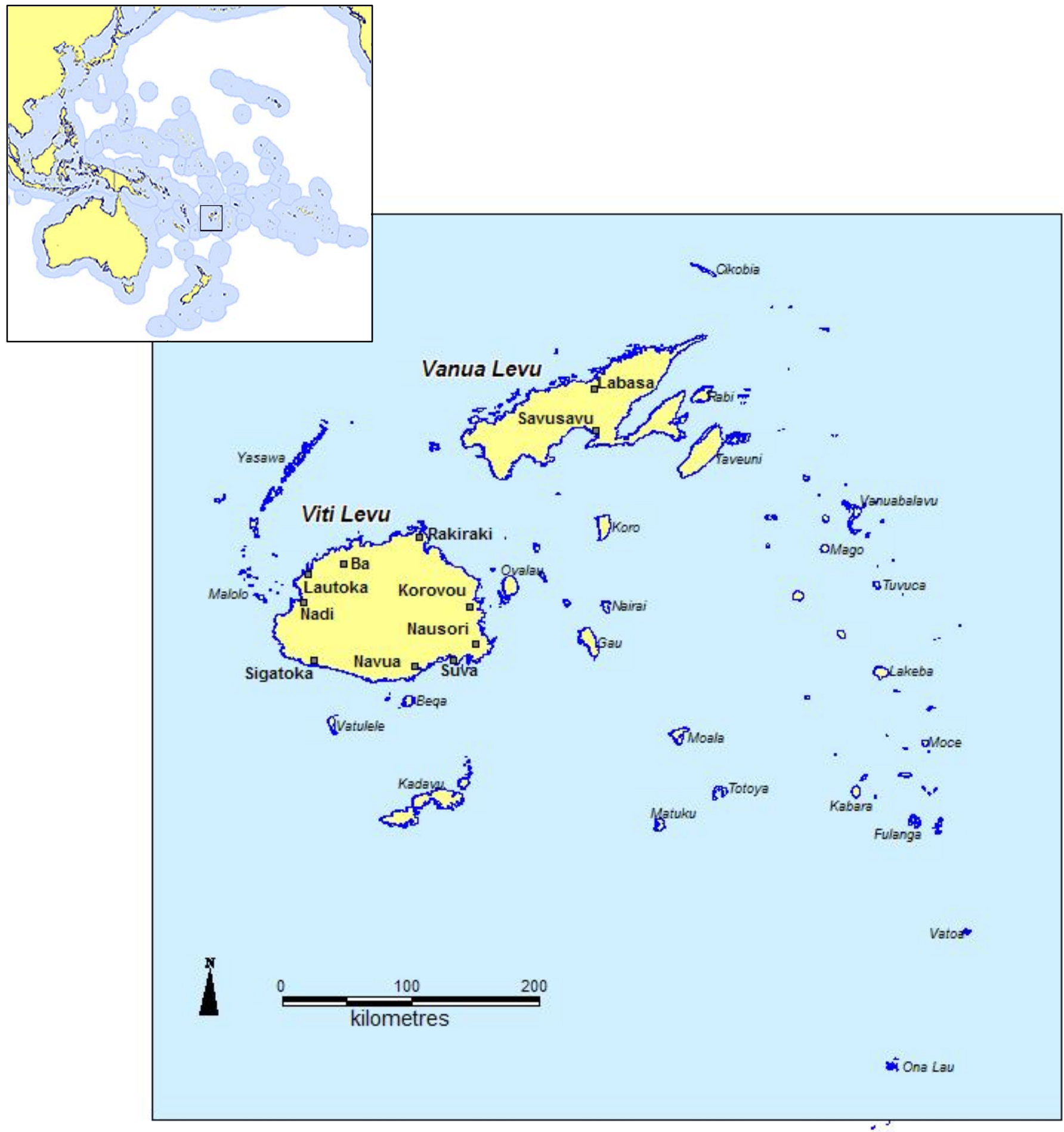

Source: Pacific Islands Applied Geoscience Commission 


\subsubsection{Floodplains and deltas}

The lowland catchments areas of Viti Levu have been observed to have formed in the Holocene period (Nunn, 1998). As mentioned earlier, Fiji sits on a mini plate known as the Fiji plate and Viti Levu is centrally located on this plate. Observations of the physical characteristics of the coastal areas and deltas, indicate that the seismic stretching of the plates has resulted in an upward northward movement of the mountain ranges and a lowering of the delta areas (Nunn, 1998), with sediment discharges on the windward side of the island, far exceeding deltas of the leeward side. The rugged topography of the island coupled with the intensity of the storms Fiji experiences often result in flooding, which is particularly frequent during the wet season (Kostaschuk et al., 2001)

\subsubsection{Socio-economic}

Fiji's socio-economic status is often a factor in the ability to mitigate natural hazards. Often the populations most at risk are those that are least prepared or those living in hazard susceptible areas such as floodplains and deltas. With Fiji's gradually rising population, it is no doubt that the risks from natural hazards will change. At the last count in 2007, the population totaled 827, 900 , an increase of 6.4\% since the last population count of 1996 (Statistics, 2007b). Migration towards the cities, towns and peri-urban areas continues, with the largest number of people living in the capital city of Suva. The recent statistics indicate the decrease in the population of those in the Northern Division has been complemented by the increase of population in the central division (Statistics, 2007b). Navua is an area in the central division whose population has increased (Statistics, 2007b).

By Pacific standards, Fiji's economy is vibrant and diverse. GDP per capita in 2006 stood at $\mathrm{F} \$ 5,474$, with the hospitality and trade sector ranked first and the strongest and the "agriculture, forestry, fishing and subsistence ${ }^{6}$ industry being the sixth in rank (Statistics, 2007b)”. However, these statistics are often offset by the losses and damages incurred on development from a natural disaster (McKenzie et al., 2005). Forestry and agriculture are some of the land-use

\footnotetext{
${ }^{6}$ Subsistence industry in this sense is when the industry concerned produces enough only for themselves, which is often the case in the agricultural industry.
} 
activities that are prevalent in the Navua catchment, which will be discussed in Chapters 5 and 6 of this thesis.

The archipelago of islands has access to two types of water sources: ground water and surface water. Over $70 \%$ of Fiji's population has access to proper piped water supplies and this percentage continues to increase (SOPAC, 2008). The rest of the population draws water from river systems. The Navua River serves this purpose for a number of villages from the provinces of Namosi and Serua (Figure 3.2). During a natural disaster, particularly during flooding, the water sources are often polluted or blocked, creating a set of secondary hazards for those within these communities (Tokalauvere and Biukoto, 2003).

\subsection{Hazards interrelationship}

Hazards consist of a range of processes or events with the potential to bring about what could be a damaging situation or event to attributes valued by mankind. All natural hazards are known to produce a range of secondary hazards which can become primary hazards in themselves with respect to the damage caused. For instance, tropical cyclone, a natural hazard is also known to initiate flooding and storm surges. Flooding can also be an initiator of landslides, especially along river banks. Earthquakes are known to initiate tsunamis particularly if they occur offshore. Earthquakes also initiate landslides both on land on the ocean surface. The table below expresses these relationships between hazards. The table is adapted from Gregg and Houghton (2006) and is formatted to reflect the natural hazards that affect the Fiji Islands (Gregg and Houghton, 2006)

Table 3.1: Primary and Secondary Natural Hazards of the Fiji Islands (Adapted from Gregg and Houghton, 2006)

\begin{tabular}{|l|l|l|}
\hline Category & Hazard / Event & Secondary Hazards \\
\hline Geological & Earthquake & $\begin{array}{l}\text { Ground shaking, ground rupture, ground } \\
\text { cracking, landslides, tsunamis, liquefaction }\end{array}$ \\
Volcanic eruption & $\begin{array}{l}\text { Tephra fall, pyroclastic density currents, lava } \\
\text { flows, volcanic gases and aerosols, ground } \\
\text { cracking, landslides, lahars, tsunamis }\end{array}$ \\
\hline
\end{tabular}




\begin{tabular}{|l|l|l|}
\hline & Landslides or mass movement & Rockfall, tsunamis \\
\hline Hydrological & $\begin{array}{l}\text { Flooding } \\
\text { El Nino and La Nina }\end{array}$ & $\begin{array}{l}\text { Erosion, landslides, high water levels } \\
\text { Drought, flooding, landslides }\end{array}$ \\
\hline Meteorological & Tropical Cyclones & $\begin{array}{l}\text { High winds, heavy rainfall, flooding, storm } \\
\text { surges, coastal erosion } \\
\text { Flooding, Storm Surges, landslips/slides } \\
\text { Wildfire, salination }\end{array}$ \\
& $\begin{array}{l}\text { Tropical Depression } \\
\text { Drought }\end{array}$ & \\
\hline
\end{tabular}

\subsection{Geological Hazards}

\subsubsection{Earthquakes}

Of the more than 12 million earthquakes that occur each year throughout the world, scientists have determined that approximately one hundred are potentially disastrous because of their size or magnitude and proximity to an urban centre or settlement (Hays, 2004). Other factors that determine the potential of an earthquake disaster are its frequency, its focal depth, the direction of the energy released, the geometry and physical properties of the soil and rock underlying the buildings and infrastructure (Hays, 2004). Earthquakes in Fiji are not as common as in other countries located within the Pacific Rim. However, the seismic and volcanic activity that has occurred in Fiji in the past 43 million years can be attributed to the anti clockwise rotation of the Fiji micro plate located in between the Pacific plate and the Indo-Australian plate, as illustrated below (personal communication with Vuetibau, 2008). 
Figure 3.2: Rotation of the Fiji Plate

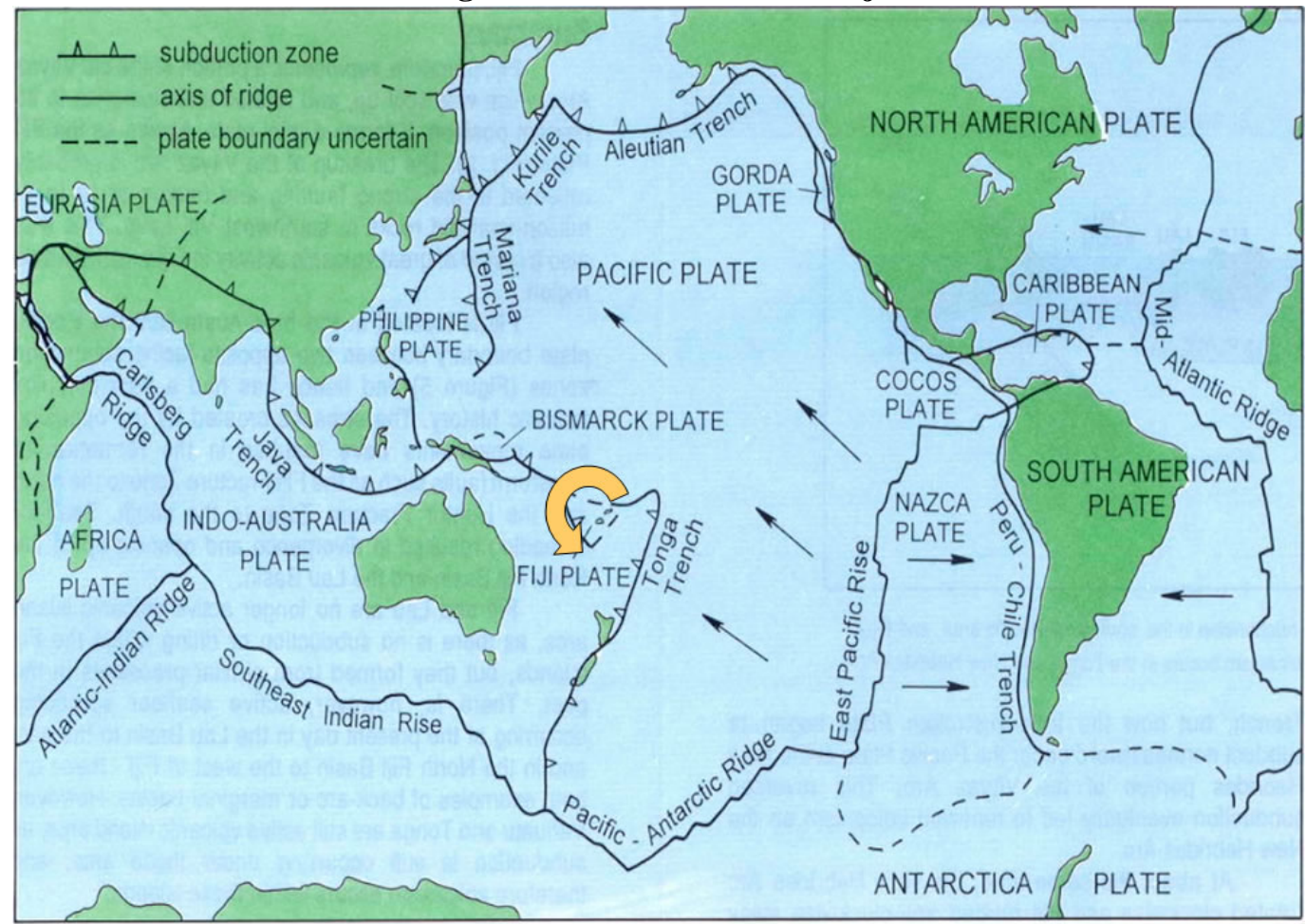

Source: Fiji Mineral Resources Department

Fiji's seismologist, Lasarusa Vuetibau (2008), states that this anti-clockwise movement is a resultant force of the two tectonic movements of the subduction of the Pacific Plate beneath the Indo-Australian plate at the Tonga trench and the subduction of the Indo-Australian plate beneath the Pacific Plate at the Vanuatu Trench, thereby forcing the Fiji micro plate to rotate anti-clockwise (personal communication with Vuetibau, 2008). This anti-clockwise movement is the primary cause of seismic and volcanic activity within the Fiji Islands, thereby placing the whole country at risk from damaging earthquakes (Figure 3.1). As highlighted in Figure 3.2, seismic activity is concentrated on the edge of the micro plate. 
Figure 3.3: Seismic Activity in the Fiji Islands from 1881 - 2001.

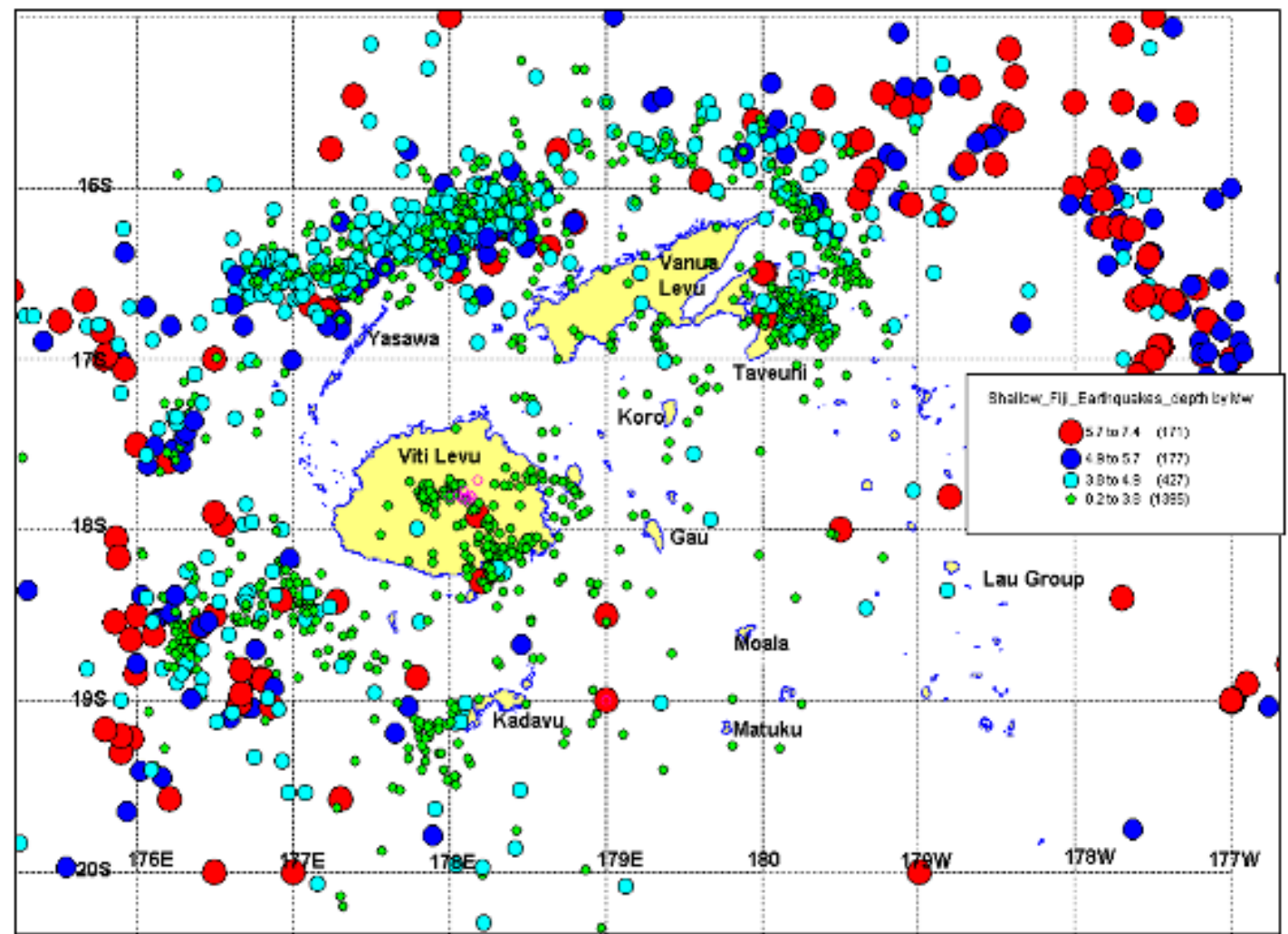

Source: Fiji Mineral Resources Department

Since reliable recordings began in 1918, a potentially dangerous earthquake of magnitude 6 or more has occurred on an average of once every three years (Mineral Resources Department, 2008). However personal communication from the Fiji Mineral Resource Department indicates that damaging earthquakes had occurred in Fiji prior to 1918, as far back as 1850 (Vuetibau, 2001). To date there has been a total of 9 damaging earthquakes that have occurred in Fiji since 1850. The table below summarizes these earthquakes, locations and magnitudes. In a sense, Fiji has been fortunate because at the time these 'damaging' earthquakes occurred, the factors that contribute to disastrous effects such as exposed and vulnerable populations, and building density, (buildings of that time were not seismic proof) were at a much lower level than today. In addition, the earthquakes occurred nearshore and not directly beneath the islands listed (Table 3.2). Given the level of land-use development at that time, these damages were quite substantial in terms of the public's ability to cope and mitigate the event. 
Table 3. 2: Damaging Earthquakes in Fiji since 1850.

\begin{tabular}{|c|c|c|c|c|}
\hline \multirow[t]{2}{*}{ Date } & \multirow[t]{2}{*}{ Location } & \multicolumn{2}{|c|}{ Epicenter } & \multirow[t]{2}{*}{ Mag } \\
\hline & & Lat & Long & \\
\hline 1850 & Kadavu & 19 & $178 \mathrm{E}$ & $\mathrm{n} / \mathrm{a}$ \\
\hline 1881 & Macuata & 16 & $179 \mathrm{E}$ & 6.8 \\
\hline 1902 & Yasawa's & 16.7 & $177.2 \mathrm{E}$ & 6.7 \\
\hline 1919 & Rabi & 16.4 & 180.0 & 6.5 \\
\hline 1932 & Koro & 17.5 & $179.6 \mathrm{E}$ & 6.6 \\
\hline 1932 & Near Rabi & 16.2 & $179.7 \mathrm{~W}$ & 6.6 \\
\hline 1953 & Suva & 18.25 & $178.25 \mathrm{E}$ & 6.8 \\
\hline 1979 & Taveuni & 16.5 & $179.75 \mathrm{~W}$ & 6.9 \\
\hline 1998 & Kadavu & $\mathrm{n} / \mathrm{a}$ & $\mathrm{n} / \mathrm{a}$ & 6.8 \\
\hline
\end{tabular}

Source: Fiji Mineral Resources Department (Vuetibau, 2001)

The responsibilities of seismic and volcanic activity, at present, lie with the Fiji Mineral Resources Department. However, the relief response, preparedness and educational awareness, is a role that is the responsibility of National Disaster Management Office of the Fiji Islands.

\subsubsection{Tsunamis}

Fiji is not immune to tsunami's, being an island nation that is surrounded by oceans and an active seismic area. Its surrounding coral reefs provide some protection to tsunamis generated by distant earthquakes. However, the country's risks from nearshore tsunami generated earthquakes are high. Other than earthquake generated tsunamis, a number of mechanisms also produce tsunamis. These are subareal or submarine landslides into and below the ocean surface, volcanic eruptions; meteorite or asteroid impact into the ocean; and atmospheric disturbances either generated by volcanic eruptions or weather related phenomena such as squall lines and tropical cyclones (Nott, 2006). Tsunamis experienced by Fiji have been generated by earthquakes (Vuetibau, 2003). The size of a tsunami is dependent on the magnitude and depth of the earthquake. Nott (2006) states that earthquakes of magnitudes 7 to 7.5 occurring at particularly shallow depths of less than $100 \mathrm{~km}$ 's, have a tendency to produce large and destructive tsunamis (Nott, 2006). A Tsunami consists of a series of waves. Within these series a large wave can occur in any position in the wave train. The wave heights generated by earthquake tsunamis are 
normally less than one meter in the open ocean but the wave height increases substantially as it travels across continental shelves and slows in velocity (Nott, 2006; Pararas-Carayannis, 2004). These sort of tsunamis are often characterized by the withdrawal of the sea; and the time lapse between the passage of successive wave crests at any given point is usually from $10-45$ minutes, providing limited time for evacuation once an earthquake generated tsunami has been detected (Nott, 2006; Vuetibau, 2003). However, as they draw closer to shore without much loss of energy, their size can reach gigantic proportions and become extremely destructive (PararasCarayannis, 2004). Near shore earthquake generated tsunamis are the most dangerous because they strike in a very short time after their generation (Mineral Resources Department, 2008).

Damaging tsunamis experienced in Fiji in the past have been generated as a result of near shore earthquakes. As illustrated in Figure 3.2, numerous near shore earthquakes occur north east and south west of Fiji, ranking the areas and islands in the vicinity of these earthquakes as a high risk zone to earthquakes and the immediate impact of tsunamis. Eleven tsunamis have been recorded in Fiji of which three were generated near shore (Vuetibau, 2003) in the 100 year period from 1881 - 2001. The last damaging earthquake generated tsunami experienced in the Fiji Islands was that of 1953, which struck at latitude 18.25 and longitude 178.25 E. The tsunami generated $5 \mathrm{~m}$ high waves destroying the coastlines along the Suva - Navua corridor as well as that of Nakasaleka in Kadavu. Figure 3.4 shows the impact of the tsunami waves within the Fiji Group as the earthquake struck in 1953. 
Figure 3.4: The extent of impact of the tsunami waves in 1953.

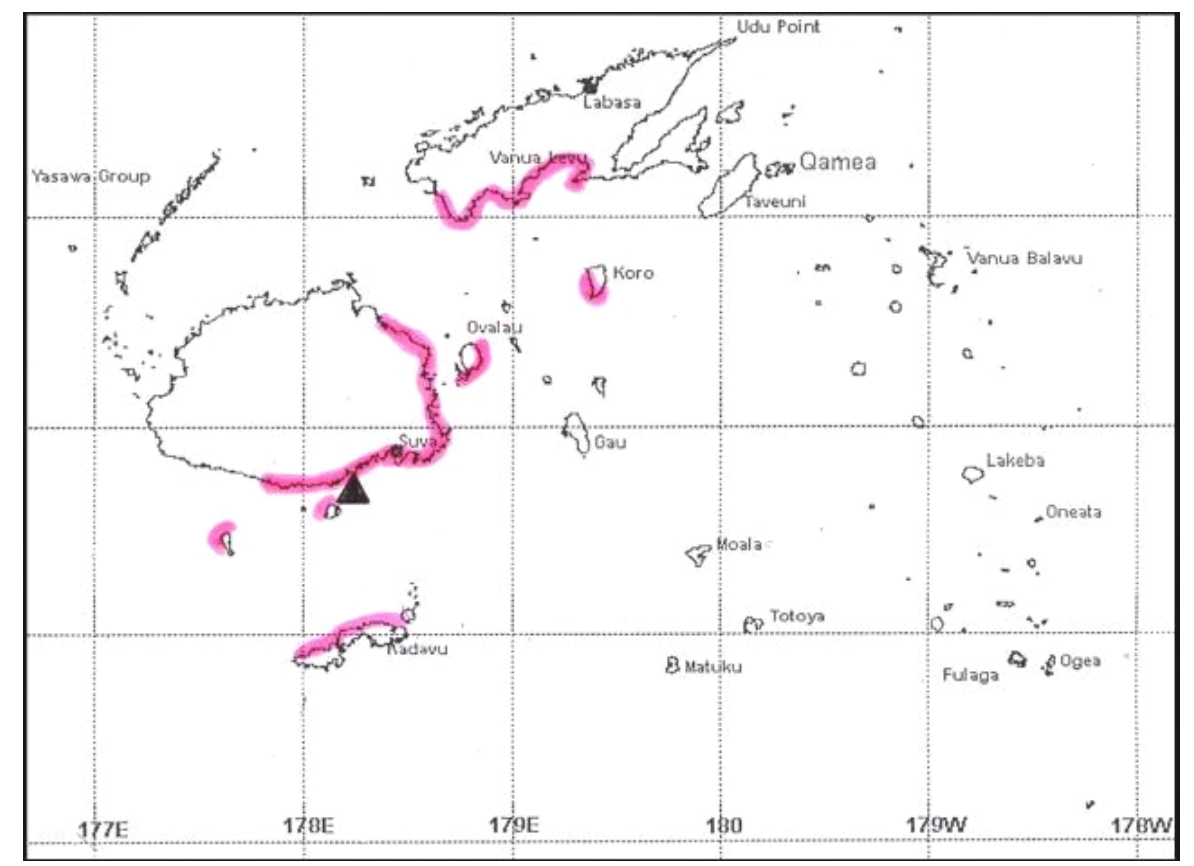

Source: Fiji Mineral Resources Department and extent of tsunami waves highlighted in pink.

\section{Case Study: Tsunami of 1953}

In 1953, an earthquake with a magnitude of Ms 6.7 occurred $25 \mathrm{~km}$ southwest of Suva with a focal depth of $15 \mathrm{~km}$. The map above indicates this location with a triangle. The earthquake triggered a submarine landslide outward and downward towards the fault line trending northeast of Viti Levu. The landslide was fan like in its spread activating tsunami waves which reached the Suva - Navua corridor within 8 minutes of the earthquake. Its impact was felt as far as Vanua Levu, Kadavu and Koro, as highlighted in the map above. The bulk of the impact was felt between Suva and Navua. Suva was inundated with waves of 5 metres in height. At that time it had a population of 10, 000 people and suffered 3 fatalities. Extensive damage was felt on the waterfront and harbour area, particularly to the wharf and seawalls along the harbour. The Suva wharf was displaced by about half a metre as a result of the earthquake. The pictures on the next page show this displacement and extent of damages of the tsunami. Other damages were to the piles that support the dock area as well as to the boats marooned within the harbour. Many parts of the seawall along the waterfront were washed out by the tsunami waves. Kadavu was impacted with waves of a height of 5 metres as well. Its population of 9000 lost five people. Three metre high waves were also felt in Savusavu on Vanua Levu. 


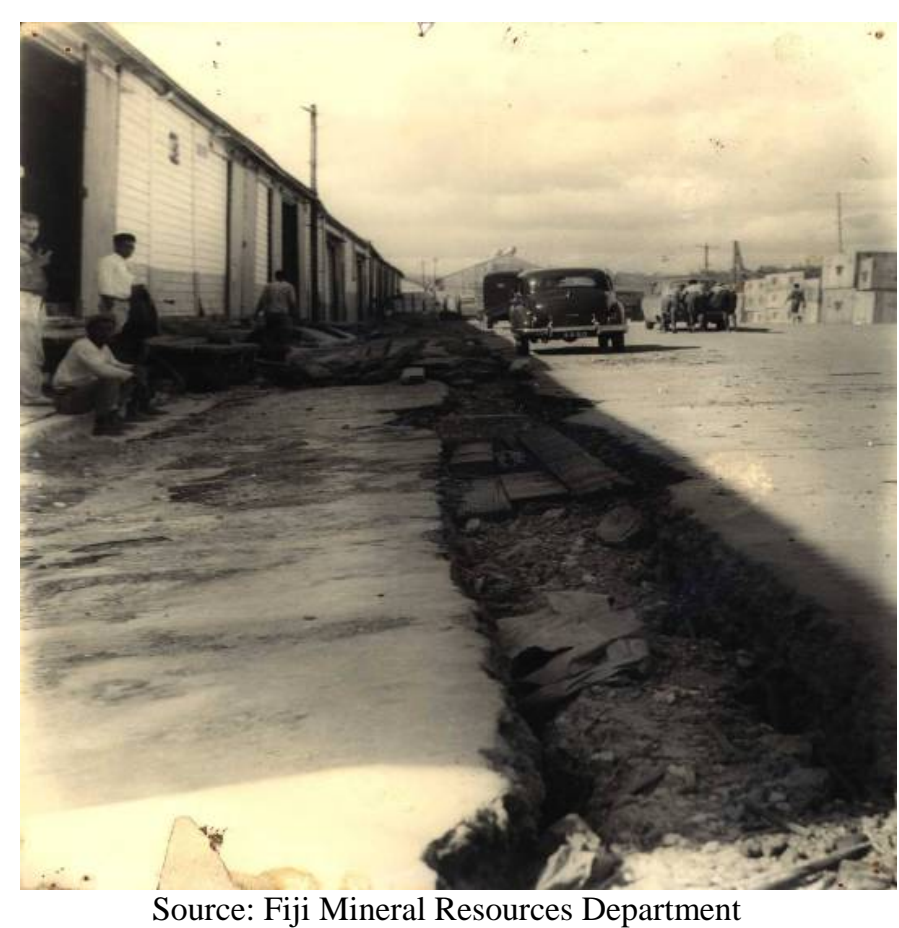

Plate 3.1: The displacement of the Suva wharf due to the earthquake in Suva in 1953.

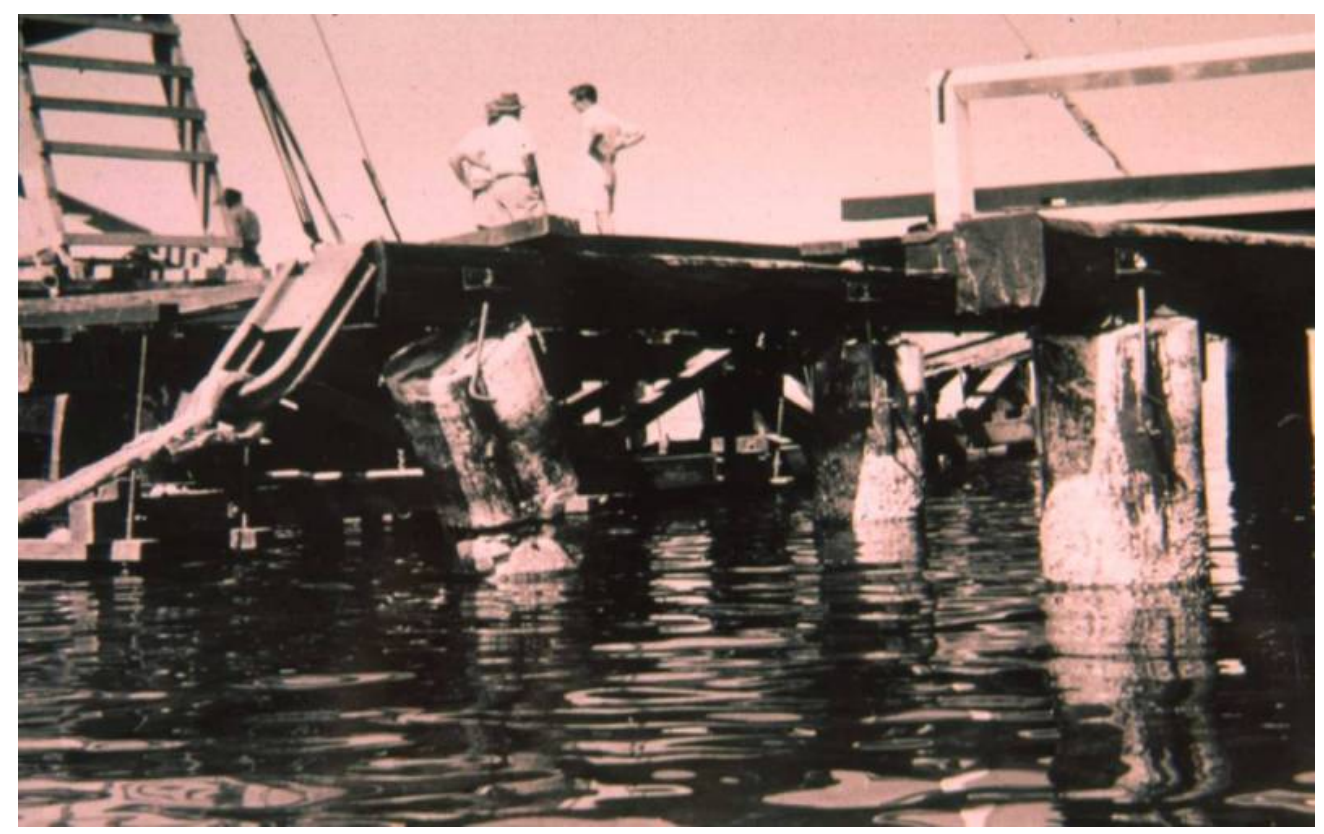

Source: Fiji Mineral Resources Department

Plate 3.2: Cracks on the piles Suva wharf due to the earthquake and the tsunami it generated. 


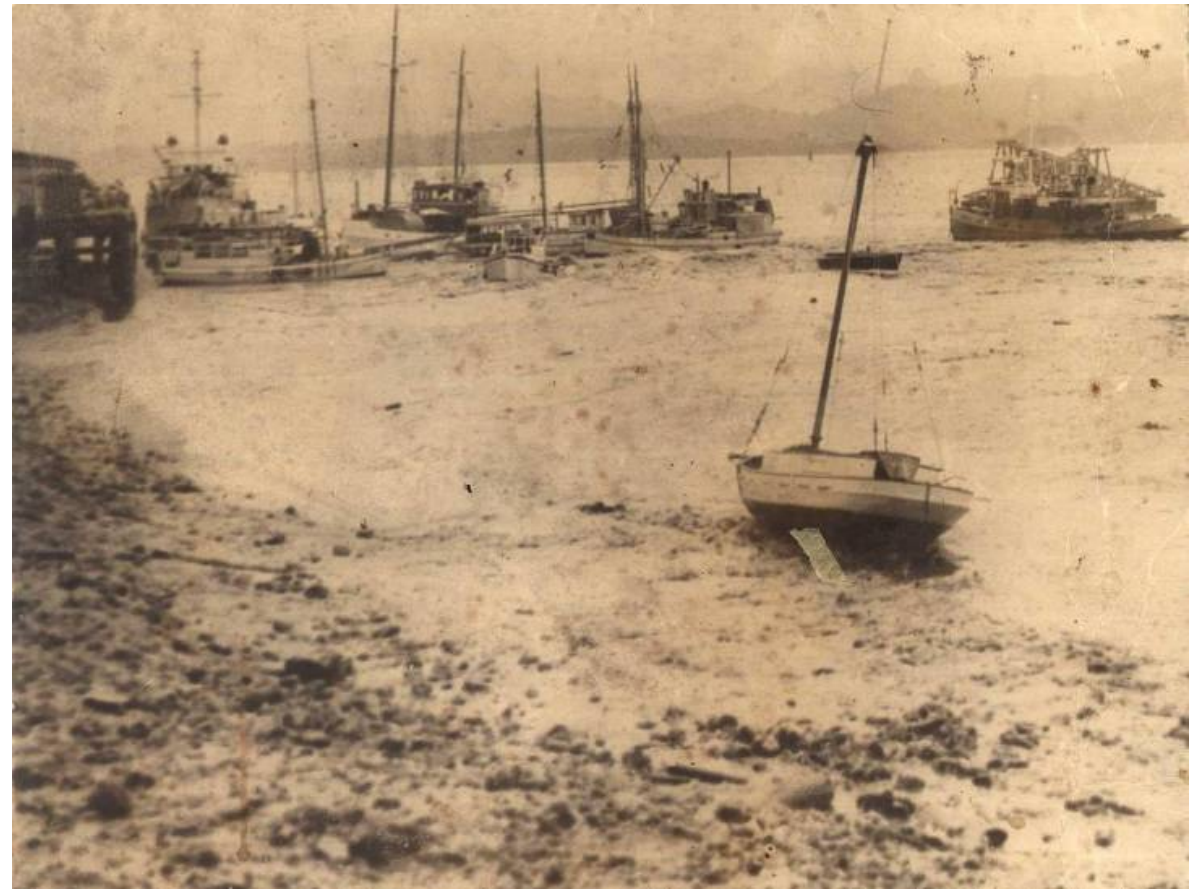

Source: Fiji Mineral Resources Department.

Plate 3.3: Boats washed ashore of Suva Harbour

\subsubsection{Mass movement: landslides}

Mass movement (the movement of earth material under the influence of gravity) can either be caused by natural forces or a combination of anthropogenic processes (DeChano, 2004). Landslides are a form of massmovement occurring on a slope that involves outward and downward movement of land along distict shear surfaces (Glade and Crozier, 2004). Landslides occur when the shear stress on a slope has exceeded the shear strength of movements of rock, soil, or waste, in turn moving these materials downslope due to gravity (Nott, 2006; SOPAC, 2006b). Various factors contribute to the shear stress or instability of a slope. The main factors that pre-dispose a slopes stability are its geology, geometry and its water conditions (SOPAC, 2006b). The causes however, are both natural and/or as a result of human activities. Some natural causes include the saturation of slope material from intense or prolonged rainfall; earthquake vibrations, volcanic eruptions and the undercutting of cliffs and banks by waves or rivers (SOPAC, 2006b). The causes via human activities include the removal of vegetation or 
interference with or changes to natural drainage, leaking pipes or modifications of slopes by construction of roads or buildings and mining activities and vibrations from heavy traffic or blasting and excavation or displacement of rocks (SOPAC, 2006b).

There are four types of mass movement; creep, falls, slides and flows (DeChano, 2004; Nott, 2006). 'Slides' are common in the Fiji Islands, though 'falls' and 'flows' are also an occurrence. Most of the landslides in Fiji are due to prolonged rainfall and human activities such as the removal of vegetation and modifications of slopes for building construction. These slides often cause fatalities and have a significant impact on infrastructure and property. For instance, in 2004, a heavy landslide forced a bus into the Wainibuka River, claiming the lives of nine people (FRCS, 2004; NDMO, 2005). Landslides have also been known to cause significant alteration to the landscape. One such occasion was a pre-historic landslide that occurred in the Namosi Gap, of which 50million $\mathrm{m}^{3}$ of debris was sent downhill building a damn of about $120 \mathrm{~m}$ thick (Bonte and Rahiman, 2006; SOPAC, 2006b). "This led to the flooding of the areas surrounding the river as a lake of 150sq km was formed. After thousands of years, the lake emptied to the South cutting the narrow Navua Gorge and creating a new river system (SOPAC, 2006b)”.

\section{Case Study: Cyclone Wally and ensuing landslides}

In 1980, three tropical cyclones struck the Fiji Islands in January, March and April respectively. The tropical cyclones were of varying intensities - Cyclone Peni was of hurricane intensity (winds greater than 64 knots), Cyclone Tia of storm intensity (48 - 63 knots) and Cyclone Wally of Gale force intensity (34-47 knots). However it was Cyclone Wally which was accompanied by extreme rainfall that caused severe damage particularly in Southern Viti Levu, though it was of the least wind speed of the three cyclones. There was flooding of the major rivers including that of the Navua River. In addition to 'severe' loss of livestock and crops from the flooding of rivers, several landslides had caused extensive damage to the main highway. There were 14 deaths reported (FMS, 2007b) while the cost of road repairs was estimated at FJ\$1.6m and telecommunications repairs estimated at FJ\$45,000. Wainitubatolu catchment, which rises into the Serua Hills from the Coral Coast of Fiji, was one of the areas most severely affected by landslides. Crozier, Howorth and Grant (1980), undertook a study assessment of this locality because of the role this area plays in terms of the communication systems of Southern Viti Levu 
(Crozier et al., 1980). In addition to damages to the nation and public utilities and infrastructure, the landslide activity of the area also affected the community of villages located within the catchment area:

a) damage to garden crops were estimated at $50 \%$ of the total crop;

b) village water supply was demolished from siltation and as a result of logs introduced into the streams; and

c) silt laden floodwaters caused damage to houses downstream in the floodplains.

Crozier et al (1980) identified the type of landslide in this area to be regolith landslides, which are basically slides triggered by intense rainfall. Over $900 \mathrm{~mm}$ of precipitation fell within a 24 hour period on $4^{\text {th }}$ April, when Cyclone Wally was at its peak. Over half of these landslides identified by the study team occurred within slope depressions or drainage lines. "The intense rainfall during the cyclone supplied water to the regolith at a rate greater than the rate of drainage downslope (Crozier et al., 1980)”. The water table soon formed enough pressure to reduce the shear resistance of the slope giving way to failure. The magnitude of the slides witnessed by inhabitants of the area was something they had not seen before in the time they had lived in the villages of the Wainitubatolu catchment. Ranked with other slides of similar magnitudes in areas of the world, the volume of material displaced in the 34 surveyed slides out of the 74 slides, amounted to $109,282 \mathrm{~m}^{3}$ placing it as one of the high magnitude slide events. In their study, Crozier et al (1980) conclude that given the condition of the slope in this area and the 'disposition' of landslide material as a consequence of the high rainfall, it indicates that a rainstorm of lower magnitude than that of Cyclone Wally would reinitiate mass movement in the catchment area.

While forested cover are said to be a deterrent to landslides and slips, it usually would require rainfall of 100 year return period to produce a certain degree of mass movement. However with the case of Wainitubatolu, it experienced landslide under all forest cover as the roots of forest trees failed to penetrate to depths greater than one metre and to bond into the bedrock beneath the regolith. The Navua Catchment consists of 95\% of forest cover (Melzner et al., 2004). With high levels of precipitation, regolith cover and slope instability, make the catchment area 
susceptible to landslides. Also, with unsustainable logging practices the impact would be most felt to communities downstream in the floodplain of the Navua peri-urban area.

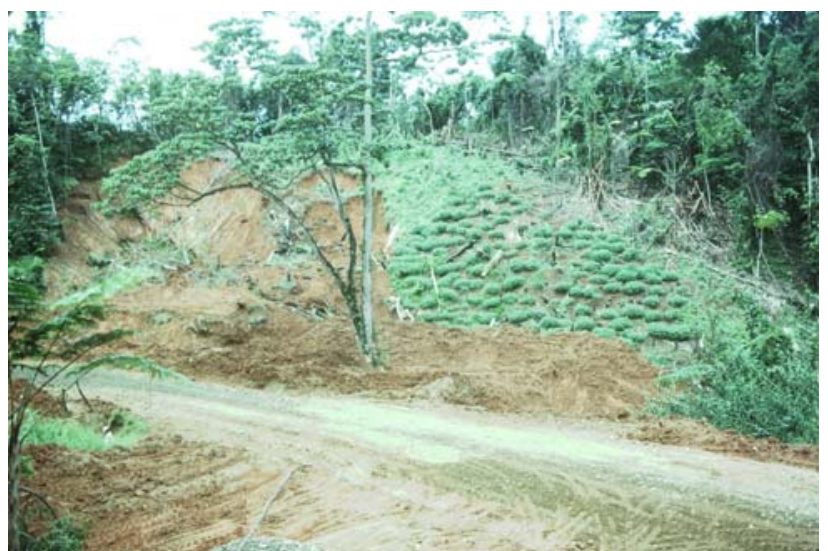

Plate 3.4: Landslide on vegetation cover for subsistence plantations

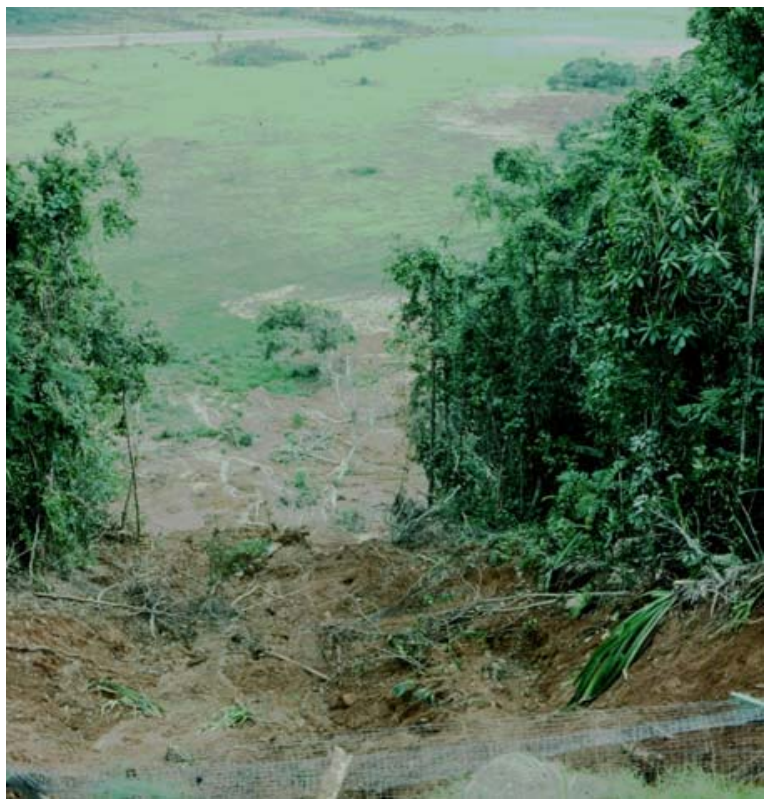

Plate 3.5: Debri flow into the lowland floodplain.

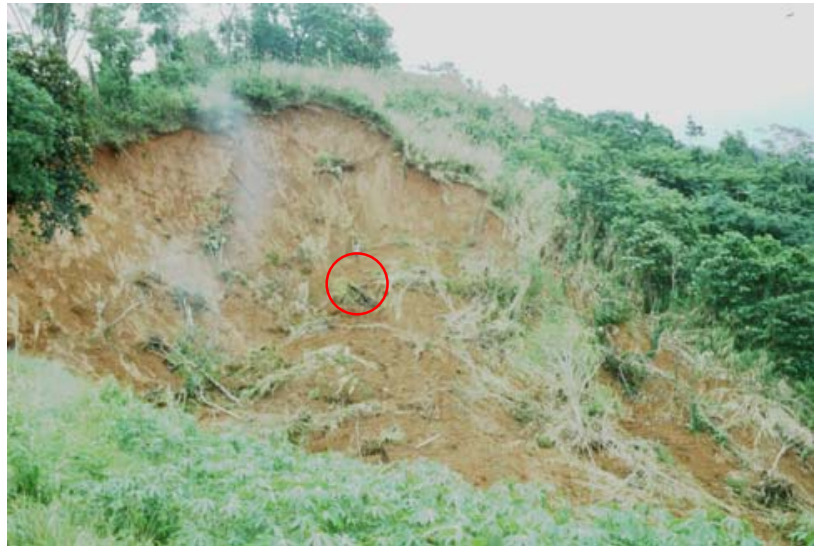

Plate 3.6: Extent of landslide in Navua Catchment area in reference to height of a human being

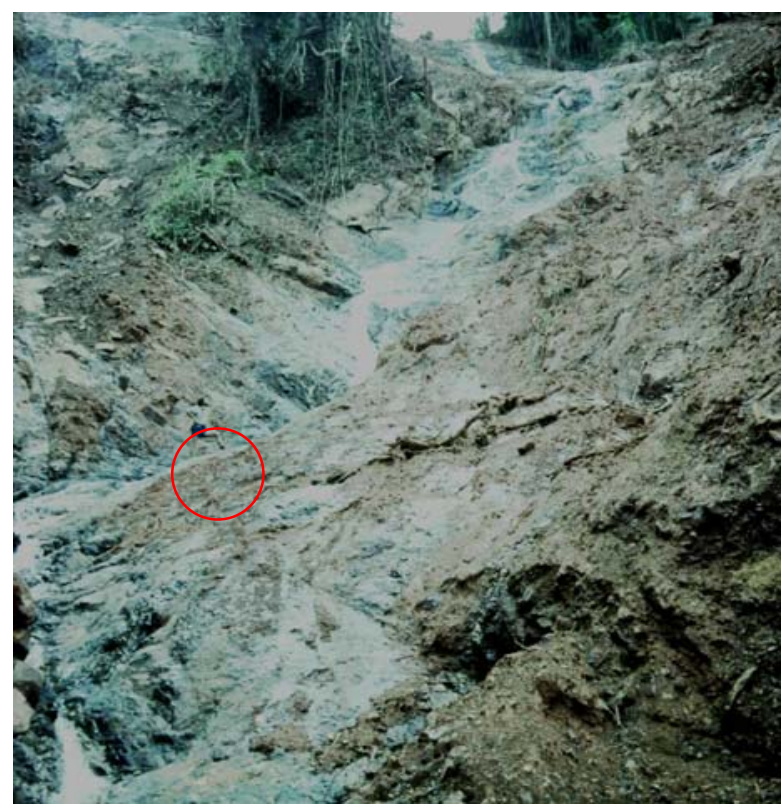

Plate 3.7: Steep topography and weather system makes the upper catchment of high risk to landslides.

Source: Michael J. Crozier. 


\section{Plate 3.8: Debri deposition downstream of the Navua River}

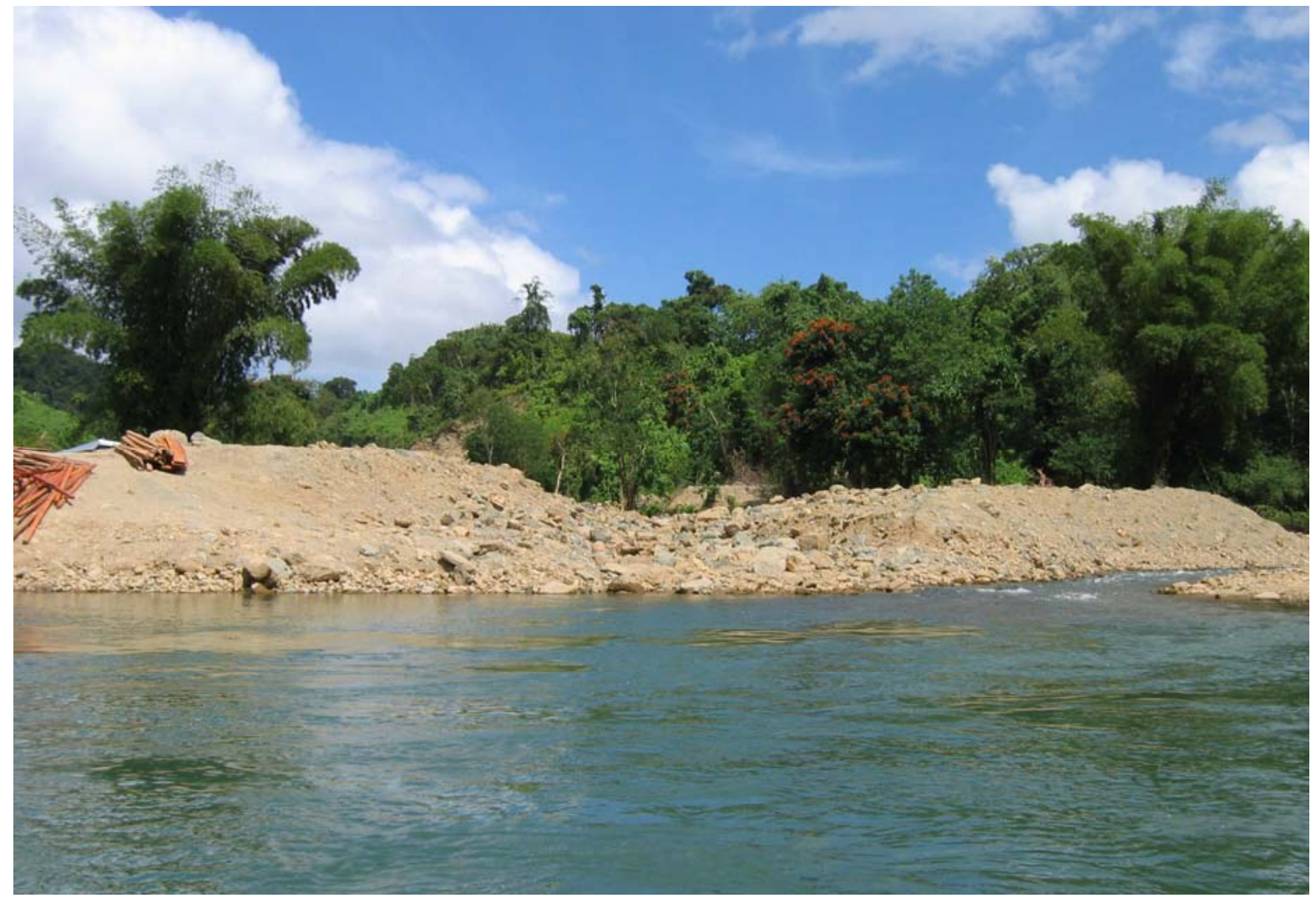

Source: Landslide Hazard Assessment in the Navua Catchment, South Viti Levu, Fiji (Melzner et al., 2004).

\subsection{Meteorological Hazards}

\subsubsection{Tropical cyclones}

Tropical Cyclones or 'hurricanes' and 'typhoons' as it is known in other parts of the world are a common occurrence in the Fiji Islands (Gibbs, 2004; Terry and Kostaschuk, 2004). The mass of oceans that surround the Pacific Islands including Fiji, and warmer temperatures are perfect conditions for cyclones to form. Its set season is from the $1^{\text {st }}$ of November to $30^{\text {th }}$ April. Though not always the case, tropical cyclones are often accompanied by flooding. This is evident in records of tropical cyclones in the Fiji Islands dating as far back as 1830 (McGree, 2002). However, there have also been cases of tropical cyclones where no flooding has occurred. 


\section{Case Study: Tropical Cyclone Bebe}

As mentioned, the Fiji cyclone season is from November to April of the calendar year. It is normally at this time, that preparedness is stepped up. As previously mentioned, Fiji's natural disaster response strategy has largely been in response to tropical cyclones. Tropical cyclones and the ensuing secondary hazards of floods and landslides that often accompany them, in the past have always had high negative consequences to the Fiji Islands. Loss of lives has been a common consequence of tropical cyclones in addition to damage to property and infrastructure (Bi, 1998). Cyclones often damage rooftops and debris from such is a common sight of cities and neighborhoods in the aftermath of a tropical cyclone. Regulations in place for cyclone-proofing housing and for preventing vegetation clearance is one attempt to reduce such losses.

Tropical Cyclone Bebe in October 1972 was unusual and a surprise in that it occurred outside of the expected season. Prior to this, there had been no previously recorded cyclones occurring in Fiji at this time. Bebe developed east of the Tuvalu Group of Islands in the Pacific and gained momentum as it moved towards the Fiji group. It was picked up on the monitoring radar at the Fiji Meteorological Services on the morning of 24 October, 1972. Bebe was of hurricane intensity, which is a wind speed greater than 64 knots according to the Australia and South Pacific Cyclone Category System. It was moving to the North Coast of Viti Levu, later crossing the south coast near Navua at around midnight of the 24 October. Wind speeds between 60 to 85 knots were recorded at this point of the cyclone which produced heavy rains over the whole of Fiji. A total of 24 lives were lost during this event and damages were reported to be from severe winds and flooding (Bi, 1998).

Damage assessments of tropical cyclones of the past have largely been in terms of the relative damage to property, lives lost and public infrastructure. Such assessments are carried out by a relief committee responsible to provide relief to the affected communities. However, over time, as 'preparedness' increased and cyclone proof housing became mandatory in cities and towns, a notable decrease in the loss of lives and damage to private property was has been observed in cities. However, the losses of lives in the peri-urban and rural areas were still notable despite improved satellite tracking, forecasting and early warning systems. The following table 3.3 highlights these inconsistencies. The increased land-use development and population density has 
resulted in an increase in the relative cost of damage to property and infrastructures. Such inconsistencies could indicate a continuing lack of preparedness of a community to tropical cyclones despite improved forecasting abilities.

Table 3.3: Loss of Lives due to Tropical Cyclones and Relative Damage of Event

\begin{tabular}{|c|c|c|c|}
\hline TC Name and Year & Intensity & Lives Lost & $\begin{array}{l}\text { Relative Damage / Cost of } \\
\text { damage \& loss }\end{array}$ \\
\hline Bebe, 1972 & Hurricane & 24 & Severe \\
\hline Lottie, 1973 & Hurricane & 70 (two vessels sunk) & Moderate \\
\hline Val, 1975 & Hurricane & 1 & Severe \\
\hline Bob, 1978 & Hurricane & 1 & Moderate \\
\hline Meli, 1979 & Hurricane & 52 & Severe \\
\hline Tia, 1980 & Storm & 4 & Moderate \\
\hline Wally, 1980 & Gale & 14 & Severe \\
\hline Oscar, 1983 & Hurricane & 9 & Severe \\
\hline Eric, 1985 & Hurricane & 25 & $\mathrm{~F} \$ 39.7 \mathrm{~m}$ \\
\hline Gavin, 1985 & Storm & 7 & F\$1Million \\
\hline Hina, 1985 & Hurricane & 3 & Severe \\
\hline Martin, 1986 & Storm & 2 & Moderate \\
\hline Raja, 1987 & Hurricane & 1 & $\mathrm{~F} \$ 14 \mathrm{~m}$ \\
\hline Bola, 1988 & Hurricane & 6 (drowning) & Minor \\
\hline Rae, 1990 & Storm & 3 & $\mathrm{~F} \$ 26.2 \mathrm{~m}$ \\
\hline Joni, 1992 & Hurricane & 1 & $\mathrm{~F} \$ 1.6 \mathrm{~m}$ \\
\hline Kina, 1992/93 & Hurricane & 23 & $\mathrm{~F} \$ 170 \mathrm{~m}$ \\
\hline Gavin, 1997 & Hurricane & $\begin{array}{l}25 \text { (10 drowning, } 1 \\
\text { landslide, } 14 \text { Other) }\end{array}$ & $\mathrm{F} \$ 33.4 \mathrm{~m}$ \\
\hline June, 1997 & Storm & 3 (landslide) & $\mathrm{F} \$ 1.01 \mathrm{~m}$ \\
\hline Neil, 2000 & Gale & 1 (flooding) & Minor \\
\hline Paula, 2001 & Hurricane & 1 & $\mathrm{~F} \$ 800,000$ \\
\hline Ami, 2003 & Hurricane & 17 & $<\mathrm{F} \$ 100 \mathrm{~m}$ \\
\hline Cliff, 2007 & Gale & 1 & Minor \\
\hline
\end{tabular}

Source: The information in the above table is adapted from data gathered from the Fiji Meteorological Services and the National Disaster management Office of Fiji. In the absence of estimated damage costs, the damage assessment rating given by the Fiji Meteorology Services is used. 


\subsubsection{Droughts}

Nott (2006), defines drought as an extended period of rainfall deficit within an otherwise higher rainfall regime (Nott, 2006). The drought regime in Fiji can be directly attributed to the influence of the El Nino/Southern Oscillation (ENSO) phenomena, whereby at intervals of every 5 - 7 years, the South East trade winds are weakened due to the disturbances in the Walker atmospheric circulation over the Pacific Ocean (Terry et al., 2001). This disturbance, called El Nino, causes a large pool of warm ocean water, usually centered around Papua New Guinea, to surge eastward across the equatorial Pacific. This disturbance tends to last for more than a year and brings droughts, prolonged wet conditions, and a high incidence of storms to different parts of the tropical pacific (Terry et al., 2001), and as sea surface temperatures rise off the America's a tongue of warm water stretches back along the equator hence increasing rainfall in this new low pressure region whereas the western Pacific suffers rainfall failure, and drought (Terry et al., 2001). As this atmospheric activity is taking place, “convective storms and tropical cyclones are generated in the eastward surge of warm ocean water passes across Fiji waters, then as El Nino conditions develop fully, shift of the South Pacific Convergence Zone away from the Fiji Islands leads to prolonged dry conditions (Terry et al., 2001). The last El Nino event in the Fiji Islands was in 1997 - 1998 when the global event led to a drought onset within Fiji (Varea, 2000).

\section{Case Study: 1997 - 1998 Fiji Droughts}

In the assessment of the impact of this drought in the Pacific, Lightfoot (1999) recalls that the drought drove the Fiji economy into the worst recession in its history at the time of the assessment (Lightfoot, 1999). The impact varied between Pacific Island countries, but the worst affected were Fiji and Papua New Guinea. However, the impact was most felt in the supply of water and agriculture with consequent social impacts of absenteeism of students from school, food shortages, and health problems. Pahalad, (in Lightfoot 1999), of the Fiji Meteorology Services stated that the drought developed around May 1997 but the impact of the drought on the agricultural sector was not felt until mid 1998, "the effect was not felt until 1997 when most parts of Fiji recorded 20 to 50 percent below normal rainfall (Lightfoot, 1999)”. In this drought period, the areas of Nadi, Ba and Labasa received a total of around 1mm of rain. By June of 1998, the Fiji government had declared the Western and Northern Divisions of Fiji a national disaster. This empowered the agencies responsible for relief work to mobilize themselves where 
a total of 54,000 families were receiving food supplies by October of that year and half the population received water deliveries (Lightfoot, 1999). The drought period did not break until October of 1998. Some known facts about the impact of the drought include:

a) The lowest rainfall was recorded in nine consecutive months throughout the Fiji Islands which was lower than the previous low of any other known drought event the country had gone through;

b) GDP in 1998 was reduced by five percent due to the impact of drought particularly on the agricultural sector;

c) As a result of this effect on the agricultural sector, individual families were affected and their take home income as well as those in the western and northern divisions who relied on household gardens for cash crop;

d) There were effects on health with a poor water supply at this time and parents concern for the health risks of their children, led to absenteeism from schools;

e) The drought also highlighted the need to have a mitigation strategy for future events. Therefore the basic categories mitigated for were identified as:
i. Water supply;
ii. Food security;
iii. Income protection; and
iv. Health maintenance.

(Lightfoot, 1999)

In addition, the now well known global El Nino condition and meteorological data serve to provide some basis in planning for mitigation of drought hazards in the future as well as to include its mitigation in the overall disaster risk reduction arrangements for (Varea, 2000).

\subsection{Hydrological Hazards}

\subsubsection{River flooding}

Flooding is a normal part of the regime of all rivers (Handmer, 2004). River flooding is when rivers overflow their banks (McGuine et al., 2002). It is a common occurrence in the Fiji Islands with its steep volcanic terrain, high rainfall and generally small catchments with a few large 
catchments (Raj, 1986; SOPAC, 2006c). Flood plains natural functions are as storage places for flood water from rivers (Priestly, 1995). Viti Levu, on which Navua is located, has four major river systems with drainage basins and associated floodplains totaling an area of $6,000 \mathrm{~km}^{2}$, which is about 58\% of the total area of Viti Levu (Yachiyo Engineering Co., 1998). River flooding is the most common form of flooding for Fiji. Flood plains are, however, known to be fertile land and it is not surprising that most communities decide to settle there for agricultural purposes. Flood plain settlement is an ongoing event posing a high risk to flooding for its inhabitants. Anecdotes of Fiji's history indicate that one of the reasons sugar mills were set up around the rivers of $\mathrm{Ba}$ and Navua back in the 1900s was because of the accessibility of transportation via boats and ships. (Fiji, 1909; Slatter, 1977; Yeo, 1998). At that time, knowledge of the risks and hazards for such a set up was non-existent. This mentality continued to be somewhat prevalent in national development processes and planning in Fiji. It wasn't until the late 1970 s to 1980 s, that natural hazards and risks were considered by the nation, let alone factored into the planning processes. Though largely reactive, the underlying paradigm of interventions set up to mitigate such disasters, was specific only to a particular hazard and this being tropical cyclones and flooding. In fact, since the formation of the Fiji Islands National Disaster Management Office (NDMO), their focus has been specifically on tropical cyclones as a hazard. Flooding was not treated separately as such. Rather it was seen as the effect of the cyclone hazard. However the impact of flooding is often seen in the damage and losses to the particular local area and in terms of the nation and such impacts were no longer easily ignored. On going damage heightened risk perceptions and river flooding was eventually considered a natural hazard in its own right.

Flooding is a common occurrence in the Fiji Islands, particularly during periods of heavy downpour and during the hurricane season. Whilst floods cause considerable damage to people and property, some benefits of flooding include an increase in soil fertility due to sediments being deposited on flood plains, pollutants being washed away and groundwater being replenished but knowledge of such remains poor and requires more studies (SOPAC, 2006c). Floods disturb fragile island economies by affecting individuals, businesses, insurance companies and governments with the costs of flooding being high, for example, Fiji's economy suffers annually losses of some FJD 20 million on average due to flooding (SOPAC, 2006c). As 
Tables 3.3 and 3.4 demonstrate, most tropical cyclones and storms result in flooding. These events also cause severe damage with the cost of such damages running into the millions for the Fiji Islands. Tropical cyclones have been the principal cause of major floods in Fiji (Raj, 1986). However, this is changing as witnessed in the two most recent flash floods of the Fiji Islands in 2004 and 2005 respectively. The area particularly affected during these flash floods was Navua on Viti Levu and Labasa in Vanua Levu. Flash flooding is a type of flooding that occurs when more rain falls over a short period than evapotranspiration, infiltration and local drainage system can handle; and often occurring in semi-arid areas where stream channels are often less developed (Handmer, 2004). Flash floods normally occur within a few hours (Handmer, 2004; Prasad, 2007; Precht et al., 2006). The Fiji Metrological Services uses a standard of 6 hours to declare flooding as flash floods within the Fiji Islands and the region that it services (Prasad, 2007). The damages incurred from flash flooding are often enormous as there is little or no warning time for evacuation.

\subsubsection{Storm surges and coastal flooding}

"Storm surges are often associated with severe tropical storms and consist of unusually large volumes of water flowing onto shorelines. The winds associated with low pressure at the centre of a hurricane causes a swell in the ocean surface which is then pushed onshore by the forward movement of the hurricane (Gibbs, 2004)”. Many of Fiji's communities reside by the coast and this has been a pattern since early settlement and one which continues today. Storm surges lead to coastal flooding and in most cases, cause coastal erosion. Coastal flooding is often a result of storm surges caused by winds and waves elevating the sea (Handmer, 2004). Coastal flooding by definition occurs when the sea inundates a stretch of coastland (McGuine et al., 2002). Other factors that contribute to the extent of inundation include the low atmospheric pressure at that particular time, the shape of the coastline and the near-shore sea bed, the tidal regime and the state of the tide. Tropical cyclones are known to generate tidal surges (Terry et al., 2004; Terry and Raj, 1999). Pacific Island Countries are always subject to coastal flooding, and in most cases, cause coastal erosion. Coastlines that funnel surges into a bay at high tide means that the waves will be heightened and the surge having much impact on the coastal area (McGuine et al., 2002). Fiji, which has many of its rural communities settled along the coast, is often subjected 
to coastal flooding and coastal erosion forcing households to relocate further inland as has been the case for some of the villages in Fiji. Other mitigation measures have been the building of sea walls and the establishment of mangroves on coastal areas. Historically, storm surges in Fiji can be traced as far back as 1869, where waves were reported to be ' 10 feet higher than normal' (McGree, 2002). Some of the tropical cyclones over the Fiji Islands where storm surges have occurred are listed in the table 3.4 below. It is clear that storm surges and flooding that ensues after such are always often the result of tropical cyclones or storms and cause relative damage to particularly coastal communities.

Table 3.4: Storm Surges that have occurred during a tropical cyclone in Fiji.

\begin{tabular}{|c|c|c|c|c|}
\hline Year & Date & Name & $\begin{array}{l}\text { Peak } \\
\text { Intensity }\end{array}$ & Storm Surge Details \\
\hline 1975 & $\begin{array}{l}31 \text { Jan }-2 \\
\text { Feb }\end{array}$ & Val & Hurricane & $\begin{array}{l}\text { Storm surge affected low-lying coastal areas of } \\
\text { Southern Viti Levu }\end{array}$ \\
\hline 1975 & $5-6$ April & Betty & Hurricane & $\begin{array}{l}\text { Storm surge with high seas caused some damage } \\
\text { to properties about low-lying areas of Viwa and } \\
\text { Vatulele Islands }\end{array}$ \\
\hline 1978 & $29-30$ Dec & Fay & Storm & Coastal damage reported in Lau \\
\hline 1980 & 24 Mar4 & Tia & Storm & Caused a moderate storm surge in Savusavu \\
\hline 1982 & 25-31 Jan & Hettie & Storm & $\begin{array}{l}\text { Prolonged gales sustained rough seas for a long } \\
\text { time and wave action caused damage to exposed } \\
\text { beaches, shallow reefs and to structures on the sea } \\
\text { (e.g. jetties) about the Southern Yasawas, } \\
\text { Mamanuca Group, Vatulele, and beaches of } \\
\text { Northern and Western Viti Levu }\end{array}$ \\
\hline 1983 & $\begin{array}{l}26 \text { Feb }-2 \\
\text { Mar }\end{array}$ & Oscar & Hurricane & $\begin{array}{l}\text { High winds, flooding due to heavy rainfall and } \\
\text { storm surge caused widespread devastation in the } \\
\text { West and South of Viti Levu and nearby islands }\end{array}$ \\
\hline 1985 & $16-20$ Jan & Nigel & Hurricane & $\begin{array}{l}\text { Three-metre storm surge and wave action affected } \\
\text { the low-lying islands in the Yasawa and } \\
\text { Mamanuca Group }\end{array}$ \\
\hline 1987 & $\begin{array}{l}22 \text { Dec }-1 \\
\text { Jan }\end{array}$ & Raja & Hurricane & $\begin{array}{l}\text { Extensive damage to crops, coastal installations } \\
\text { and buildings through strong winds, flooding, } \\
\text { landslides, storm surge and wave action on most } \\
\text { of Vanua Levu, parts of the Lau group and } \\
\text { Rotuma }\end{array}$ \\
\hline 1998 & $3-8$ Jan & Susan & Hurricane & $\begin{array}{l}\text { In Kadavu swells and high seas generated by } \\
\text { Susan damaged the jetty and parts of the road and } \\
\text { flooded a coastal village }\end{array}$ \\
\hline
\end{tabular}




\begin{tabular}{|l|l|l|l|l|}
\hline 2001 & $\begin{array}{l}25 \mathrm{Feb}-3 \\
\text { Mar }\end{array}$ & Paula & Hurricane & $\begin{array}{l}\text { Storm surge caused major damage along the } \\
\text { southwest coastline of Viti Levu, Kadavu, Matuku } \\
\text { and Southern Lau Group }\end{array}$ \\
\hline
\end{tabular}

Source: Fiji Meteorology Services 


\section{Chapter 4: Navua Catchments Characteristics}

\subsection{Introduction}

This chapter fulfills the second objective of this thesis which is to trace the evolution of flood hazards and risks through the course of development. Therefore it is critical to have an understanding of the natural characteristics and the built environment of the Navua Catchment, despite its natural function as a floodplain.

\subsection{Physical Characteristics}

\subsubsection{Geology}

The Navua region is located on the southeast of Fiji's main island of Viti Levu as indicated in figure 4.1. Viti Levu was formed from a series of ancient island arcs, most of which are exposed only in the interior (Nunn, 1998). The erosion of these arcs have largely formed Fiji's coasts and deltas including that of the Navua delta (Nunn, 1998). The Navua delta has been observed by geologists to have formed in the later quaternary period of inundation and is the drainage system for the Namosi and Serua highlands. As such, flooding has always been a frequent occurrence in Navua. Parry (1981), states that the delta is relatively young, as the alluvial deposits are only a thin veneer layer overlying marine sediments which form the floor of the delta slightly above present mean sea level. In 2004, however, a discovery of quaternary lake deposits was made indicating the damming of a lake of about 100 - 150 sq. kilometers, that existed 10s of thousands of years ago causing the separation between the Wainidina and Navua river systems. The Wainidina river system drains out into the Rewa Delta, which is the largest catchment on Viti Levu. Geologists suggest that this probably is one of the underlying reasons the Navua delta is frequently flooded as opposed to the Rewa delta (Bonte and Rahiman, 2006). To date, the Navua Delta consists of silt, sand and gravel with rapid build up of alluvium deposits due to erosions in the middle and upper reaches of the Navua River (Rahiman, 2002). Navua is subjected to river flooding, coastal flooding and most recently, flash flooding. 


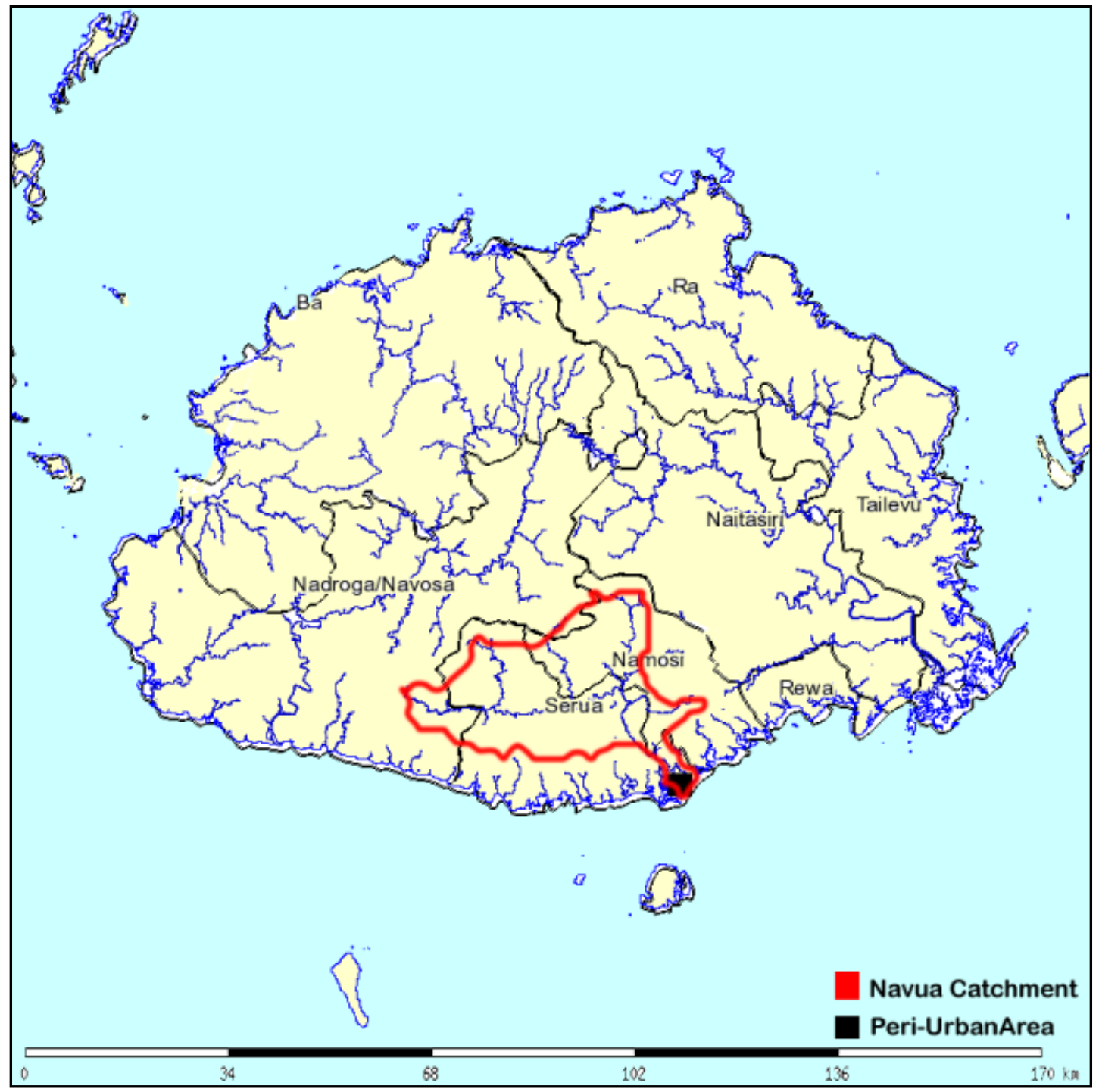

Source: Maps manipulated from 'Mape Kei Viti’, the Fiji Map Server accessed at http://map.mrd.gov.fj

\subsubsection{Hydrology and catchments characteristics}

The Navua catchment area is the third largest river system in Fiji. The upper catchment originates in the mountainous volcanic hills of the Forested Namosi and Serua highlands (figure 4.1) while the drainage area covers a total area of $1070 \mathrm{~km}^{3}$ with the river length extending $91 \mathrm{~km}$ (Melzner et al., 2004; SKM, 2000). Its delta area spans a total of 47 sq. km (Parry, 1981). The delta area is predominantly flat and low-lying with a few residual hills and the active erosions within the river rapidly forming a bay head delta (Rahiman, 2002). Natural levees are found along the main distributaries channels but are not as well developed as those of the Rewa delta 
(Howorth et al., 1993; Parry, 1981). Forest plantations span the upper catchment area while the central business district is located at a bend in the river (Figure 4.2). The central business district includes a market, jetty and bus depot and residential areas on the east side. Situated on the west side of Navua are mainly agricultural lands and the telecommunications tower that provides coverage for the region. Agricultural activities are predominant on the low-lying flood plain with other agricultural activity such as cattle grazing and chicken farming taking place in the middle catchment. Further down the river is a network of irrigation channels and flood gates at the coast which was previously were used to control water needed for commercial rice farming (Mataki et al., 2006).

\subsection{Environment Characteristics}

\subsubsection{Climate system}

Navua is subjected to the overall climate system of Fiji, "the tropical latitude and influence of the nearby warm Southern Equatorial Ocean Current gives Viti Levu a wet/dry tropical climate (Terry et al., 2001)”. Abundant rainfall is usually characteristic of the larger islands in the wet season and often deficient during the rest of the year. The heaviest rainfall occurs on the windward parts of the larger islands - which includes Navua. Annual rainfall in these zones ranges from $3000 \mathrm{~mm}$ around the coast to $6000 \mathrm{~mm}$ on the mountainous sites (FMS, 2007a; Services, 2007). The south-eastern parts of the main islands, generally receive monthly total rainfall of $150 \mathrm{~mm}$ during the dry season and $400 \mathrm{~mm}$ during the wettest months. These parts of the islands have rain on about six out of ten days for the dry season and about eight out of ten days in wet season. During the wet season, brief heavy afternoon showers and thunderstorms are common. In addition, Navua is subject to the south east trade winds and therefore receives much more precipitation than the other catchments in the northwest side of Viti Levu (Terry et al., 2001). The climate particularly continuous heavy rain is a huge initiator of land-form erosion (Crozier et al., 1980; Terry et al., 2001),. 
Figure 4.2: Topography of Navua Peri Urban Area

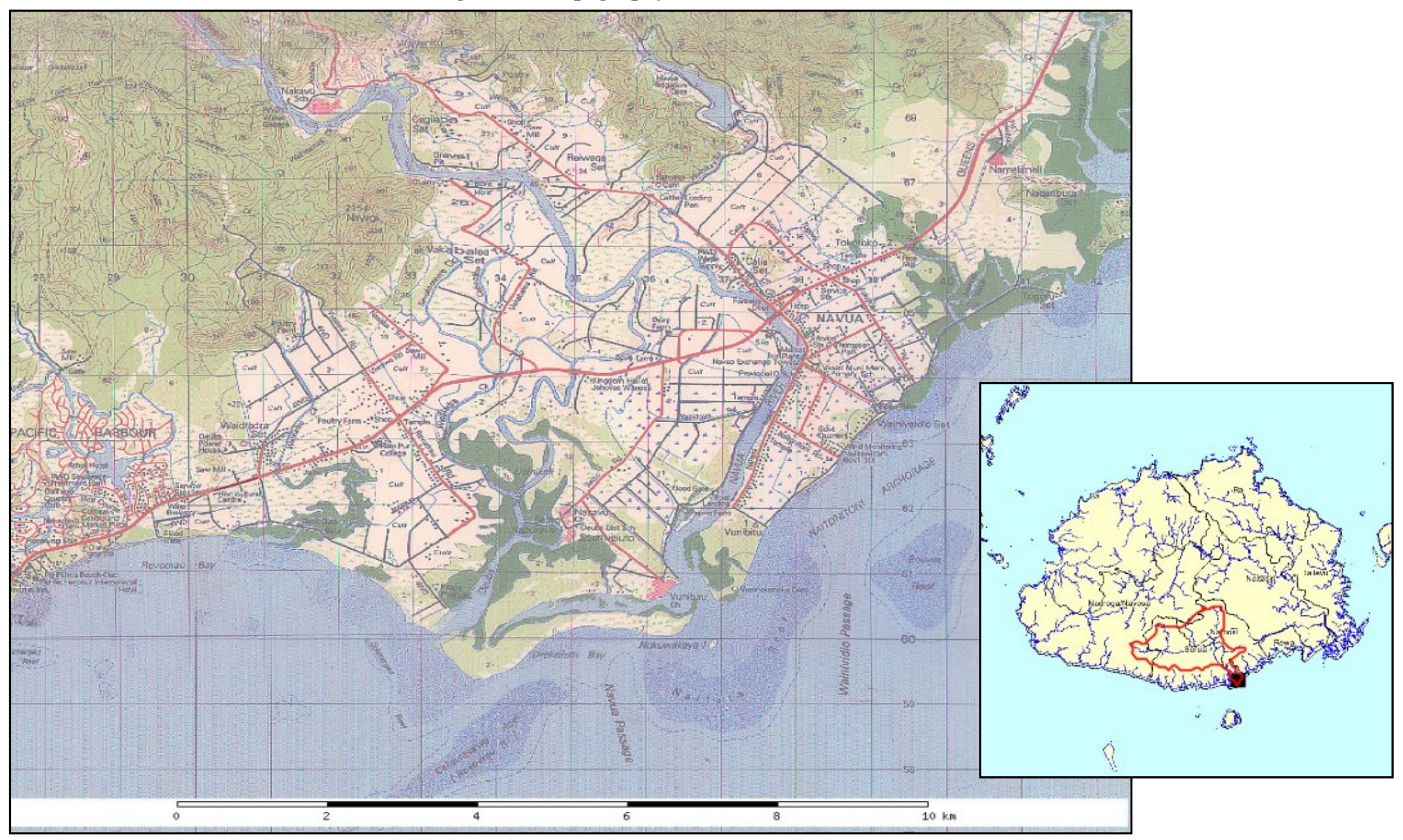

Source: Maps manipulated from 'Mape Kei Viti’, the Fiji Map Server accessed at http://map.mrd.gov.fj 


\subsubsection{Environmental features}

Mahogany plantations are found in the Namosi and Serua hills. From the coast, there is a thin fringe of mangrove ecosystem around the river mouth and extending onto floodplains, which now has been cleared as the land is either under cultivation, fallow or used for grazing (SKM, 2000). Vegetation cover and plants found in the area are also found elsewhere in Fiji and not exclusive to the catchment area. The majority of these plants is indigenous contributing $74 \%$ of the fauna while naturalized plant species make up $25 \%$ of the flora and only $1 \%$ of the flora is endemic (SKM, 2000). Sinclair Knight Merz (2000), report in their environmental impact assessment of the dredging of the river mouth area that these endemic species can be found in other lowland forest throughout Fiji and on their check with Fiji's Environment Department, none of these plants were endangered in any way (SKM, 2000). Navua is surrounded by coral reefs with a vibrant reef ecosystem. Benthic fauna and algae are characteristic of this reef ecosystem. In addition, fish life at the river mouth has been a sufficient source of income for market vendors as well as for subsistence consumption (SKM, 2000). The Navua river mouth is also the access way to the outlying Beqa Island, home of the Beqa people of Fiji and also serves as holiday spots for tourists.

\subsection{Social Characteristics}

\subsubsection{Demographic characteristics}

The Navua community while diverse in its make up is predominantly populated by Fijians of Indian descent as the statistics in Table 4.1 indicate (Statistics, 2007b). On a line graph, the statistics show a gradual increase in the population of the Navua peri-urban area. One of the reasons for this increase is that the area is home for a number of farmers from the northern division, whose land leases had expired (Laddpeter, 2002), and subsequently resettled in the Navua peri-urban area by the Fiji Government. Other reasons include the lower costs of setting up home in this area driven by an unregulated real estate industry. The Navua Peri Urban area is that of the lower catchment (Figure 4.2) 
Table 4.1: Population Statistics of the Provinces and Peri-urban area

\begin{tabular}{|l|l|l|l|l|l|l|l|l|l|l|}
\hline & \multicolumn{4}{|c|}{1996} & \multicolumn{4}{c|}{ 2007 } & \multirow{2}{*}{ \% } \\
\cline { 2 - 11 } & Total & Fijian & Indian & Others & Total & Fijian & Indian & Rotuman & Others & Increase \\
\hline Serua & 15,461 & 8465 & 6003 & 993 & 18,420 & 11,318 & 6,119 & 147 & 836 & 19.1 \\
\hline Namosi & 5742 & 5221 & 411 & 110 & 6901 & 6206 & 518 & 50 & 127 & 20.2 \\
\hline $\begin{array}{l}\text { Navua } \\
\text { Peri } \\
\text { Urban }\end{array}$ & 4183 & 841 & 3228 & 114 & 4969 & 1597 & 3209 & 31 & 132 & 18.8 \\
\hline
\end{tabular}

Source: Fiji Islands Bureau of Statistics

\subsubsection{Governance structure}

Navua has yet to be recognised as a town but is unique in its settlement and purpose as it serves as the central business district and government administrative centre for two small provinces of the Fiji Islands; the provinces of Serua and Namosi (Figure 4.1). Essential public services and amenities exist in this township and they include a district administration, key government offices such as agriculture, a commercial centre including a market, hospital, schools, and residential area. The area is governed by a local authority called the Navua Rural Local authority. A rural local authority has jurisdiction of all areas outside that of proclaimed cities, towns and Fijian villages and are also the public health authority under the Public Health Act. The Navua Rural Local Authority is authorized to control public health, building construction and other matters governed by the Public Health Act. "Many of them have considerable periurban housing development power but they have no powers to charge rates even though they are the planning authority for their relevant areas under the Act. The Central Board of Health, constituted by the Minister for Health, maintains overall coordination of the activities of the rural local authorities (Tuiloma, 2006).” At present, the Navua area does not have any existing disaster risk reduction and disaster management arrangements that is unique to their local area. The overarching National Disaster Management Act while addressing the natural hazards and risks of the country, have yet to implement local area specific hazard and risk management plans. 


\subsection{Economic characteristics}

There are no marked difference in the economic capability of the population of the Navua community. With the exception of three big businesses (by Fiji standards), the majority of those that reside in Navua have jobs in Suva City or are involved in small business enterprises and market stalls. The two big businesses that operate within the Navua catchment are enterprises that are owned by non-residents and contribute to the overall economy of Fiji (Mua, 2007; Statistics, 2007a)

\subsection{Future development plans for navua}

Other than general strategies outlined in the Fiji Strategic Development Plan 2007 - 2011 concentrating resources on the development of rural areas, there are no major plans by government to turn Navua into a town (Fiji, 2006b). The only long-term activity of the area directly involving the Fiji government is the logging of the mahogany plantations in the forested hills of the catchment area as well as the development of a flood early warning system for the people of Navua and improved river monitoring of the Navua River (personal communication with Michael Bonte and NDMO). With the introduction of the Enviromental Mangement Act (EMA) all development activity, particularly river dredging or irrigation, now require an Environmental Impact Assessment, prior to approval of any such work (Fiji, 2005). At the same time, National Standards for forest management are in its draft stages, whereby it will become mandatory for any logging company to have sustainable forest management plans in place. The standards are currently being drafted by the National Forest Management Standards Committee (Sue, 2006) 


\section{Chapter 5: Navua Catchment's Evolution of Flood Hazards and Risk Management}

\subsection{Introduction}

The Navua delta lies quite close to sea-level. 0.8 metres and 1.3 metres from the two trigonometry stations in Vunivitu and Tokotoko respectively (Parry, 1981) while the hills of the upper catchment rise to levels of between 300 to 600 plus metres above sea level. In addition to river flooding, Navua is also subjected to coastal flooding and flash floods as characteristic of catchment areas and low lying deltas. One of the primary initiators of the flooding history of the Fiji Islands, are tropical cyclones. The Navua River has been constantly known to burst its banks or be inundated from storm surges. Parry (1981) states that there has been an inconsistent record of these flooding events until recently. While no river discharge records are available to ascertain the volumes of discharge of the early 1900s, flood history can be deduced from old government reports and other reports of the then Colony of the Fiji Islands. The primary reasons of occupation at that time were for land development for commercial and trade purposes. Therefore settlement of the Navua flood plain area was primarily for this purpose. Native Fijians on the other hand were concentrated more in the upper catchments. The old reports of the then Fiji Colony, highlight that often development was impeded through damages and loss incurred due to the occurrence of natural hazards, particularly by tropical cyclones and flooding, given that the main medium of transport at that time were on waterways. Native Fijians on the other hand were landowning units whose reasons for cultivating their land were primarily for their day to day survival as opposed to development for trade and commerce. History already establishes a pattern that land-use is synonymous with development and that natural hazards are a crucial part of the development process. Firstly, a look into how the perception of flood hazards and risks has evolved through time. 


\subsection{Development prior to 1904}

Because flood plains are fertile, there is a general tendency for human populations worldwide to settle in these areas (Priestley, 1995). This trait can be seen in the land-use history of the Navua Region from the late 1800s onwards. Some of the early settlers were mainly plantation owners, traders and or merchants. These settlers were some of the first land developers of the Navua region, either developing land for various reasons such as coffee, cotton, sugar cane and banana planting; and or for trading purposes. The then, agricultural and business centre potential of Navua was first discovered during a hurricane in 1865.

A cotton planter and trader was surveying the vicinity of the nearshore areas of Viti Levu for cotton planting and after finding no satisfactory site, made the return journey to Rewa. As they approached the mouth of the Navua River, a severe hurricane necessitated their landing in Navua upon which the 'magnificent characteristics of the country, especially its marvelous fertility were impressed upon this party' (Fiji, 1984). Land was purchased using the barter system and soon after began the clearing of the land for agricultural and pastoral activities. In the event that agricultural activities such as cotton and banana planting were unsuccessful, it was replaced with cattle farming. By the 1900's, sugar cane planting was the predominant activity of the Navua area. In 1884, a sugar mill was built half a mile upstream of the Navua River. One of the uses of the Navua River area was as a base for beach-de-mer and pearl shell trading. One of the early settlers at that time was a master mariner who acquired a fleet of 'ten-ton cutters' for this purpose as well as for inter-island traffic. However, his business operations suffered a 'heavy loss of a number of his craft in a severe hurricane' (Fiji, 1984).

The loss from such hazards was one of the reasons traders and settlers of the area opted to concentrate on the sugar industry and other on land activities in the heart of Navua towards the beginning of the 1900s. In addition to the sugar mills on both sides of the river, residence was taken up alongside the river by those involved with the industry. A jetty was built at Naitonitoni of which the foundation is still clearly visible. Navua was referred to by the colonial administrators at that time as the sugar centre of Fiji (Fiji, 1920). 


\subsection{Developments from 1904 - 1914}

The sugar mills closed down in 1905 and 1906, due to ill-management and the 1906 mill shut down was only to see it rebuilt at a larger scale further up the Navua River in October of that same year. In an extract from an interview feature in the Fiji Times of 1977, a daughter of the sugar mill manager of 1906 recalls a flood during her childhood, soon after her family had settled into the Navua plains in 1906. She has a "distinct memory of seeing Fijians paddling around in canoes on water everywhere (Slatter, 1977)". Information sheets from the Fiji Metrology Services Office show that there were hurricanes that affected the west and south of Viti Levu in 1908 and the entire Fiji Islands region in 1909 (McGree, 2002). The ensuing floods might have been what the interviewee in the newspaper article was referring to, who spent two years at the sugar plantation in Navua. The Fiji Colony reports that an assessment of the damage was undertaken in Suva and Navua; however there was no indication of risk management solutions traditional or otherwise but the prevailing perception of it being 'acts of God' underlay the Colony at that time. The Sugar industry was one of the reasons the Suva Navua highway was built. Prior to this the regular means of communication to Navua was by steam launches (Fiji, 1920; Fiji, 1984).

In 1910, the colony of Fiji experienced a hurricane that swept through the entire Fiji group of islands from a northeastern direction. The hurricane hit the Fiji Islands with its eye passing over Suva and by Navua (Fiji, 1920; McGree, 2002). The Fiji colony report cites that 'tidal waves' (now known as storm surges) as high as 8 feet were recorded to have hit the areas of Gau, Koro and Bau; and after midnight in Navua (Fiji, 1920). As a result there was widespread flooding from both the river bursting its banks and from storm surges (Fiji, 1920). There were no records of river level discharges at that time. However the total rainfall recorded at Navua was 86 points in barometrical reading (Fiji, 1939). An extract from the colonial reports of Fiji specifically on the hurricane of 1910 states the following assessment:

On the Navua River the damage to launches and lighters and 'floating stores' is reported as being heavy: several of the latter are missing with their stock in trade. Government buildings have suffered very considerable damage. Part of the Navua Company's mill is unroofed and also various stores in the vicinity. [It is ] 
Reported that the bulk of the native villages and Free Indian settlements have suffered considerable loss in regards to housing. The banana industry will be set back at least 12 months. Cane crop has been "flattened," but as most of it is young the ultimate result may not be affected to the extent of 10 per cent. The total fall recorded in barometrical reading was 86 points (Fiji, 1939).

The extent of damage can be deduced to be severe.

\subsection{Development in the period 1914 - 1934}

Sugar operations ceased in 1922 because of difficulties of "too much rain and unsatisfactory drainage, deficiency of sunlight and a strike by Indian labourers in 1920 (Slatter, 1977)”. Earlier in 1913, dredging work was being undertaken on the Wainibokasi River on Viti Levu to clear the waterway for launches. The majority of Fiji's trade was conducted in the vicinity of Levuka, Rewa and Suva and had just started branching out into Navua with travel and communication mostly on water via steam launches. However the dredging work soon ceased as the frequency of flooding of the river and the heavy currents associated with it, made the dredging of no practical value. Therefore on the advice of the Commissioner of Works, dredging work ceased.

"After carefully considering the evidence tendered by Captain Cuthbert and the views expressed by the Commissioner of Works, the Committee is of the opinion -

(1) That the dredge is unsuitable and its capacity is insufficient to cope with the amount of work to be performed;

(2) That the strong currents and heavy floods to which the Wainibokasi River is subject render the work which the dredge is capable of performing ineffective, and of no practical value; and

(3) That the whole of the bed of the river must be cleared of silt and the banks protected to effect any permanent improvement.

This was one of the first recorded flood mitigation measures undertaken in the Fiji Islands which however was not applied to the Navua delta despite clear evidence of how prone to flooding the 
area was and the shutting down of the Sugar Mill because of unsatisfactory drainage and the use of the Navua river by steam launches.. Most of the productive land area of Navua was developed for daily farmland, mainly cattle grazing. In 1924, the Propriety Factory of the Fiji Pastoral Company opened in Navua and was already in operation for pastoral farming. Eventually, the pastoral company managed a farm area of 3,500 acres, including the land on the western bank of the river which is now under Viti Corp Management (Lonergan, 2005). However, the generally water logged clay soil and rampant weeds of the area meant the investment into expensive land management techniques (Lonergan, 2005).

In 1929 a severe cyclone was experienced in the Fiji Islands Group that was wide in spread and slow moving across the group. Tropical cyclone records compiled in 2002 by the Fiji Metrology Services indicate that it changed its course and passed directly over Eastern Viti Levu, directly passing over Navua (McGree, 2002). This was also the year, Navua experienced the biggest flood (Bonte, 2007; MacDonald, 1949). By 1931, rescue and evacuation measures were practiced by the Fiji population. This is evident in the flooding of all the river valleys in Fiji of this same year where evacuees moved with their possessions to higher ground. Records indicate that Indian farmers were less vulnerable compared to Fijian farmers because of their light homestead and possessions and store of food in paddy sacks. The Fijian neighbor on the other hand, with his heavy 'bure' and his food plantation concentrated on sloping ground on the edge of a stream (Fiji, 1933). In areas of the Rewa River, the previous floods of the vicinity served as a warning system for this flood and so early refuge was sort. The flood of 1931 was one of the worst in the Fiji Islands, with 150 people reported to have drowned or swept away in the middle of the night and in some cases, whole families drowned leaving no survivors (Fiji, 1933).

\subsection{Development in the period $1934-1954$}

Investigations into the potential for hydro electric scheme development in the Northwest areas of Fiji began in 1936 and in 1947 a hydro electric and conservation project was considered and recommended for the Navua Area. Prior to 1957, a survey for the most suitable damn site was carried out in the Navua Gorge in 1946, about 8 miles from the sea. Three tentative sites were identified and drilling works begun to determine the nature of rock underlying the riverbed. 
However, before drilling was complete, a heavy flood washed away the camp site of the engineers thereby stopping the work. "However, a depth of fifty feet was reached in hole No. 2 on the right bank, and thirty five feet in No. 1 on the left bank, before an unusually high flood swept the camp away and stopped work (MacDonald, 1949)”. The Fiji Meteorology Services indicate that a tropical cyclone struck the west and the south of the Fiji Group with winds reaching gale force (McGree, 2002), with the engineers of this project citing in their report that the flood occurred on 10 April, 1946 (MacDonald, 1949). “According to fairly reliable local evidence, this was the highest for at least five years, but a considerably higher one occurred in 1935. Again in 1941 a big flood carried away spans of the Deuba Bridge (MacDonald, 1949)”. This was initiated by a severe tropical cyclone, just west of Navua (Suva's worst hurricane since 1910), flooding out the Navua River and the loss of 6 lives were reported (McGree, 2002). Assessment work resumed in September of the same year. The engineers of this project cited the lack of long-term records of flow and rainfall, to determine the capacity of the dam to be built. Therefore cases from the USA and New South Wales were their reference point of building for flood discharges and the siltation of the riverbed (MacDonald, 1949). However this project never eventuated for reasons not cited in any government report. The Navua Gorge is now well known for tourism in the form of white water rafting, and the upper Navua has been designated Fiji’s first Ramsar Wetlands Convention site.

Under colonial rule, Navua was being developed into a centre similar to that of Suva. By 1951, Navua had developed into a small commercial centre for the agricultural activities of its catchments area. Lonergan (2005), identifies a similar pattern in building development in the Navua peri-urban area by looking at land use data of 1994, 1978 and 1951. She concludes in her dissertation that building patterns in the Navua peri-urban area are centered around the following landscape features:
a) River;
b) Forest resources (defined as non-fragmented vegetation cover greater than one hectare);
c) Closest neighboring building;
d) Road / Highway; and
e) Navua town centre. 
She reports that in 1951, the average distance of a building to the town centre was 1200 metres, while the average distance from the Navua River was 200 metres. In this period the predominant land-use of the area were agricultural activities of low and high value.

\subsection{Development in the period 1955, through Independence, to 1974}

In the period from 1951 to 1978, there was a decrease in these averages of the distances of a building to the town centre, meaning that the density of population began to increase despite knowledge of the flooding of the river and floodplains and losses amassed from previous tropical cyclones. In this period, some of the national initiatives in Fiji included rice planting while forestry was for the first time considered for the area. "While the majority of presently readily accessible forest areas considered to be of economic value has been assessed, the complete inventory of forest resources is far from achievement. There are extensively (sic) densely forest areas north of the Navua River, in the Waimanu Basin in Central Viti Levu, and covering the 'backbone' of Vanua Levu, of which little or nothing specific is known about volumes of accessibility (Fiji, 1960)”. For these initiatives, a pre-investment study was done in 1969 to determine the soil characteristics of the Navua area. Howeever, Hurricane Bebe occurred in 1972, causing severe flooding and considerable damage from strong winds. The jetty at Naitonitoni, which was built to cater for the sugar industry and transportation to and from Navua, was destroyed, resulting in the decline of water transport (Walsh, 1976). Reliable recording of river discharges were available at this time and the time of peak discharge was in the middle of the night of Tropical Cyclone Bebe. By 1973, plans were in place for the irrigated development of 1380 acres of land, the second largest land area in Fiji at that time for rice farming. "The leveling and other related earth and structural work of the first 40 acres (16 ha) ready for cultivation was completed. Construction of supply channel pad involving over 40, 000 cu.yds (33,500 cu. Metres) of earthworks was completed and excavation of drains continued (Fiji, 1976)"

The programme was delayed in 1974 due to the lack of a qualified resident engineer on the project in 1973. Funds initially marked for it was directed to the Northen Division. "In spite of 
difficulties some progress was made, the main achievements being the initial and/or re-digging of major and minor drains to profile levels and the completion of all major access roads on the Navua central area, of the earthen dam to stop tidal inundation and of a major culvert crossing to join the main drain from Waidova and Vunibau / Deuba area (Fiji, 1976). In 1975, a survey was undertaken of the Navua area. The survey established that the old administrations centre at Naitonitoni had now moved upstream, but was still in a vulnerable location next to the river (Walsh, 1976). The survey also cites poor standard dwellings within and close to the town centre as often liable to flooding.

\subsection{Development in the period 1975 - 1993}

No major construction works were undertaken on the Navua Project during 1977 due to the lack of funds of the then Fiji Government. However during this period, previously operated pumping facilities were operated by a diesel motor were converted to electric power. Minor works to complete the development of 12 ha commenced in 1976 were completed. Apart from the above, works on the Navua Project involved routine maintenance and works in relation to cultivation as described above (Fiji, 1979). By 1978, the density of residential and commercial buildings within the area had increased. Lonergan (2005), states that the average distances of the buildings to the town centre was 1100 metres and that the building density was closer to the river. In a baseline survey of Navua conducted in 1975, one of the impediments to land development of the Navua area was land tenureship, a problem that exists up till today, right across Fiji. Historical records dating as far back as the late 1800's cite these reasons also as the underlying cause of full development (Walsh, 1976); (Fiji, 1984). However almost all the initiatives that went ahead have very much been agricultural based. In the period from 1950 to 1965, the Fiji economy was predominantly driven by the agricultural sector. The trend began to change in 1970 with the increase of private services, namely the private ownership of property and tourism (Fiji, 1980). Tropical cyclones were still identified as the cause of the flooding in the Navua area. In 1980, Cyclone Wally caused widespread landslides in the upper Serua Hills (Crozier et al., 1980), in addition to damage from flooding. Large scale sedimentation was also observed in the Navua and Rewa Rivers, prompting the Fiji government to look into mitigation options for the effective management of the effects of flooding and sedimentation (Mudgeway, 1997). The mitigation 
options utilized were the dredging of the Navua River, the construction of levees meant to pond water within the lower lying rice paddies and a higher leeve of 1 metre above the rice paddies which were the drainage irrigation network (Howorth et al., 1993). Dredging of the Navua River began in 1987.

One of the Fiji government's objectives during the five year period from 1981 - 1985 was to "promote a more equitable distribution of the benefits of development and improve social conditions, especially in rural areas and the provision of basic social and economic infrastructure to integrate them (rural area development) more fully to the development process (Fiji, 1980)”, thus, the discussions of the Fiji government in designating Navua as a town. In 1981, following "protracted negotiations and discussions with other government departments, a comprehensive subdivision was approved within the centre of Navua which was to provide sites for 27 Shops, a market, bus stand, parking areas, open space, central and local government offices and residential lots (Fiji, 1983)”. It was hoped that this comprehensive scheme would provide focus for the new development in Navua, one of which was to confer the status of a town on Navua. While the subdivision is evident today, the latter is still to be executed. A severe tropical cyclone in 1993, Cyclone Kina, initiated severe flooding in the rivers of Viti Levu causing substantial damage to infrastructure. There was an almost complete loss of crops in the Sigatoka and Navua Deltas. The total loss to the Fiji economy was assessed to be FJ\$170 million (FMS, 2007b). As a result of this, it was obvious to residents of the Navua area that the irrigation works and ponding effects within the rice paddies were aggravating the extent of flooding:

"It is very obvious that a series of ponding effects took place within the rice paddies; within the leeves of the drainage and irrigation network; north of the highway and adjacent to the dredge piles. These are all relatively recent structures and the surge of excess water, as one ponding system spilled over to another, took the public unaware and by surprise. Interviews with old residents confirmed that flood waters reached them from all directions, which had not been experienced by them in the past (Howorth et al., 1993, p.15)” 
Howorth et al (1993), notes in their investigation of the effects of Cyclone Kina on the physical environment, that the large quantity of sedimentation eroded from the upper catchment into the river and estuaries formed sand bars at the river mouth, and lower reaches of the main channel making it impossible to enter and leave the river mouth even at half tide (Howorth et al., 1993). This was confirmed in an environmental impact assessment of the Navua River in 2000 (SKM, 2000). A series of floodgates had also been constructed in the estuaries as part of the irrigation system of the rice paddies.

\subsection{Development in the period $1994-2004$}

By 1994, a marked shift in the land-use pattern of the Navua area was noted by Lonergan (Lonergan, 2005). There was a distinct shift from the large scale agricultural activity to the building and back-yard, small scale agriculture activity. Lonergan (2005), identified and classified the major land-use features of the Navua Area as primarily for (Lonergan, 2005):

a) residential purposes including buildings and associated gardens, driveways, parking areas and house yards;

b) civic and community type land use buildings, waste disposal sites, cemeteries, roads, sports fields and parks. For Navua, civic and community type of land use mainly served for education, medical, government or religious purposes;

c) large scale commercial agriculture enterprises, subsistence agriculture and low value grazing land and its associated agricultural buildings, sheds and infrastructure. The low value crazing are large tracts of degraded unattended rice fields;

d) natural drainage lines, the South Pacific Ocean and fragments of inland mangrove forests; and

e) commercial non-agricultural land use include dredging and excavation activities, supermarkets , shops, tourism, sites and offices and timber works and stockpiles

However with such widespread development for a catchment of that size with necessary population, flood hazard and risk management were still largely ignored. Furthermore, in 2000, the area just west of Navua was the site for resettled farmers displaced by expiring land leases from 2000 and onwards. In 2004, flash flooding inundated the Navua area, which really 
prompted decision makers and other agencies responsible for disaster management and its underlying risks to take action and assess the risks. 


\section{Chapter 6: Risk Assessment of Navua Flood of 2004}

\subsection{Introduction}

Utilizing the damage and loss data collected by the Pacific Applied Geoscience Commission (SOPAC) and the University of the South Pacific (USP), this chapter includes a risk assessment exercise to highlight the risks to the people of Navua where the elements at risk are the land-use features identified by Lonergan (2005). This chapter is to fulfill the third objective of this thesis which is to determine the role of elements at risk, vulnerability and management in explaining flood losses by using the 2004 floods as a case study. This chapter is divided into two main sections; a) analysis of the lower catchment referred to as the Navua Peri-Urban area (Figure 6.1) and b) analysis of the upper catchment which is the forested hills of the provinces of Namosi and Serua (Figure 4.1). The land-use classifications of the Navua area, which is essentially the elements at risk for the Navua Community, are in five categories (Table 6.1):

Table 6.1: Land Use Classification of Navua

\begin{tabular}{|l|l|}
\hline Land-Use Classification & Features \\
\hline Residential purpose & $\begin{array}{l}\text { Building and associated gardens, driveways, parking areas and } \\
\text { house yards }\end{array}$ \\
\hline Civic and Community & $\begin{array}{l}\text { Buildings, waste disposal sites, cemeteries, roads, sports fields and } \\
\text { parks }\end{array}$ \\
\hline Commercial Agriculture & $\begin{array}{l}\text { Large Scale Agricultural Enterprises, subsistence agriculture, low } \\
\text { value grazing and its associated buildings, sheds and infrastructure }\end{array}$ \\
\hline Natural Drainage Lines & $\begin{array}{l}\text { Estuaries, South Pacific Ocean and fragments of inland mangrove } \\
\text { forests }\end{array}$ \\
\hline Commercial non-agricultural & $\begin{array}{l}\text { Dredging and excavation activities, supermarkets, shops, tourism, } \\
\text { sites and offices, timber works and stockpiles }\end{array}$ \\
\hline
\end{tabular}


Figure 6.1 Topography Map of Navua Peri-Urban area.

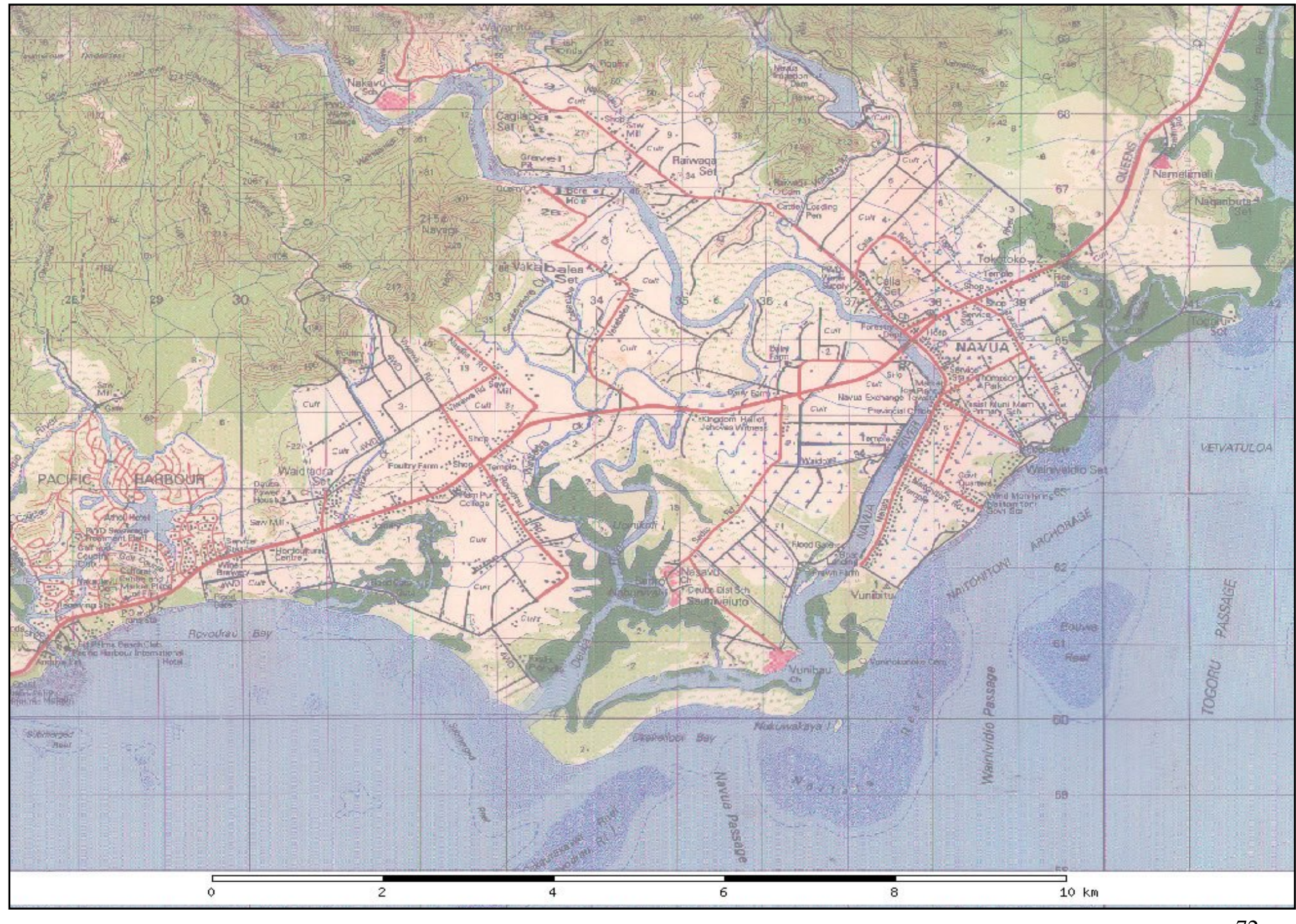




\subsection{Lower Catchment}

Because Navua has not been officially recognized as a town, the Fiji Islands Bureau of Statistics has a system of census enumeration which was utilized by SOPAC and USP to conduct a thorough survey, three years after the flood of 2004. The surveyed area covers the entire Navua peri-urban area excluding the upper catchment of the study site. An earlier survey by USP conducted in the period immediately after the 2004 flood is deemed to be a more accurate account of the events of 2004, given that recollections of its impact were still fresh in the minds of those settled in the vicinity directly affected by the flood. The damage and losses data will be analysed according to the land-use classification system of Navua. Firstly, a flood hazard analysis.

\subsubsection{Navua flood hazard analysis:}

The flood history of Navua, as far as when reliable river recording data began, suggests that Navua is subject to a return flood in magnitude, every 7 years. During Cyclone Wally of 1980 and Cyclone Kina of 1993, the Navua River had flooded to heights of $12.3 \mathrm{~m}$ and $11.0 \mathrm{~m}$ respectively (Bonte, 2007). In the flood of 2004, the river level rose to a height of $10.1 \mathrm{~m}$, slightly lower than the flood water heights of Cyclone Bebe in 1972 of $10.9 \mathrm{~m}$. However in all three instances, it was at a time when the population and land-use activities were not as dense as that of the flood of April 2004. The history of Navua suggests that the flooding of its river and flood plain has always been initiated by tropical cyclones. However in 2004, a tropical depression over the Fiji Group caused heavy rainfall in the Navua region as well as in other parts of Fiji. The National Disaster Management Office titled it a 'flash flood'. 


\subsubsection{Vulnerability}

There are various methodologies used to measure vulnerability or factors that make people vulnerable (Messner and Meyer, 2006; Turner et al., 2003). In a workshop of the Navua community representatives held on 8 and 9 August, 2007, they were asked to identify factors that made them vulnerable to floods. Appendix 2 lists the sectors of the Navua Community represented at this workshop and those factors they identified that made them vulnerable to floods. The participants were divided into six groups and were asked to define the factors which they believe made them vulnerable.. The factors they identified were all based on their first hand experiences of flooding within their community. These responses are then fitted into the four sectors as outlined in the table below:

Table 6.2: Vulnerability factors identified by six groups of Navua community leaders in Aug 2007

\begin{tabular}{|c|c|}
\hline Sectoral Areas & What makes them vulnerable? \\
\hline Social & $\begin{array}{l}\text { 1. Isolation } \\
\text { 2. Laid back attitude often characteristic of Fijian Rural } \\
\text { Communities commonly known as the 'malua' (a lack of } \\
\text { swiftness in response to anything) fever } \\
\text { 3. Lack of disaster awareness information on hazards and risks }\end{array}$ \\
\hline Environment (natural) & $\begin{array}{l}\text { 1. Low lying area } \\
\text { 2. Catchment area location of Navua business district } \\
\text { 3. Narrow river mouth } \\
\text { 4. Shallow River } \\
\text { 5. Uncertainty }\end{array}$ \\
\hline Built Environment & $\begin{array}{l}\text { 1. Poor drainage, land development } \\
\text { 2. Private mitigation methods of their neighbor down the road } \\
\text { has implications on someone else } \\
\text { 3. Narrow River Mouth } \\
\text { 4. Development of Land } \\
\text { 5. Squatting along river bank lives little room for developing }\end{array}$ \\
\hline
\end{tabular}




\begin{tabular}{|l|l|}
\hline & \multicolumn{2}{|c|}{ mitigating measures } \\
& 6. Uncertainty \\
\hline Economic & 1. Poverty \\
& 2. Uncertainty \\
\hline
\end{tabular}




\subsubsection{Elements at risk}

a) Land Use for Residential Purposes

Of the 222 households (every $6^{\text {th }}$ house) surveyed by SOPAC, the length of time in which they have resided in the Navua peri urban area ranged from as early as1980s right to the time of the survey in 2006. The majority of those surveyed being residents from the year 2000 onwards. With the exception of one respondent who has been residing in the Navua area since 1970. Not everyone indicated the length of time in which they have resided in Navua. However for those that did, more than 54\% have resided in Navua since 2000. Most of the surveyed participants had some form of association with a religious group or a community group whom they identified as places of refuge in a time of a disaster. In an earlier survey in 2003, USP reported that most Navua households surveyed while aware of the flood prone areas of the flood plain, only moved house or raised their house on stilts, in the period immediately following a flood to reduce their risks of future flooding. Of the 42 households surveyed by USP immediately after the flood, all their houses are either raised on piles or stilts at an average of 0.45 metres off the ground. However, these measures were not effective as most of the houses were still affected by the flood waters and silt and had damages to either the structure of the house or their contents and in some cases, to both property structure and content.

According to the USP survey of households, the total loss or damage to residents and their property because of the 2004 flood came to a total of FJ\$314, 870: This worked out to an average damage per household in the 2004 flood was F\$J6497.90.

Table 6.3: Estimated Damage of Losses to Households from 2004 Flood

\begin{tabular}{|l|rr|}
\hline Estimate Damage & \multicolumn{2}{|c|}{ FJ\$ } \\
\hline Building Structure & $\$$ & $28,760.00$ \\
\hline Contents & $\$$ & $200,750.00$ \\
\hline Crops & $\$$ & $11,600.00$ \\
\hline Livestock & $\$$ & $28,960.00$ \\
\hline Other Possessions e.g Car & $\$$ & $44,800.00$ \\
\hline Total Estimate Damage/Loss & $\mathbf{\$}$ & $\mathbf{3 1 4 , 8 7 0 . 0 0}$ \\
\hline
\end{tabular}


With a flood return in magnitude of every 7 years, the risks calculation to households for every flood could be expressed as:

$\mathrm{H}: 1 / 7 \times 100=14 \%$

Estimate Total Damage $=\$ 314,870$

Total Households: $42 / 100=0.42$

Risks for every flood for residents of Navua could be expressed as;

$$
0.14 \text { x } \$ 314,870 \times .42=\text { FJ\$18,514. }
$$

Given the average income of residents in the Navua area, the risk per household is very high.

\section{b) Civic and Community Land Use and Services}

Naitata Road, on the right of the river (figure 6.1), where the business district of Navua is concentrated was flooded during this time. As a result, most of the essential services were affected. I personally recall the flood waters inundating the plains on both sides of the river forcing the closure of the Navua Bridge as flood waters had inundated the Queens Road (the main Suva - Nadi highway) and the low lying land area on both sides of the Navua Bridge. During a time of natural disaster, evacuation centres are normally either civic and/or educational buildings. One such evacuation centre is the Vashist Muni College which was however flooded in 2004. The USP survey indicates the school had flooded to a depth of $1.75 \mathrm{~m}$ for the duration of 6 hours. In addition, other essential services such as the Navua Hospital and the Navua telephone exchange were severely affected as well. The hospital building and compound was in 8 feet of water despite it being raised and was flooded for the duration of 17 hours. The average estimate time of travel to these evacuation centres from residential houses is about 25 minutes. The further away one is from an evacuation centre, the longer it would take. Some respondents said that their travel time to an evacuation centre is dependant on the current of the Navua River. Some travel by boat, car, taxi or are able to walk to the evacuation centre. During the 2004 floods, damages to essential public services were valued nationally as other areas within Fiji flooded as well. The damages caused by the 2004 flooding Fiji wide was estimated by the Fiji 
government at FJ\$11, 585, 392.00 (NDMO, 2005). A breakdown of these estimates is in table 6.4

Table 6.4: Civic and Community Estimate Loss / Damage from 2004 flood

\begin{tabular}{|c|c|c|c|}
\hline Item & National cost & Navua value & Comment \\
\hline \multicolumn{4}{|l|}{ Government losses: } \\
\hline $\begin{array}{l}\text { - Replacement of destroyed } \\
\text { lean-tos }\end{array}$ & & 34800 & \\
\hline $\begin{array}{l}\text { Infrastructure } \\
\text { rehabilitation }\end{array}$ & & 400000 & Underestimate \\
\hline - $\quad$ Medical services & & 2000000 & \\
\hline - $\quad$ Education & & 25625 & Underestimate \\
\hline - $\quad$ Provision of water tanks & & 0 & \\
\hline - $\quad$ Emergency clothing & & 1000 & \\
\hline $\begin{array}{l}\text { Coordination by } \\
\text { government }\end{array}$ & & Not known & \\
\hline $\begin{array}{ll}\text { - } & \text { Food rations and disaster } \\
\text { sundries }\end{array}$ & & 10908 & \\
\hline $\begin{array}{ll}\text { - } & \text { Agricultural and fisheries } \\
\text { losses }\end{array}$ & & 832388 & $\begin{array}{r}\text { Agriculture component } \\
\text { possible overestimate }\end{array}$ \\
\hline \multicolumn{4}{|l|}{ Unvalued humanitarian aid: } \\
\hline - $\quad$ Blankets & Not known & Not known & \\
\hline $\begin{array}{l}\text { - } \begin{array}{l}10000 \text { oral rehydration } \\
\text { salts }\end{array} \\
\end{array}$ & & Not known & \\
\hline - 2400 litres bottled water & & Not known & \\
\hline - 11 cartons Fiji water & & Not known & \\
\hline - $\quad$ Red Cross provisions & Not known & Not known & \\
\hline \multicolumn{4}{|l|}{ Other losses } \\
\hline $\begin{array}{l}\text { Early school break for } \\
\text { Catholic primary School } \\
\text { due to need for fresh water }\end{array}$ & Not known & Not known & \\
\hline $\begin{array}{l}\text { - Volunteers to government } \\
\text { and NGOs }\end{array}$ & Not known & Not known & \\
\hline $\begin{array}{ll}\text { - Trauma and irreplaceable } \\
\text { items }\end{array}$ & Not known & Not known & \\
\hline ESTIMATED TOTAL & & 3304721 & \\
\hline
\end{tabular}

Source: Figures adapted from total economic losses of Navua Community table from Economic Cost and Benefit of Early Warning System Survey of Navua.

The above losses amount to $28.5 \%$ of the total losses to Fiji as a result of the 2004 flood. In this context, risks of floods in Navua in terms of civic losses to the Fiji government can be expressed as:

$.14 \times \$ 11,585,392 \times .28=\mathrm{FJ} \$ 45,4147.36$ 


\section{c) Land Use for Commercial Agriculture}

Of the 11 large (by Fiji Standards) commercial activities in the Navua peri-urban area, six are non-agriculture based. In their survey of Navua in 2007, SOPAC estimated the total losses to these large commercial business in terms of the content to be FJ\$788977. For one of the big agriculture based business Dairy Farm of Fiji (DFF), the amount of lost business as a result of damage to property and agricultural products was estimated at FJ\$1.5m. Two of the five agricultural based are explored in this section.

Goodman and Felder's Crest Chicken Farm which is located in Vakabalea in Navua (figure 6.1) reported a sharp decline in hatching after the flood (Mua, 2007). Mua (2007), states that the reason Goodman and Felder's farm is located in Vakabalea is because the location is in an environment that is far away from other livestock. The Vakabalea Farm is specifically for breeding chickens which are then supplied wholesale to supermarkets within the Fiji Islands. In the flood, the loss accrued by the company in four hours amounted to \$909, 913 (Mua, 2007). The floodwaters damaged equipment as well as farm products. The table below provides a summary of the type of losses incurred by the company in the flood:

Table 6.5: Losses to Commercial Company 1

\begin{tabular}{|l|cc|}
\hline & \multicolumn{2}{|c|}{ Cost (F\$) } \\
\hline Electrical & $\$$ & $5,785.00$ \\
\hline Waste Management & $\$$ & $3,080.00$ \\
\hline Cartage & $\$$ & $12,000.00$ \\
\hline Woodshavings & $\$$ & $3,700.00$ \\
\hline Equipment & $\$$ & $51,760.00$ \\
\hline Labour & $\$$ & $7,500.00$ \\
\hline Bird Loss & $\$$ & $86,067.00$ \\
\hline Egg Loss & $\$$ & $729,370.00$ \\
\hline TOTAL LOSS & $\$ \mathbf{8 9 9 , 2 6 2 . 0 0}$ \\
\hline
\end{tabular}

In response to the flood and the losses they incurred, the company instituted a flood mitigation strategy to mitigate against future flood events. These measures include the building of a flood bund wall to retain flood waters outside the compound of their breeder sheds as well as the installation of flood gates. They have also raised the shed floor $40 \mathrm{~cm}$ off the ground. Other measures they have instituted include the maintenance of the surrounding drain to protect their 
property and assets against floods as well as the receiving of daily weather reports from the Fiji Meteorology Services office. The cost of the mitigation amounted to almost $\$ 20,000$ (Table 6.6).

Table 6.6: Cost of Mitigation Measure to Commercial Company 1

\begin{tabular}{|l|r|}
\hline & Cost (FJ\$) \\
\hline Flood Bund Wall & $\$ 150,000$ \\
\hline High Flow Electric Water Pumps & $\$ 8227$ \\
\hline Flood Gate & $\$ 4,100$ \\
\hline Additional Buttresses & $\$ 15,078$ \\
\hline Aluminum Boat & $\$ 5,000$ \\
\hline Life Jacket and Oars & $\$ 1,500$ \\
\hline Outboard Motor & $\$ 2,000$ \\
\hline Maintaining Surrounding Drains & $\$ 4,000$ \\
\hline Weather Station on Site & $\$ 1,000$ \\
\hline Road Upgrade & $\$ 5,000$ \\
\hline TOTAL & $\mathbf{\$ 1 9 5 , 9 0 5}$ \\
\hline
\end{tabular}

Goodman and Felder's structural approach to flood mitigation while commendable is of the paradigm of behaviouralist, whereby flood mitigation is to protect against the event. Part of their mitigation strategy was the installation of rain gutters that ran outside of the bund wall around the breeder farm as well as the building of levees on the river side of their property.

Downstream from the Breeder Farm, on the other side of the bridge, is Viti Corp, a pastoral farming company located closer to the estuaries. Viti Corp which was formed in 1970 is a Fiji government owned industry currently under lease to a Dairy Farm Fiji Ltd (DFF) ${ }^{7}$ whose current initiative is prawn farming. The initiative is in collaboration with the University of the South Pacific which provides technical advice and labour to the farm on a cost recovery basis (Ponia, 2007). The Viti Corp buildings are not built on piles or raised off the ground. During the 2004 flood, flood waters inundated its compound to a height of less than four feet for a period of about $12 \frac{1}{2} 2$ hours, despite flood gates being built at the estuary further downstream. The depth of flood waters in the buildings was 0.91 meters, as noted by the USP Survey. Damages to the building

\footnotetext{
${ }^{7}$ DFF is a small portfolio of two entrepreneurs from New Zealand. "The primary business of the parent operation in Fiji (Highway Stabilizers Ltd) is road works, bridge construction and other road projects. The Viti-Corp lease for the DFF prawn farm was added as an 'industry good' project, intended to raise the company profile" http://www.spc.int/coastfish/news/Fish_News/120/Aquaculture_120.pdf
} 
structure, content as well as their products were estimated at about half a million as indicated in the table below.

Table 6.7: Losses to Commercial Company 2

\begin{tabular}{|l|l|}
\hline & \multicolumn{1}{|c|}{ Cost (FJ\$) } \\
\hline Damage to Building Structure & $\$ 250,000.00$ \\
\hline Damage to Contents & $\$ 100,000.00$ \\
\hline Damage to Crops & $\$ 500.00$ \\
\hline Damage to Livestock & $\$ 59,400.00$ \\
\hline Estimated Total Damage & $\mathbf{\$ 4 0 9 , 9 0 0 . 0 0}$ \\
\hline
\end{tabular}

Other abandoned initiatives in the Navua flood plain include the rice farming project which involved a great deal of structural works, such as the building of levees, flood gates and irrigation systems which residents of the Navua area claim to aggravate the inundation of flood waters as it hindered the flow regime of the river.

Total losses to commercial agricultural companies as a result of the 2004 Flood are as follows:

Table 6.8: Total Losses to Commercial Agricultural Land Use in 2004 Flood

\begin{tabular}{|l|cc|}
\hline & \multicolumn{2}{|c|}{ FJ\$ } \\
\hline Commercial Company 1 & $\$$ & $899,262.00$ \\
\hline Commercial Company 2 & $\$$ & $409,900.00$ \\
\hline Other Commercial Companies & $\$$ & $78,977.00$ \\
\hline Total Estimate Losses & $\mathbf{\$}$ & $\mathbf{1 , 3 8 8 , 1 3 9 . 0 0}$ \\
\hline
\end{tabular}

In their survey of the Navua flood, SOPAC found that the total business losses suffered by business operating in the Navua community amounted to FJ\$2,980,837. These include the small market stalls and business that operate in the Navua Business District. Commercial Agricultural losses were $46 \%$ of the total losses suffered to the business community as a whole. The value of commercial company 2 alone is FJ\$7.2 million. To express the risks suffered to commercial company 2 as a result of the flood, it could be expressed as:

$0.14 \times \$ 7,200,000 \times 0.05=\mathrm{FJ} \$ 5040$ 
Commercial Company 2 is a pastoral and dairy company whose risks to flooding are low in relation to the overall value of the business. Because their risks are of a low probability, one could make the assumption that this is probably why they have yet to put in mitigation measures to the extent that Commercial Company 1 has. Even mitigation measures such as raising the company sheds on piles or relocation are options worth considering.

\section{d) Natural Drainage Lines}

While there has yet to be any methodology on measuring debri flow, in a flood (PenningRowsell et al., 2005), it is obvious from landslides study and during floods that intensive rainfall initiates slope failure and that debri flow from slope failure often take the course of natural drainage lines (Crozier et al., 1980). Slope failure and erosion is also related to deforestation. However, it's the activities downstream that contribute to flood waters having a wider impact when the natural capacities of rivers have reached its end and storage places of the flood plain have been modified.

As stated previously, the rice farming initiative of the 1970s saw the construction of levees, one metre above the rice paddies to allow for ponding of water. In addition, irrigation channels were constructed alongside the levees and floodgates were also constructed at the estuaries. Figure 6.1 shows the locations of these floodgates in the estuaries closer to the river mouth. The initiatives have long been abandoned, the floodgates are not maintained and the irrigation channels are now often blocked from debri flow from the upper catchment (USP Survey). In the survey of Navua residents and business, it was clear that the majority of the inhabitants have observed of the human activities that impact on flooding, for example, the impact on the natural drainage system which they believe ought to naturally drain out into the Pacific Ocean, which does not happen when they are inoperable and not maintained. The residents also believe that the soil erosion from the logging activities in the upper catchment causes sediments to be deposited in the river areas from the 'bridge to the mouth of the river'. In their Environmental Impact Assessment (EIA) for the dredging of the Navua River, the contracted assessors confirmed that the natural flow and regime of the river does build up at the river mouth, due to sedimentation of the river channel. The sediment build up is such that even boats from the outlying island of Beqa find it impossible at times to get through the river mouth to the Navua business centre, even during high 
tide (SKM, 2000). This debri flow also blocks the drainage system, that was built for the rice farming project. In addition, the inconsistency in the dredging of the river as part of the watershed management programme of the Fiji government executed through the Ministry of Agriculture of Forest and Fisheries all contribute to the extent of floodwaters impacting on the flood plain.

The Navua residents actually believe that the removal of the irrigation channels and floodgates will allow for the unhindered natural flow regime of the river outwards towards the ocean. For the Naitonitoni area (figure 6.1), a resident believes that there is a "need for a water outlet in Naitonitoni, especially at the beach side where the public block the side by building seawall without any outlet”. However, when one looks at aerial photographs of the Navua area over the periods of 1951, 1978, 1994, the difference in the meandering of the Navua River is evident as a result of natural processes of river erosion and to some extent human activities such as river dredging. River dredging has been proven to alter the flow and regime of any river (Marker et al., 2005).

\section{e) Commercial Non-Agriculture}

Commercial non-agricultural activities in Navua are concentrated in the business district centre (Figure 6.1). In analysing the survey data, a total of 62 different entities come under this category. They range in their services from service stations, market stalls and non-market services to concrete industries involved in the aggregate mining of the Navua River (Table 6.9).

Table 6.9: Commercial Activities within the Catchment

\begin{tabular}{|l|r|}
\hline Commercial Activity & Number \\
\hline Service Station & 1 \\
\hline Building Construction & 1 \\
\hline Retail Supermarket & 1 \\
\hline Pioneer Concrete Industries & 1 \\
\hline Shopping Centre & 17 \\
\hline Market Stalls (selling crops, fruits and vegetables) & \\
\hline $\begin{array}{l}\text { Non-Market (grocery, retailer, nursery, fast-food, } \\
\text { tourism related, handicraft, Liquor Shop, tours, barber } \\
\text { etc) }\end{array}$ & 41 \\
\hline TOTAL & $\mathbf{6 3}$ \\
\hline
\end{tabular}


However, being alongside the river, most of these initiatives felt the brunt of the impact of the floods. The total losses of these businesses as a result of the flood, was estimated to be FJ\$1,592,698. These losses included products as well as damage to assets. The losses are enormous in relation to losses suffered by the other commercial companies whose businesses have a proportionally higher value than the smaller business beside the river.

\subsubsection{Recovery and mitigation strategy}

The high risks to land-use incurred to the Navua community are quite high that recovery and mitigation strategies are integral across the board, from private households, to businesses (market stalls, cooperatives and bigger business), to commercial agricultural and non agricultural entity's and to the Navua Community as a whole. In private households, most of the residents of Navua are aware of the repercussions of flooding. Some instill their own backyard (so to speak) type of mitigation by the raising of their floor by either piles, concrete or stilts to heights of an average of .45 metres off the ground. Others are more aware of evacuation centres and the places they could roost at in the event of a flood. Civic buildings and roads on the other hands, have called on the government to be more proactive in the facilitating of flood hazards and mitigation within the Navua area. As a result of the 2004 Flood, there are now talks of relocating the Navua Hospital away from its current location of 100 metres next to the river. Commercial agricultural business on the other hand have implemented their own mitigation measures to protect their business from future events in the hopes that they would be best prepared should something of this nature re-occur. Business owners particularly are calling on the government to clear drainage or remove the drainage channels constructed for the rice industry, to dredge the river regularly and for the installation of an early warning system which should at least give them sufficient time to evacuate and save what they can in the event of a flood. There is a sense of working together from community groups that operate within the Navua area. 


\subsection{Upper Catchment}

The upper catchment of Navua is characterised by steep volcanic terrain, a gorge, wet tropical rainforests, and mahogany plantations. Nestled amongst it are villages of Serua and Namosi Provinces. With its high levels of precipitation the area is often a recipient of the major impacts of tropical cyclones and/or tropical depressions. These natural factors make the area susceptible to frequent landslides (Crozier et al., 1980; Melzner et al., 2004). In earlier landslide assessment work undertaken in the area following Cyclone Wally in 1980, landslide activity was considered the source of most of the problems experienced by the Navua community, having demolished the village water supply as well as introduced silt and logs into the stream system (Crozier et al., 1980). These sentiments were reiterated by village inhabitants in a stakeholder consultation workshop by the Fiji government in 2003 to identify the issues surrounding water, aggregates and hazards of the area and the vulnerabilities that these inhabitants face (Tokalauvere and Biukoto, 2003).

In 2006, landslide hazards were mapped in conjunction with the Forestry Department of Fiji to enable the department to delineate logging concessions without endangering communities and infrastructures (Tokalauvere and Biukoto, 2003) The only other major activities in the upper catchment are river mining for aggregates and tourism (white water rafting) in the Navua Gorge (Naiova, 2007; Tawake and Tokalauvere, 2007). In the landslide mapping exercise, Melzner (2004), identified the types of landslides that the catchment area is subject to. The slides which she identifies as being typical of the Navua area are translational and rotational slides, debris flows, rock falls and complex features (Melzner et al., 2004). The translational slides and some shallow rotational slides she observes to be very common along the logging roads and often develop into debris flows because of the steep relief and high precipitation of the area. Melzner (2004), states that the debris flow consist of fine material and often found in the headwaters of the tributary catchments and along roads and rivers (Melzner et al., 2004). Crozier et al (1980), concluded that the landslides initiated by natural factors represents a "rare high in magnitude event” with repercussions downstream of stream contamination and sediment build up in flood plains even with smaller rainstorms that has been stalled by vegetation cover along the way. The high magnitude event demonstrated that vegetation cover acts as a deterrent to the velocity of 
debris flow with piles of debris as high as 5 metres in height entangled in trees during Cyclone Wally (Crozier et al., 1980)

In addition to natural causes of landslides, mass movement is also attributed to deforestation and dredging of the rivers for aggregates (Naiova, 2007). In the review of rural land use completed in 2002, Leslie and Ratukalou (2002) highlight how the land resources division’s survey of 1966 - 69, showed that 30 - 33\% of the indigenous forest serve as protection forest for stream flow and watershed conservation (Leslie and Ratukalou, 2002a). The report also highlights that the encroachment by logging and clearing was quite common as of 1988 and so was improper landuse and forestry harvesting practices (Leslie and Ratukalou, 2002a).

\subsubsection{Logging, river mining and dredging}

The rainforests and mahogany plantations make up 95\% of the total catchment area of Navua (Melzner et al., 2004; Tokalauvere and Biukoto, 2003). Mahogany planting had started in Fiji in the early 1930s and in the Navua area in the 1960s. Accelerated deforestation however, probably , began in the 1900's when land began to be cleared for pastoral farming and other agricultural activities, with deforestation for the purposes of logging begining in the upper catchment in the 1960s to 1970s. Forestry plantations in the Upper Catchment are being harvested extensively by the Fiji government owned Fijian Hardwood Limited (Tokalauvere and Biukoto, 2003).

As earlier studies conclude, the vegetation cover is a deterrent to the velocity of water and debris flow, and its removal of it through unsustainable forest management practices allows its flow downstream towards the central business district. In fact unsustainable logging practices actually contribute to amount of debris available for downstream movement in the form of branches and other by-products of logging. Such debris flow was characteristic of the floods of 2004. Debris was found downstream at the Navua bridge and in the central business district where buildings and land development had allowed for infilling within compounds of private properties and within houses. As an example, the Navua hospital was covered in two feet of mud when the water levels had resided. 
In addition, the river regime and delta of Navua and the reefs on the outer estuary creates natural deposit points for sediments and other debris to build up at the estuary and or to flow back inwards with the changing tides, a process known as infilling. In 2000, the Fiji Ministry of Agriculture contracted a private company, Sinclair Knight Merz, to undertake an EIA of the dredging of the Navua River mouth. In their assessment they set about determining the flow regime of the river as well as to determine the drift of the waves. Under both cyclonic and normal conditions, they deployed drogues to determine the rate of the flow. Their assessment concluded that drogues deployed under cyclonic conditions, were moving very fast indicating the rate at which the river regime flows in and out of the river mouth. Because the estuary is subjected to a long-shore drift, this would mean that there would be infilling of the dredged areas particularly under cyclonic conditions when the regime moved at a faster pace. The assessors recommended dredging of the river mouth for navigation purposes only and not for flood mitigation. To dredge for flood mitigation would mean dredging at a deeper depth than dredging for navigational purposes. However, some contradictions emerge in their EIA report. They report that since the river had been dredged in 1987 as part of the wider watershed flood management programme of the Fiji Government, there had been no floods in the Navua catchment since 1991. The EIA was conducted in 1999 and subsequent report produced in 2000. The report later cites a big flood in 1993, where river levels rose to a height of 11.1 metres (SKM, 2000), higher than the floods of 2004. Records with the Fiji Meteorology Services indicate that Tropical Cyclone Kina occurred in December 1992 to January 1993 where severe damage was reported in the Navua delta.

In their presentation at the focus group meeting of 2008, Goodman Felder highlighted that their other farm in Vakabalea was not flooded because of the dredging activity not far from their farm (Mua, 2007). However, although the next dredging activity of the Navua River was scheduled to take place in 2004, but for reasons, unknown, it did not eventuate (Mataki, pers com). In 2007 an EIA of river mining for aggregates was undertaken on behalf of the people of Navua where it was concluded that loose river dredging practices in the lower catchment had resulted in the lowering of river levels in the upper catchment exposing the communities of the upper catchment to degrees of vulnerability, as well as further increasing the likelihood of risk to those in the 
lower catchment and floodplain. The EIA report shows strong evidence of erosion taking place in the back of the Navua River where dredging is taking place. The EIA also concludes that:

- the river bank has widened due to the impact of extraction upstream;

- $\quad$ past and current extraction practices have caused river bank erosion;

- continuous bank erosion may threaten the village in the future;

- notable decreases in water level in the river have occured; and

- tourist transportation may be affected if unsustainable river aggregate extraction continues(Naiova, 2007).

The Environmental Impact Assessors conclude that while aggregate mining was responsible for the extraction of gravel and other debris, the loose particles of fine sand and mud were transported downstream often building up as sediments around the river mouth and blocking navigational access or distributed into private homes and property as well as the town in a flood, as it was the case in the big flood of 2004.

Since there are no set methodologies to determine the amount of debris flow, it is however common knowledge that deforestation of an upper catchment area has repercussions downstream and that river aggregate mining have been found to alter the flow regime of a river. In the absence of such a methodology, a cost/benefit analysis is the closest to weighing the risks suffered by the Navua Peri-Urban area as a consequence of the activities of logging and river mining, as illustrated in table 6.10: 
Table 6.10: Cost and Benefits of Upper Catchment activities over flood losses of Navua

\begin{tabular}{|l|l|l|}
\hline & \multicolumn{1}{|c|}{ Benefits FJ\$ } & \multicolumn{1}{|c|}{ Costs FJ\$ } \\
\hline Mining and Quarrying & $\$ 43,384$ & \\
\hline GDP in 2004 from forest production & $\$ 38,366$. & \\
\hline Navua Business District total loss & & $\$ 2,980,837$ \\
\hline Total ‘Services' Losses & & $\$ 3,304,721$ \\
\hline TOTAL & $\mathbf{\$ 8 1 , 7 5 0}$ & $\mathbf{\$ ~ 6 , ~ 2 8 5 , 5 5 8}$ \\
\hline
\end{tabular}

The figures in the mining and quarrying column above includes gold mining, which is not an activity of Navua. However, gold mining has not had a significant impact on the Fiji economy for some time, while the past years has seen a boom in the construction industry (Statistics, 2007b). Therefore the total amount for which Fiji benefits from the mining and quarry industry is largely from quarrying activities. The total flood losses for 2004 nation wide for Fiji was assessed at \$11,585,392.00 (NDMO, 2004). Economic Benefits analysis of aggregate mining presented to the villages in the Upper Catchment of Navua forecast annual revenue of FJ\$52,000 (Naiova, 2007). The costs incurred from one area alone (Navua, in this case) from flooding, is still far greater than the overall benefits that to Fiji that mining and quarrying contributes.

\subsection{Discussions}

In looking through the history of land-use in Navua, the baseline town survey, the flood related data gathered by the various institutions with an interest in Navua, various assessment reports, cost-benefit analysis of floods and other natural hazards, a few questions comes to mind. Some of these are:

a) Why can't the economic benefits of human activities such as river aggregate mining be invested back into flood risks management considering that floods are the hazard that the Navua area is most susceptible too?

b) How can large private companies operating in the Navua area be made responsible for flood hazard and mitigation?

c) Even if the country has put in place flood hazard and risk mitigation measures, how can they move away from the paradigm of flood hazard and risks mitigation for protection towards the more structuralist paradigm of taking into account the socio-economic and aesthetic value of an area, such as Navua. In addition, how can flood hazard and risks 
mitigation measures take into account future business trends such as if the project is abandoned (like the irrigation project of the past), what are the plans in place to minimize the impact of flooding due to land development.

d) Why are there no agreed standards for risk management in Fiji?

e) Are the previous projects of the Fiji government reversible? Can the irrigation channels be removed?

f) What are the implications of stockpiling the dredged river bed contents to act as levees on the banks of the Navua River?

These questions prompt a look into the governance structure of hazards and risk management in Fiji as well as governance structures that relate to land-use in Fiji. 


\section{Chapter 7: Governance Structure}

\subsection{Introduction}

The EIA of river mining for aggregates and the flood mitigation practices of significant land use initiatives in the Navua area, has highlighted the existence of inadequate governance systems and structures that are somewhat ineffective when it comes to disaster risk reduction and risk management. In addition, the high levels of vulnerability of the people in Navua due to their location as well as the impact of their neighbours' actions on their property highlights this as well. The absence of regulatory frameworks contributes to vulnerability in itself. As indicated in Chapter 4 all development activities within the Navua area are approved through the Navua Local Authority. The research has also highlighted the absence of risk management standards for Fiji which could be utilized across the sectors to measure their levels of risk particularly for development projects. To date, disaster risk reduction and risk management is governed by the Natural Disaster Management Act of 1998. Prior to that, natural hazards and risks were governed by the Fiji National Disaster Management Plan of 1995, replacing the Emergency Services Committee (EMSEC) Precautionary Manual for Emergency 1979. Importantly, Fiji has a commitment to the global process of disaster risk reduction and risk management. This has been an ongoing commitment since the first World Conference on Disaster Reduction in 1994.

\subsection{Global Context}

As highlighted in literature and outlined in Chapter 1, flood hazard and risk is a global issue. It cuts across other disciplines and, which in the past has been addressed from a behaviouralist paradigm of utilizing physical measures to protect against hydrological hazards and minimize its risks to human lives and property. However these same physical measures have been found to aggravate the flood impact, which in turn serves to enhance risk rather than provide mitigating and adaptation measures, as seen in the examples highlighted in the first chapter and in the flood analysis of the Navua area. At the same time global partnerships were formed to create a culture 
of disaster prevention following the Rio Summit ${ }^{8}$ and the adoption of Agenda 21 by nations of the world. Accordingly, the first world conference on disaster reduction was held in Yokohama, Japan in 1994, where nations, non-governmental organizations, scientific institutions, business, industry, the media and civil society organisations gathered to adopt a strategy titled the Yokohama Strategy and Plan of Action. At this meeting commitments were made in principle to develop national action plans focussed on natural hazards and the prevention, mitigation, preparedness and relief of the disasters that arise from within these nations (UNISDR, 1994). These commitments reinforced the mentality of addressing the hazards and risks to human beings and national capital assets but at the same time overlooking the other factors, particularly human activities which also aggravate the impact of flood hazards and risks. Ten years after the first conference, a review of the first 10 years of global partnership was undertaken in Kobe, Japan in 2005, where a wholistic and integrative framework was endorsed to address all hazards as well as the other factors that create risks. The framework titled Hyogo Framework for Action 2005 - 2015: Building the Resilience of Nations and Communities to Disasters, is an inclusive framework that encompasses a structuralist approach and was adopted by Pacific nations and subsequently adapted nationally by Fiji to shape the way in which disaster risk ought to be reduced or managed in the following 10 years (personal communication with Fiji NDMO). The Framework for Action outlines gaps in which the way disaster has been managed in the past ten years and summarises these into five key thematic areas to reflect the more holistic and integrated way of managing hazards and risks. These five themes are:

a) Governance: organizational, legal and policy frameworks;

b) Risk identification, assessment, monitoring and early warning;

c) Knowledge management and education;

d) Reducing underlying risk factors; and

e) Preparedness for effective response and recovery.

Relevant to my research objectives are the thematic areas of:

\footnotetext{
${ }^{8}$ The Rio Summit in 1992 was the first time more than 100 heads of state met in Rio, Brazil to address urgent problems of environmental protection and socio-economic development. "The assembled leaders signed the Convention on Climate Change and the Convention on Biological Diversity, endorsed the Rio Declaration and the Forest Principles, and adopted Agenda 21, a 300 page plan for achieving sustainable development in the 21st century (http://www.un.org/esa/earthsummit/)”
} 
a) governance: organizational, legal and policy frameworks;

b) risk identification, assessment, monitoring and early warnings; and

c) reducing underlying risk factors.

The first section of this research analysis looked at the management of flood hazards and risks over the course of development and the second section looked at the assessment of flood hazards and risks and its underlying factors and how such information should inform the governance of flood hazards and risks in a rural area such as Navua.

The Hyogo Framework 2005 - 2015 Building the Resilience of Nations and Communities to Disasters summarises the themes of relevance to this thesis as:

\section{Ensure[ing] that disaster risk reduction is a national and a local priority with a strong institutional basis for implementation}

16. Countries that develop policy, legislative and institutional frameworks for disaster risk reduction and that are able to develop and track progress through specific and measurable indicators have greater capacity to manage risks and to achieve widespread consensus for, engagement in and compliance with disaster risk reduction measures across all sectors of society.

\section{Risk Identification, assessment, monitoring and early warnings:}

17. The starting point for reducing disaster risk and for promoting a culture of disaster resilience lies in the knowledge of the hazards and the physical, social, economic and environmental vulnerabilities to disasters that most societies face, and of the ways in which hazards and vulnerabilities are changing in the short and long term, followed by action taken on the basis of that knowledge.

\section{Reducing Underlying risk factors:}

19. Disaster risks related to changing social, economic, environmental conditions and land use, and the impact of hazards associated with geological events, weather, water, 
climate variability and climate change, are addressed in sector development planning and programmes as well as in post-disaster situations

(UNISDR, 2005)

These thematic areas then go on to specify the various sectors, disciplines and existing structures within a nation and or institution through which disaster risk reduction and risk management ought to be strengthened and mainstreamed. For example, under governance, one of the key national activities highlighted in the framework is the integration of risk reduction into development policies and planning in all levels of government as well as "adopt, or modify where necessary, legislation to support disaster risk reduction, including regulations and mechanisms that encourage compliance and that promote incentives for undertaking risk reduction and mitigation activities (UNISDR, 2005)”.

\subsection{Pacific Context}

The Hyogo Framework for Action 2005 - 2015 was adapted to the Pacific context of "big ocean and small islands", whose geology and geography are already a disadvantage when it comes to vulnerability (SOPAC, 2005). The framework, like the Hyogo Framework underscored the extreme vulnerability of these states in comparison to the other vulnerable regions of the world. As with other public goods that affect the Pacific as a whole, multilateral agreements are the binding guidelines which Pacific nations in turn acknowledge or adopt into the content of their policy or use as a guideline for their organisational structure and objectives. As such, the Pacific Framework for Action was endorsed by disaster managers and government representatives overseeing national disaster management of the Pacific countries and subsequently endorsed by the Pacific Forum Leaders in October 2005. Thus began the reform and restructure of the current national disaster risk reduction and risk management arrangements of Pacific countries. One of the expected outcomes of the Pacific Framework for Action for 2015 is the good governance by all stakeholders of disaster risk reduction and disaster management and that the management of economic, social, and environmental risks be factored into the national planning and budgetary processes (SOPAC, 2005). 
In terms of risk assessment factors, the key guiding principle agreed to by Pacific Disaster Managers is that the starting point for "reducing disaster risks, planning for disaster management and promoting a culture of resilience, lies in a greater level of understanding of the cause and effects of hazards and the physical, social, economic and environmental vulnerabilities to disasters that Pacific Island nations and communities face (SOPAC, 2005)”. These guiding principles are consistent with that of the Hyogo Framework and also captures the notion that in order to address underlying risks the changing social, economic, environmental conditions including those associated with resource use, climate variability and climate change, ought to be addressed in national and sectoral adaptation planning and programmes

Out of these endorsements at international and Pacific regional level, the Draft Fiji National Disaster Risk Management Arrangements have been formed.

\subsection{Fiji Context}

The drafting of the National Disaster Risk Management Arrangements 2006 is a culmination of the National Disaster Management Plan of 1995 and the Natural Disaster Management Act of 1998 (Fiji, 2006a). The National Disaster Management Plan (NDMP) of 1995 is a comprehensive plan centered largely on the emergency management part of the natural hazard management cycle. The natural hazard management cycle is essentially in two parts:

a) the emergency management component, which comprises of preparedness for the disaster, response after the disaster has occurred, and the recovery or rehabilitation and development of the stricken region;

b) the risk management component is the prevention and the mitigation part of the hazard management cycle (Fiji, 2006a).

The NDMP details agency roles and responsibilities, emergency operations, relief and rehabilitation, mitigation and public awareness and training on disaster management in Fiji (Fiji, 1995), from the national level, to divisional level and right down to district level . It has a strong emphasis on emergency or disaster management while reference is made within the plan of the role of other government departments in risk management; tsunamis and earthquakes with the 
Mineral Resources Department, coastal riverine flooding with the Drainage, and Irrigation Department and flood control and watershed management programme with the Ministry of Agriculture, Forest and Fisheries, Land and Water Resources Management Department.

A natural progression was to enact an Act that would govern Natural Disaster Management and so in 1998, the Natural Disaster Management Act was passed by the Fiji Parliament, mandating the government and relevant agencies to function more effectively in relation to managing natural disasters. This saw the establishment of the National Disaster Management Office as well as the continuation of the functions of the various government departments with a role in the natural hazard management cycle. The Act is a reflection of the existing roles of the other government ministries; which basically constituted a system of administration inherited from the pre-independence days. An example of this inheritance is the watershed management programme of Fiji, where flood mitigation or irrigation was the responsibility of the Ministry of Agriculture, Forest and Fisheries a trend that is still continuing today. Part 7 of the Act which is focused on Mitigation, Public Awareness and training, cites the following in section 39 (3):

S 39 (3) The assessment of the threat of natural disaster shall be carried out by the following departments of government -

(a) the Mineral Resources Department assessment of earthquakes, tsunamis and landslides

(b) the Drainage and Irrigation Department - assessment of coastal riverine flooding;

(c) the Ministry responsible for the rural housing programme - implementing cyclone resistant rural housing programmes;

(d) the Ministry of Agriculture - implementing programmes to reduce the vulnerability of agricultural commodities

(e) the Ministry of Agriculture in liaison with the Public Works Department - flood control and watershed management programmes (Fiji, 1998)

However the formulation of policies with regards to disaster mitigation and prevention policies still rests with the National Disaster Management Office. 
The spirit of the Act can be deduced from the interpretation of section in Part 1 of the Act. Like the NDMP, a thorough inspection of the Act when weighed against the natural hazards and risk management can be observed to be strongly focused on the emergency management component of the natural hazard management cycle. The Act makes no reference to the formulation of national risk management standards though it gives the NDMO the powers to formulate policies as such, hence the crafting of the Draft National Disaster Risk Management Arrangements.

\subsubsection{National disaster risk management arrangements}

The Draft NDRMA of 2006 succinctly outlines that it replaces the Fiji National Disaster Management Plan of 1995. Section 1.1 states:

The NDRMA sets out the arrangements for disaster risk reduction and disaster management in Fiji. It also ushers in a new focus for the national disaster machinery in terms of assigning overall responsibility for the management of both natural and human-caused disasters (Fiji, 2006a).

The NDRM acknowledges the following as natural and human caused disasters.

Table 7.1: Natural and Human Caused Disasters.

\begin{tabular}{|l|l|}
\hline Natural & Human Caused \\
\hline Cyclone & Aircraft Accident - Air/Sea/Land \\
\hline Drought & Animal Disease \\
\hline Earthquake & Epidemics / Pandemics \\
\hline Flood & Fire - bush /structure \\
\hline Landslide & Hazardous Materials Spills - Marine / Land \\
\hline Storm Tide (surge) & Invasive species \\
\hline Tsunami & Mass Civil Disorder \\
\hline Volcanic Eruptions & Oil Spill - Marine / Land \\
\hline & Shipping Accidents \\
\hline
\end{tabular}

Source: Adapted from Fiji Draft NDRM 2006 
No reference though is made to hazards caused by land-use development. However some new ways of operation are suggested in the Draft NDRMA 2006. One is the formation of the disaster risk reduction committee to particularly look into the adaptation of Comprehensive Hazard Assessment and Risk Management (CHARM) process to assist in decision making and disaster management planning. Another proposed way of operation is the movement away from the Fiji National Disaster Management Office into the establishment of the Fiji Islands Disaster Management Authority (FIDMA). The move is intended to centralize the overall coordination of responses to disasters under a single organization, something which was limited under the current arrangements as an office (Fiji, 2006a). Amongst the other functions proposed of the disaster risk reduction committee, two are to develop a) a national plan of action on disaster risk reduction and b) to develop a hazard mitigation plan for Fiji (Fiji, 2006a). The recognition of risk as a focus separate from hazard departs from the traditional approach which sees impacts as a function of the physical layout.

\subsubsection{Strategic Development Plan 2007 - 2011}

The Strategic Development Plan (SDP) 2007 - 2011 is heralded as a new systematic way of advancing national development (Fiji, 2006b). As such it sets out the priority areas for ministries and key performance indicators for their portfolios as well as assigning them for the delivery of its outputs through their annual corporate plan. One of the foci of the SDP is on rural and outer island development through increasing resources for rural areas to assist with faster implementation of development projects (Fiji, 2006b). Within the plan, the Fiji government also outlines a strong emphasis on the integration of risk management into the development process; and in the analysis and evaluation of hazards, vulnerabilities and hazards at risk. For this to be done, the CHARM process is to be recognized within government departments and ministry as the accepted risk management standard (SOPAC, 2002). This is an area largely ignored in the previous NDMP 1995 and the National Disaster Management Act 1998. The SDP further outlines the need to mainstream disaster risk reduction into other sectoral development plans, policies and programmes listing the following Key Performance Indicators (KPI) as the measure for disaster risk reduction and disaster management in Fiji in general: 
Table 7.2: Policy Objectives, Strategies and Key Performance Indicators

\begin{tabular}{|c|c|c|}
\hline Policy Objectives & Strategies & Key Performance Indicators \\
\hline $\begin{array}{l}\text { Communities are better } \\
\text { protected from risks of } \\
\text { disasters and better able } \\
\text { to protect themselves } \\
\text { and cope with the } \\
\text { consequences of } \\
\text { disasters }\end{array}$ & 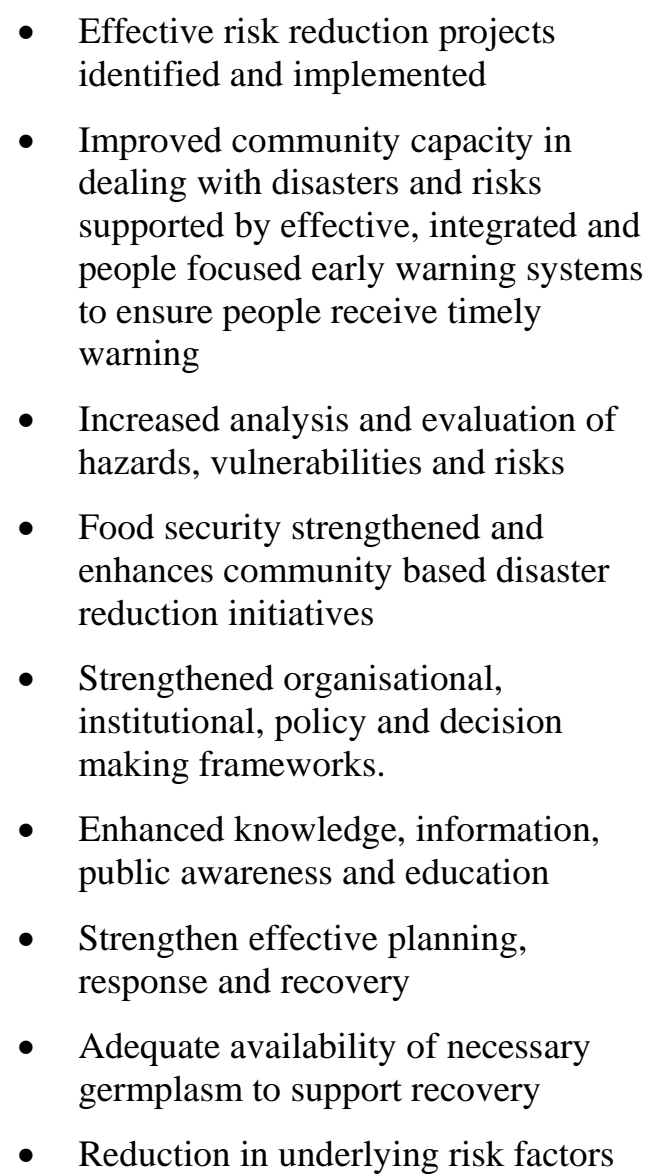 & $\begin{array}{l}\text { - Government responds to } \\
\text { disaster situation within the } \\
\text { first } 24 \text { hours } \\
\text { - Casualties reduced from } 30 \\
\text { per year to none. }\end{array}$ \\
\hline
\end{tabular}

Source: (Fiji, 2006b)

I draw attention to the strategies behind the KPI that are shown in Table 7.2. They recognise that in order to reduce the casualty rate and improve the response time to a disaster, that communities need to be strengthened; hazards and risks evaluated more frequently; underlying risks reduced; and organizational, institutional, policy and decision making frameworks strengthened. However, since the change in administration through a coup-de-tat in December 2006, the implementation of the Strategic Development Plan 2007 - 2011 has been derailed and a People's Charter formed instead. The People's Charter proposes to take into account the recommendations of the Summit Working Groups formed to produce the SDP 2007 - 2011 (www.fijilive.com ). 


\subsubsection{Rural land-use arrangements:}

A thorough review of land use arrangements in Fiji was completed in 2002 (Leslie and Ratukalou, 2002a). This review of land use arrangements involved the scrutiny of all legislation enacted within Fiji related to land use and the review of projects undertaken and the ministries with oversight into these development projects (Leslie and Ratukalou, 2002a). The review is consistent with the Fiji government's long term plans to concentrate development in the rural areas as they constitute more than $50 \%$ of Fiji's population, a condition that still exists as indicated by the recent population census at 2007 (Leslie and Ratukalou, 2002a; Statistics, 2007b). The need to focus more resources in rural areas is also captured in the SDP 2007 - 2011 and is reflected in most of the Key Performance Indicators outlined in the plan. However, out of the land use review in 2002, the rural land use policy of the Fiji Islands was adopted (Leslie and Ratukalou, 2002b); personal communication with Luke Ratukalou). The review highlighted how unregulated and unsustainable logging practice was seen as a cause of erosion that led to sedimentation in most of the river beds (Leslie and Ratukalou, 2002a), particularly in Navua being the catchment outlet for where much forestry is concentrated in the Fiji Islands.

\section{a) Rural Land Use Policy}

The policy highlights and summarizes some primary rural land use issues that impinge on disaster risk and management. Of relevance to this thesis is issue number 4:

4. Because of the predominantly poor adoption of and application of land husbandry practices and the resultant degradation of land and water resources, the impacts from natural disasters are becoming increasingly acute, in particular, vulnerability to droughts and flooding (Leslie and Ratukalou, 2002b).

The policy further states that the "lack of understanding of biophysical processes and trends and the failure to use information about natural resources have led to land degradation, inappropriate land uses and [has] increased the risk of drought and flooding (Leslie and Ratukalou, 2002b)". One of the strategies to address this is the proposal to maintain and extend indigenous forests and plantation forest coverage so that by 2010, the vulnerability of the rural sector to flooding, droughts, cyclones and other frequent natural hazards is significantly reduced. Section 4 (7), 
highlights the proposed policy of "protection of water and soil values" where the following is relevant to the objective of this thesis:

7.10. Promoting effective integrated watershed land and water management to improve water quality and quantity in degraded catchments;

7.12 Avoiding, mitigating and remedying the impacts of land related hazards, including flooding, mass movement and soil erosion (Leslie and Ratukalou, 2002b).

The policy further underpins the roles of the various government departments and ministries responsible for the upholding of the different areas that wholistically contribute to the sustainable land use in Fiji. As part of their commitment to Agenda 21, the then Ministry of Agriculture, Fisheries and Forests committed to an environmental strategy where they proposed to "provide agricultural engineering services to enhance agricultural production without depletion of ecosystem values, maintain proper land conservation systems and to minimize the impact of flooding (Leslie and Ratukalou, 2002b), which was to fall in line with their aim of reducing land degradation by 50\% as of 2001 (Leslie and Ratukalou, 2002b). In their review of rural land use, Leslie and Ratukalou (2002) identify that some practices of land use were still reversible and therefore ensuring the sustainable development of land use was still very achieveable with the current rates of development in Fiji (Leslie and Ratukalou, 2002b).

\subsubsection{Development in Fiji}

Any type of development in Fiji requires the approval of the town and country planning office in Fiji. This includes development for construction, subdivision, building and earthworks and proposals to change the use of existing buildings. These developments are managed through the Town Planning Act and the Subdivision of Land Act. The Town Planning Act governs subdivisions within the boundary of declared towns, while the Subdivision of Land Act applies to subdivision activities outside of town boundaries with the exception of the following as stated in section 2 of the Subdivision of Land Act: 
(a) Crown land which is not the subject of a registered lease;

(b) land included within the boundaries of any city or town to which the Local

Government Act applies; and (Cap 125)

(c) land included in any native reserve constituted under the Native Land Trust Act .

The Subdivision of Land Act applies to the Navua area. Under the act, all subdivision proposals are required by law to undergo a process of approval with the Town and Country Planning Office. The decision of the Town and Country Planning Office can however be overturned by the Minister responsible for the portfolio of town and country planning. Proposals for subdivision of land need to be registered with the local authority first, who then proceed to lodge it with the Town and Country Planning Office. Some development projects require certain procedures prior to lodgment, such as those that require EIA like river dredging /or mining. As such, all development in the Navua area are required by law to be lodged first with the Navua Local Authority and have followed the requirements of other planning controls in place such as and EIA as required by Law under the Environmental Management Act 2005 (Fiji, 2005).

These processes associated with land subdivision could seem to be the most appropriate place to assess the impact pf land-use activities on enhancing hazard and risk. Any EIA should be required to address how subdivision activities might enhance hazard (for example, from runoff or sediment generation) and risk (for example, by encouraging settlement in hazard prone areas). 


\section{Chapter 8: Final Conclusions and Recommendations}

\subsection{Natural Hazards in Fiji}

The interwoven nature and causes of natural hazards and impacts warrants an approach that considers all secondary hazards that would normally arise from the primary hazard or from the event. As the hazard history of the Fiji Islands, suggests, the 'single hazard' approach previously undertaken in hazard management is inadequate as the primary hazard commonly produces a range of secondary hazards that should not which cannot be ignored in hazards and risk management. In addition, factors that increase risk such as the increasing population density and the stresses placed on the environment by ill-managed rural land use practices, exacerbates the impact of the hazard as well as increases the risks that ought to be managed. Geologically, Fiji is already at risk given the seismic activity of the plate it sits on. Its physical geography is characterized by a dynamic weather system and location close to the equator; making the country susceptible to climate and hydro-meteorological hazards. A trend that can be observed in this thesis analysis is that while the cities have improved their resilience capacity to hazards such as tropical cyclones, little changes has occurred in rural areas such as Navua. Complacency, negligence and reactive, rather than proactive approaches have increased losses incurred from tropical cyclones in these communities. Further, the nation's commitment to increase rural area development beginning with capital projects in the form of bridges and sealed roads would also warrant accompanying risk management strategies and planning to reduce the risks in these communities.

\subsection{Navua Catchment Characteristics}

The small size of the Navua catchment, its topography; weather system, size of the population of Navua and its locatin of a large flood plain make the area particularly vulnerable to the natural hazards, such as tropical cyclones, flooding, landslides, earthquakes and tsunamis. Ironically, its agricultural potential was first discovered in the early 1900's during a tropical cyclone. However, through time and the experiences gained from past natural hazards, its potential for economic development has been largely being narrowed down to pastoral, farming and forestry 
activities a trend that population settlement does not mirror and which is not reflected in the development plans of the area. It is obvious the mentality during its first discovery as a potential for horticultural production and pastoral farming, can be observed as still characteristic of the development within this flood plain.

\subsection{Evolution of Flood Hazards in Navua}

The evolution of flood hazards and risks management in the Navua area can be observered to be characteristic of the broader disaster management approach of the Fiji Islands in general. The conventional reactive approach of responding to a disaster after the event as opposed to a more pro-active risk management and planning approach was characteristic of the past, and remain characteristic of rural area development today. The 20 or so years of Fiji's commitment to global processes to reduce risk and build community resilience to natural hazards is still yet to infiltrate the rural areas judging by the hazard statistics and the vulnerability perception of the Navua community. Despite knowledge of the clear flood history of Navua, land use activities continued to be concentrated around the river area of the flood plain. Structural measures such as the dredging of the river that have been put in place were not to mitigate floods but for the purposes of access by boat to the Navua floodplain via the river mouths. Land use activities such as the construction of irrigation channels and floodgates for rice farming, have enhanced hazard by interpreting the natural drainage of the areas particularly as this scheme has now been abandoned and lacks maintenance.

\subsection{Flood Risk Assessment of Navua Flood}

It is clear that losses incurred through flooding of the Navua area far outweigh the benefits both financially and aesthetically in both the upper catchment and the day to day existence of activities in the lower catchment. Navua, already a high risk area by default, continues to increase its population, subsequently increasing the development on land, effectively increasing the risks to river flooding and flash flooding. Flood hazard management and responses to other hazards is yet to be infiltrated right through to such communities and to be reflected in settlement development plans or development plans in general. Property development also reflects the overarching mentality of responding after a disaster has struck rather than putting in place, 
measures that would reduce the risk in the future. This is reflected in the development of private property whereby building on raised platforms was only to heights of the previous flood. This coupled with the inconsistency of implementing mitigation measures such as river dredging to mitigate for floods and the lack of care towards monitoring river levels, the risks of flooding faced by the Navua community. Such observations warrant a look at the governance structure and how actions on the ground could be obliged to operate within a framework that seeks to effectively manage risks concurrently with development and which ensures the sustainability of the catchment area for generations to come.

\subsection{Governance Structure}

An examination of the current governance structure shows that the current approach to hazard management in Fiji is still reflective of the paradigm of behaviouralist theory. With a particular focus on flood hazards, engineering measures have been introduced to mitigate and protect areas from flooding rather than to reduce risks. On the global front, the paradigm has shifted to reflect a more structuralist approach to flood hazard and risks. The shift is now more towards risk management frameworks which recognize the importance of vulnerability, resilience and governance structure. Fiji's adoption of a national disaster risk management framework to respond to all hazards (natural and human induced), is beginning to incorporate such issues. While there are moves at the national level to reflect the need for this paradigm shift, rural areas are still struggling with the previous approach of flood protection. In an examination of the history of Navua, it was clear that the structures in place within government to deal with flood hazards and risks, have been inherited from the colonial era whereby flood hazards and risk management is the responsibility of the Ministry of Agriculture's Forest and Fisheries, Land and Water Resources Department; river monitoring is the responsibility of the Public Works Department; and response and rehabilitation is the responsibility of the National Disaster Management Office. The division of responsibility inherent in such structures has previously led to a lack of collaborative effort in flood hazard and risk management. 


\subsection{Summary}

Exploration of the risk management approach has led to the discovery of the lack of a general risk management standard or scale or rank which weigh risks in Fiji. The current proposed CHARM framework of risk management is primarily intended for the employment by government departments and ministries. However as my research has indicated, commercial companies are putting in place their own mitigation measures, as is in the case of one company within the Navua area. While such a move is commendable, it is still largely behavirouralist in its approach in that the mitigation measures employed are to protect their business entity from flood hazards and to deviate flood waters away from their breeder sheds. Such an approach has little or no considerations for repercussions of their actions on those downstream, despite their claim to be environmentally responsible. It represents a transferal of risk rather than a reduction in risk especially for the community as a whole.

\subsection{Recommendations}

The following recommendations arise from this research work:

a) As Schanze (2006) has highlighted, a flood risk management framework ought to address the underlying causes of risk, analyse the risk as well as look into options for treating the causes of risks (figure 2.1). She proposes a framework for the North Atlantic Treaty Organisation (NATO) countries which reflects the paradigm shift from behaviouralist to structuralist. Such a framework for reducing flood hazards and risks ought to be put in place for the Fiji Islands and should have clearly defined applicability to risk in rural areas. The sorts of issues that would need to be addressed in the rural sector have been identified and discussed earlier in this thesis. They should go beyond the implementation of physical flood protection measures and include measures such as education and planning that would reduce vulnerability and enhance resilience of communities. While the new National Disaster Risk Management Arrangements for Fiji are a first step in the right direction, a comprehensive plan, currently in draft stages ought to reflect more faithfully the paradigm shift that the country has already committed to globally.

b) To develop a Risk Management Standard, a rating system should be developed in consultation with all stakeholders. The CHARM framework being proposed for Fiji 
needs to be reviewed to reflect the holistic approach agreed to in principle through Fiji's endorsement of the Hyogo Framework for Action and the subsequent Pacific Framework for Action. While the CHARM framework is proposed for the adoption by government departments and Ministries, I suggest that there ought to be moves by the relevant authorities to initiate dialogue and mobilize all stakeholders for the adoption of agreed Risk Management Standards for the Fiji Islands which could also obligate private companies or particularly, large land-use development projects to act. In terms of private property, obligation should also extend to building codes and subdivision procedures for the Fiji Islands.

c) Commercial businesses, agricultural based or otherwise, should adopt business continuity plans with a responsibility to society in terms of risk reduction and not just as a reactive response to disasters or risk transferal. Such entities should be obligated to mitigate measures that ought to have a responsibility to society as opposes to their own protection from such hazards. This would require much research, consultation and modeling to see how it would best work in a real situation.

d) Definitive guidelines need to be established on what constitutes public goods across the board for the people of Navua and the environmental values of those goods need to be determined so that resource use at one end of the catchment does not have ramifications at the other end of the catchment. An agreement could be reached amongst the villages and township as to the importance and significance of these goods as a whole rather than in terms of benefits to a particular village or individual family unit. Such agreements based on trust would ensure that the whole area benefits from risk reduction measures and that development activity are in line benefits to the whole community. 


\section{Appendices}

\section{Appendix 1: List of Surveys Conducted for the Navua Region}

1. 1945 - An agricultural survey of Indian farmers in Navua.

2. 1969 - Pre-Investment Study on the Agricultural potential of Navua

3. 1975 Town baseline Survey

4. 2004 USP AIACC Tropical Depression Survey.

5. Melzner, S., Lagataki, S. and Bonte-Grapentin, M. 2004: Landslide Hazard Assessment in the Navua Catchment, South Viti Levu, Fiji. SOPAC 2004 STAR Session Suva: SOPAC.

6. 2004 - National Disaster Management Office - Damage Assessment of Navua 2004 Flood and survey of impacts

7. Lonergan, C. 2005: Modelling Land Use Change in Navua, Fiji: Improvements to Vulnerability and Adaptation Assessment of Climate Change Impacts in the Pacific. Hamilton: University of Waikato, 238.

8. Pacific Applied Geoscience Commission (2007): Cost Benefit Analysis of a Flood Early Warning System for Navua. 
Appendix 2: List of Participants of Navua Flood Response Planning Workshop

Name

Sairusi Bosenaqali

Semisi Kauata

Iliesa Marawa

Peni Seniyasi

Alipate Natoba

Epeli Lagi

Tiko K. Saumalua

Vijay Maharaj

Suresh Chand Gosai

Epeneri Danavanua

Veniana Anthony

Ismail Yusuf

Nabi Buksg

Rev. Isala Tuinuku

Rev. Demesi Sitei

Ashok Kumar Bah

Jone Mua

Malakai Rarawa

Margaret Logavatu

Capt. Tiko Lepani

May Peni Mario

Sanaila Seru

Roshni Chand

Talei Rokotuibau

Jonathan Travis

Joeli Rokovada

Akisi

\section{Designation}

P.A. Serua, Navua

P.A. Tailevu, Nausori

Dep. Of Agriculture, Navua

Health Officer, RLA

Namosi, Provincial Office

Police, Navua

Hospital, Navua

Chair, DAC, Navua

Vashist Muni Collage, Navua

LWRM/ MoA, Suva

Member, DAC, Navua

Member, DAC, Navua

Fire station, Navua

Methodist Church, Navua

Angelican Church, Navua

Telecom, Navua

Crest Chicken, Navua

Fiji Navy, Suva

PCDF, Suva

RFMF Logistic Dept., Suva

RMFM, Suva

RFMF, Suva

FSPI, Suva

Local Government, Suva

Peace Ccorps Volunteer, Suva

NDMO , Suva

NDMO, Suva 
Viliame Tumianu

Faga Finiasi

Rajendra Prasad
NDMO, Suva

Hydrology, Suva

Fiji MET, Nadi 


\title{
Appendix 3: Participant Information Sheet and Consent Form for the Data Gathering On Human Activities on a Flood Plain
}

\author{
Katalaine Duaibe \\ MSc Candidate \\ School of Geography, Environment and Earth Science \\ Victoria University of Wellington \\ PO Box 600 \\ Wellington \\ New Zealand \\ Ph: +64-4-463-9463 \\ Email: duaibekata@student.vuw.ac.nz
}

\section{PARTICIPANT INFORMATION SHEET}

\begin{abstract}
Researcher: Katalaine Duaibe: School of Geography, Environment and Earth Science, Victoria University of Wellington
\end{abstract}

Bula Vinaka! I am a Masters student in Physical Geography at Victoria University of Wellington, New Zealand. Part II of this degree is a thesis of which field work is an integral part. One of the gaps that has yet to be addressed in the all-hazards management approach adopted by Pacific Countries including Fiji are the impacts of human induced hazards on development. To that end my thesis is focusing on human induced hazards in the Navua Plain and how these activities aggravate flood hazards and its risks.

While there are known facts of the impact of human activities on river hydraulics and such which in turn contributes to flooding, this field research is mainly to prove this and to determine the specific activities within the Navua Plain that are a contributing factor.

This letter seeks your permission for a 20 - 30 minute interview to be conducted in your office or if you rather at a nearby public place. Information derived from you, the institution or organisation that you represent will be used solely for the purpose of the completion of this thesis. All information will be accredited to the sector/organisation/business from which it was derived from. It will be reported in such a way where the organisation or individual is not identifiable. You may also withdraw from this research at any time up till December 2007, without having to sight reasons of doing so. To do so, you are required to contact me either by email or letter at the details on the top of this page.

Results of this field work and thesis may be submitted to a journal for publication, at a conference and/or seminar as a presentation and may also be produced as a report. The completed thesis will be submitted to the School of Geography, Environment and Earth Science for marking as well as being deposited at the Victoria University Library.

If you have any questions or require further information about this research, don't hesitate to contact me or my Supervisor, Professor Dr. Michael Crozier, at the same address at the top of this page or by telephone +64-4-463-5279

Sincerely 


\section{PARTICIPANT CONSENT FORM}

Title: Human Induced Hazards on the Navua Flood Plain

I have read and understood the context of the research outlined in the information and explained by you.

I agree to supply information that would aid in the completion of your field work to contribute towards your thesis.

I agree to take part in an interview.

I understand that the information gathered from me / this organisation / institution will be used in the formal publication of a thesis, report and could be made as a presentation at a seminar / conference or submitted as an article to a journal and hereby give consent to the use and credit of the organisation / institution / public sector as the named source in your publication.

I understand that any confidential information will be treated as such that myself / my organisation will not be identified in the thesis or any publication. Such information will be destroyed upon the completion of the thesis.

I understand that I may withdraw any information I or my organisation provide prior to December 2007.

I would like to receive a summary of the research findings.

\section{Signed:}

Name of Participant:

Date:

Address to which summary can be sent to: 


\section{Appendix 4: Questionnaire Guidelines}

\section{RESEARCH QUESTION GUIDELINES}

\section{PART A: Role and length of time in community}

1. Briefly describe the nature of your activities here in Navua? i.e what role or position do you have in the community?

2. How long have you been operating in this role here in Navua?

\section{PART B: Event Management}

3. What are your impressions of the relief response and disaster management of the area?

\section{PART C: Personal recovery and mitigation strategy}

4. How many floods have you witnessed? Over what time frame in your professional capacity?

5. What has/have been the impacts of such flood to you personally by that I mean to your business / organization / family / livelihood?

6. How have you recovered from such events?

7. Do you have any plans or taken any actions to protect yourself in the event of a flood?

8. What can be done to reduce flood damage? 
PART D: Perceived Cause of Flood

9. What causes floods?

a. Rank the human causes:

Most likely Likely

Unlikely

i. Land degradation

ii. Zoning and control of flood plain development
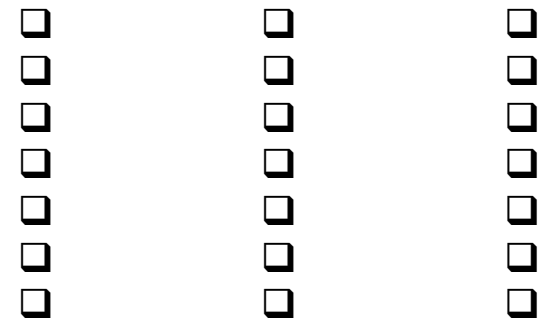

10. Rank the physical causes:

i. Steep Slopes

Most Likely Likely

Unlikely

ii. Changing of river hydraulics due to sand mining

iii. Climate Change

iv. Dredging of the river bed

v. High Tide

\section{PART F: Perceived cause of damage and loss}

11. Rank the perceived cause of damage and loss: Most Likely Likely

Unlikely

i. Building in wrong place

ii. Poor building construction

iii. Lack of knowledge 


\section{Bibliography}

Bi, N. 1998: Tropical Cyclone Bebe: 23 - 25 October 1975. In Services, F.M., editor: Fiji Meteorological Services, 2.

Boer, J.Z. and Sanders, D.T. 2002: Volcanoes in Human History. Princetown: Princetown University Press.

Bogardi, I. 2006: Coping With Uncertainties in Flood Management. Transboundary Floods; Reducing Risks Through Flood Management, 12.

Bonte, M. 2007: Greater Navua Flood Response Planning Workshop: Purpose, Objectives and Project Milestones. Suva: Pacific Applied Geosicence Commission, 8.

Bonte, M. and Rahiman, T. 2006: The Story of an Ancient Lake in Vitilevu. Reducing Vulnerability of Pacific ACP States: Information Brochure, Suva: South Pacific Applied Geoscience Commission, 4.

Castree, N., Rodgers, A. and Sherman, D., editors 2005: Questioning Geography: Fundamental Debates: Blackwell Publishing.

Criss, R.E. and Shock, E.L. 2001: Flood enhancement through flood control. 875-a-878.

Crozier, M.J. 2006: Natural Hazards: A selection of illustrations used in lectures. Wellington: Victoria University of Wellington, 70.

Crozier, M.J. and Glade, T. 2004: Landslide Hazard and Risk: Issues, Concepts and Approach. In Glade, T., Anderson, M. and Crozier, M.J., editors, Landslide Hazard and Risk: John Wiley \& Sons, Ltd.

Crozier, M.J., Howorth, R. and Grant, I.J. 1980: Notes and Comments: Landslide Activity During Cyclone Wally, Fiji: A Case Study of Wainitubatolu Catchment. Pacific Viewpoint 22, 69-88.

Curry, M.R. 2005: Meta-theory / Many Theories. In Castree, N., Rogers, A. and Sherman, D., editors, Questioning Geography: Fundamental Debate: Blackwell Publishing, 20.

DeChano, L.M. 2004: Mass Movement. In Stoltman, J.P., Lindstone, J. and DeChano, L.M., editors, International Perspectives on Natural Disasters: Occurence, Mitigation and Consequences, Dordrecht: Kluwer Academic Publishers, 16. 
Demeritt, D. and Wainwright, J. 2005: Models, Modelling and Geography. In Castree, N., Rogers, A. and Sherman, D., editors, Questioning Geography: Fundamental Debates: Blackwell Publishing, 20.

Dixit, A. 2003: Floods and Vulnerability: Need to Rethink Flood Management. Natural Hazards 28, 155 - 179.

Dull, R.A. 2007: Evidence for forest clearance, agriculture, and human-induced erosion in Precolumbian El Salvador. Annals of the Association of American Geographers 97, 127-141.

Fiji, C.o. 1909: Minutes of the Proceedings of the Legislative Council 1909. In Agriculture, editor: Legislative Council Fiji, 27.

Fiji, C.o. 1920: Fiji Colonial Report 1905 - 1920. Suva: Colony of Fiji.

Fiji, C.o. 1960: Report on Board of Inquiry into Utilization of Natural Forest Resources. Journal of the Legislative Colony Sessions of 1960 Part 1 No. 2, 14.

Fiji, G.o. 1933: Annual Report of the Social and Economic Progress of the People of Fiji, 1931. Fiji Colonial Report 1931 - 1934 No. 1604, 104.

Fiji, G.o. 1939: Annual Report of the Social and Economic Progress of the People of Fiji, 1938. Fiji Colonial Report 1935 - 1938 No. 1910, 70.

Fiji, G.o. 1980: Fiji 8th Development Plan. Suva: Central Planning Department.

Fiji, G.o. 1984: Navua. The Cyclopedia of Fiji: A Complete Historical and Commercial Review of Fiji: R. McMillan Publisher, 336.

Fiji, G.o. 1995: Fiji National Dsiaster Management Plan. In Agencies, N.D.M.C.a.G., editor: Government of Fiji.

Fiji, G.o. 2005: Environment Management Act. In Fiji, P.o., editor: Parliament of Fiji.

Fiji, G.o. 2006a: Fiji National Disaster Risk Management Arrangements. In Office, N.D.M., editor: Government of Fiji.

Fiji, G.o. 2006b: Strategic Development Plan 2007 - 2011: Maintaining Stability and Sustaining Growth to Achieve a Peaceful, Properous Fiji: Ministry of Finance and National Planning.

Fiji, P.o. 1976: Ministry of Agriculture, Fisheries and Forests Annual Report of the year 1973. In Ministry of Agriculture, F.a.F., editor: Parliament of Fiji, 54. 
Fiji, P.o. 1979: Public Works Department Annual Report for the year 1977. In Department, P.W., editor: Parliament of Fiji, 35.

Fiji, P.o. 1983: Town and Country Planning Report for the Year 1981. In Fiji, P.o., editor: Parliament of Fiji, 8.

Fiji, P.o. 1998: Natural Disaster Management Act 1998. Parliament of Fiji.

FMS 2007a: General Information on the Climate of the Fiji Islands. Nadi: Fiji Meteorology Services.

FMS 2007b: List of Tropical Cyclones Affecting Fiji from 1969/70 to Present. Information Sheet No. 123, Nadi: Fiji Meteorological Services, 6.

FRCS 2004: Report to the FRANZ on the 2004 Floods and the Implementation of the Emergency Rehabilitation Project. Suva: Fiji Red Cross Society, 77.

Gibbs, T. 2004: Windstorms. In Stoltman, J.P., Lidstone, J. and DeChano, L.M., editors, International Perspectives on Natural Disasters: Occurence, Mitigation and Consequences, Dordrecht: Kluwer Academic Publishers, 24.

Glade, T. and Crozier, M.J. 2004: The Nature of Landslide Hazard Impact. In Glade, T., Anderson, M. and Crozier, M.J., editors, Landslide Hazards and Risk, London: John Wiley \& Sons, Ltd, 32.

Graham, E. 2005: Theory and Theorising. In Castree, N., Rogers, A. and Sherman, D., editors, Questioning Geography: Fundamental Debates: Blackwell Publishing, 17.

Gregg, C.E. and Houghton, B.F. 2006: Natural Hazards. Disaster Resilience: An intergrated Approach, Springfield: Charles C Thomas Publisher Ltd.

Guzzetti, F., Stark, C.P. and Salvati, P. 2005: Evaluation of flood and landslide risk to the population of Italy. Environmental Management 36, 15-36.

Handmer, J. 2004: Global Flooding. In Stoltman, J.P., Lidstone, J. and DeChano, L.M., editors, International Perspectives on Natural Disasters: Occurence, Mitigation and Consequences, Dordrecht: Kluwer Academic Publishers, 20.

Haque, C.E. 2005: Special Issue: Mitigation of natural hazards and disasters: international perspectives. Mitigation and Adaptation Strategies for Global Change 10, 333-571. 
Harrison, S. 2005: What Kind Of Science Is Physical Geography? In Castree, N., Rodgers, A. and Sherman, D., editors, Questioning Geography: Fundamental Debates: Blackwell Publishing, 17.

Hays, W. 2004: Earthquakes. In Stoltman, J.P., Lidstone, J. and DeChano, L.M., editors, International Perspectives on Natural Disasters: Occurence, Mitigation and Consequences, Dordrecht: Kluwer Academic Publishers, 26.

Howorth, R., Balenaivalu, V. and Prasad, S. 1993: Initial Reconnaissance of the Effects of Cyclone Kina in Central and Eastern Viti Levu. Suva: South Pacific Applied Geoscience Commission and Fiji Mineral Resources Deparment, 27.

Kambhampati, U.S. 2004: Development and the Developing World. Cambridge: Polity.

Kostaschuk, R., Terry, J. and Raj, R. 2001: Tropical cyclones and floods in Fiji. Hydrological Sciences 43, 16.

Laddpeter, B. 2002: Navua on the way to development. The Fiji Times, Suva, 68.

Leslie, D. and Ratukalou, I. 2002a: Review of Rural Land Use in Fiji: Opportunities for the New Millennium. Suva: Ministry of Agriculture, Sugar and Land Resettlement, 175.

Leslie, D. and Ratukalou, I. 2002b: Rural Land Use Policy for Fiji. In Ministry of Agriculture, S.a.L.R., editor: Secretariat of the Pacific Community.

Lightfoot, C. 1999: Regional El Nino Social and Economic Drought Impact Assessment and Mitigation Study. In SOPAC, editor, Suva: Pacific Applied Geoscience Commission, 58.

Lonergan, C. 2005: Modelling Lan Use Change in Navua, Fiji: Improvements to Vulnerability and Adaptation Assessment of Climate Change Impacts in the Pacific. Hamilton: University of Waikato, 238.

MacDonald, G.N. 1949: The Navua Hydro-Electric and Conservation Project. Transactions of the Fijian Society 1938 - 1954: The Fiji Society.

Marker, B.R., Petterseon, M.G., McEvoy, F. and Stephenson, M.H., editors 2005: Sustainable minerals operations in the developing world. London: The Geological Society.

Mataki, M., Koshy, K. and Nair, V. 2006: Implementing Climate Change Adaptation in the Pacific Islands: Adapting to Present Climate Variability and Extreme Weather Events in Navua (Fiji). AIACC. 
McGree, S. 2002: Lits of Tropical Cyclones Affecting Fiji from 1830/31 ro 1968/69 Seasons. Information Sheet No. 120, Nadi: Fiji Metrology Services, 9.

McGuine, B., M., I. and Kilburn, C. 2002: Natural Hazards and Environmental Change. New York: Oxford University Press Inc.

McKenzie, E., Chand, B. and Kaloumaira, A. 2005: Economic Impact of Natural Disaster on Development in the Pacific : Volume 1 Research Report. Suva: AusAID, 92.

Melzner, S., Lagataki, S. and Bonte-Grapentin, M. 2004: Landslide Hazard Assessment in the Navua Catchment, South Viti Levu, Fiji. SOPAC 2004 STAR Session Suva: SOPAC.

Messner, F. and Meyer, V. 2006: Flood Damage, Vulnerability and Risk Perception - Challenges for Flood Damage Research. Flood Risk Management: Hazards, Vulnerability and Mitigation Measures, 149-167.

Mineral Resources Department, F. 2008: Earthquakes in Fiji. Suva: Fiji Mineral Resources Department.

Mohapatra, P.K. and Singh, R.D. 2003: Flood Management in India. Natural Hazards 28, 131 143.

Mua, J. 2007: Breeder Farm Floods. Suva: Goodmen Fielder Fiji.

Mudgeway, L. 1997: Watershed Management and Flood Control on Viti Levu. In Planitz, A. and Chung, J., editors, VIII Pacific Science Ingter-Congress, University of the South Pacific: Pacific Science Inter Congress, 10.

Naiova, M. 2007: Fiji Preliminary Environmental Impact Assessment Report - Aggregate Extraction in Selected Sites of the Navua and Sigatoka Rivers and the Sigatoka Sand Dunes, South Viti Levu. In SOPAC, editor, EU EDF-SOPAC Reducing Vulnerability of Pacific ACP States, Suva: Pacific Applied Geoscience Commission, 83.

NDMO 2004: Interim Report of the Flood (TD10F) 2004. Suva: Fiji Ministry of Home Affairs, Immigration and National Disaster Management

NDMO 2005: Summary of Major Disasters in Fiji 1985 - 2005. Suva: Fiji National Disaster Management Office.

Nirupama, N. and Simonovic, S.P. 2006: Increase of Flood Risk due to Urbanisation: A Canadian Example. Natural Hazards 40, 25 - 41. 
Nott, J. 2006: Extreme Events: A Physical Reconstruction and Risk Assessment. Cambridge: Cambridge University Press.

Nunn, P.D. 1998: Pacific Island Landscape. Suva: Institute of Pacific Studies, The University of the South Pacific.

Papankova, Z., Horvat, O., Hlavcova, K., Szolgay, J. and Kohnova, S. 2006: Scenarios of Flood Regime Changes Due to Land Use Change in the Hron River Basin. Transboundary Floods: Reducing Risks Through Flood Management, 99 - 110.

Pararas-Carayannis, G. 2004: Natural Disasters in Oceania. In Stoltman, J.P., Lidstone, J. and Dechano, L.M., editors, International Perspectives on Natural Disasters: Occurence, Mitigation and Consequences, Dordrecht: Kluwer Academic Publishers, 18.

Parry, J.T. 1981: Ring Ditch Fortification in the Navua Delta, Fiji: Air Photo Interpretation and Analysis: Fiji Museum.

Paton, D. and Johnston, D. 2006: Disaster Resilience: An Intergrated Approach. Springfield: Charles C Thomas Publisher Ltd.

Penning-Rowsell, E., Floyd, P., Ramsbottom, D. and Surendran, S. 2005: Estimating Injury and Loss of Life in Floods: A Deterministic Framework. Natural Hazards 36, 43 - 64.

Ponia, B. 2007: Fiji: Update on Dairy Farms Fiji's Macrobrachium shrimp farm and J. Hunter Ltd's Pearl Farm. SPC Fisheries Newsletter.

Prasad, R. 2007: Fiji Meterological Services Presentation on Early Warning System for Floods. Greater Navua Flood Response Planning Workshop, Suva: Fiji Meterological Services, 12.

Precht, E., Ammentorp, H.C. and Larsen, O. 2006: Management Strategies for Flash Floods in Saxony Germany. In Schanze, J., Zeman, E.a. and Marsalek, J., editors, Flood Risk Management: Hazards, Vulnerability and Mitigation Measures, Ostrov: Springer.

Priestley, S. 1995: Comprehensive catchment planning; a flood hazard management techniques. Proceedings of the natural hazards management workshop '95, Lower Hutt: Institute of Geological \& Nuclear Sciences (N.Z.), 85-88.

Rahiman, T. 2002: Geophysical Investigations at the Navua River Gravel Extraction Site. MRD Note BP79/24, Suva: Fiji Government Mineral Resource Department, 10.

Raj, R. 1986: Rewa River: A Study of Floods and Frequency. Suva: Fiji Public Works Deparment. 
Rhoads, B.L. 2005: Process / Form. In Castree, N., Rogers, A. and Sherman, D., editors, Questioning Geography: Fundamental Debates: Blackwell Publishing, 20.

Schanze, J. 2006: Flood Risk Management - A Basic Framework. Flood Risk Management: Hazards, Vulnerability and Mitigation Measures, 1-20.

Schanze, J., Zeman, E.a. and Marsalek, J., editors 2006: Flood Risk Management: Hazards, Vulnerability and Mitigation Measures. Ostrov: Springer.

Services, F.M. 2007: General Information on the Climate of the Fiji Islands.

SKM 2000: Environmental Impact Assessment for the Navua River Mouth Dredging Project. In Merz, S.K., editor, Suva: Ministry of Agriculture, Fisheries and Forests, 43.

Slatter, C. 1977: Sentimental Journey to Fiji. The Fiji Times, Suva, 2.

Smith, K. 2004: Environmental Hazards: Assessing Risk and Reducing Disaster. London: Routledge.

SOPAC 2002: Regional Comprehensive Hazard and Risk Management: Guidelines for Pacific Island Countries. Suva: Pacific Applied Geoscience Commission.

SOPAC 2005: An investment for Sustainable Development in the Pacific Island Countries Disaster Risk Reduction and Disaster Management: A Framework for Action 2005 - 2015 Building the Resilience of Nations and Communities to Disasters. In Commission, P.I.A.G., editor, Suva: Pacific Islands Applied Geoscience Commission, 34.

SOPAC 2006a: Earthquakes. Natural Hazards in the Pacific Fact Sheet, Suva: Pacific Applied Geoscience Commission, 2.

SOPAC 2006b: Landslides. Natural Hazards in the Pacific Fact Sheet, Suva: Pacific Applied Geoscience Commission, 2.

SOPAC 2006c: River Floods. Natural Hazards in the Pacific Fact Sheet, Suva: Pacific Applied Geoscience Commission, 2.

SOPAC 2008: Member Country Briefing Papers Prepared for 3WWF Consultation. Suva: Pacific Islands Applied Geoscience Commission.

Statistics, F.I.B.o. 2007a: Fiji Facts and Figures 2007. Fiji Islands Bureau of Statistics. 
Statistics, F.I.B.o. 2007b: Provisional Results - 2007 and Housing Census. Suva: Fiji Islands Bureau of Statistics.

Sue, D. 2006: Fiji Standard for Forest Managemnet and Certification - Draft. Suva: Fiji Ministry of Fisheries and Forests, 47.

Tawake, A. and Tokalauvere, V. 2007: Fiji Country Mission and Technical Advisory Note: Aggregates Assessment and Community Awareness in Selected Areas of the Navua River. In SOPAC, editor, EU EDF-SOPAC Reducing Vulnerability of Pacific ACP States, Suva: Pacific Applied Geoscience Commission.

Terry, J.P. and Kostaschuk, R.A. 2004: Extreme River Behaviour in the Pacific Islands - Case Studies from Samoa and Fiji. In APHW, editor, The Second Conference of Asia Pacific Association of Hydrology and Water Resources, Kyoto, Japan: Kyoto University Water Resources Research Centre, 10.

Terry, J.P., McGree, S. and Raj, R. 2004: The Exceptional Flooding on Vanua Levu Island, Fiji, during Tropical Cyclone Ami in January 2003. Journal of Natural Disaster Science 26, 27 - 36.

Terry, J.P. and Raj, R. 1999: Island Environment and Landscape Responses to 1997 Tropical Cyclones in Fiji. Pacific Science 53, 16.

Terry, J.P., Raj, R. and Kostaschuk, R.A. 2001: Links between the Southern Oscillation Index and Hydrological Hazards on a Tropical Pacific Island. Pacific Science 55, 275.

Thornton, I. 1996: Krakatau: The destruction and reassembly of an Island Ecosystem. Cambridge: Havard University Press.

Tokalauvere, V. and Biukoto, L. 2003: Proceedings of the 4th National Fiji Multi-Stakeholder Consultations. EU-SOPAC Project: Reducing Vulnerability of Pacific ACP States - 4th National Fiji Multi-Stakeholder Consultations, Navua: South Pacific Applied Geoscience Commission, 39.

Tuiloma, C. 2006: Fiji: A Guide to Obtaining Development and Building Permits. In Planning, T.a.C., editor: Fiji Islands Trade and Investment Board, 22.

Turner, B.L., Matson, P.A., McCarthy, J.J., Corell, R.W., Christensen, L., Eckley, N., Hovelsrud-Broda, G.K., Kasperson, J.X., Kasperson, R.E., Luers, A., Martello, M.L., Mathiesen, S., Naylor, R., Polsky, C., Pulsipher, A., Schiller, A., Selin, H. and Tyler, N. 2003: Illustrating the coupled human-environment system for vulnerability analysis; three case studies. Science and technology for sustainable development, Washington, DC: National Academy of Sciences, 8080-8085. 
UNISDR 1994: Yokohama Strategy and Plan of Action for a Safer World: Guidelines for Natural Disaster Prevention, Preparedness and Mitigation. World Conference on Natural Disaster Reduction Yokohama, Japan, 23-27 May 1994, Yokohama, Japan: UNISDR.

UNISDR 2005: Report of the World Conference on Disaster Reduction. In UNISDR, editor, Second World Conference on Disaster Reduction, Kobe, Hyogo, Japan: United Nations International Strategy for Disaster Reduction.

van Heerden, I.L. 2007: The Failure of the New Orleans Levee System Following Hurricane Katrina and the Pathway Forward. Public Administration Review 67, 24-35.

Varea, S. 2000: Managing the Implementation of the Fiji Study on "Reducing the Impacts of Environmental Emergencies Through Early Warning and Preparedness, The Case of the El Nino Southern Oscillation (ENSO)". In SOPAC, editor, Suva: Pacific Applied Geoscience Commission, 16.

Vuetibau, L. 2001: Major Earthquakes in Fiji. Fiji Mineral Resources Department.

Vuetibau, L. 2003: Tsunamis. Fiji Mineral Resources Department.

Vuetibau, L. 2008: Why the Fiji Microplate is Rotating in an Anticlockwise Direction. In Duaibe, K., editor, Suva: Fiji Mineral Resources Department.

Walsh, A.C. 1976: Navua, 1975: town baseline survey: SSED, USP.

Wheater, H.S. 2006: Flood hazard and management: a UK Perspective. Philosophical Transactions of the Royal Society A 364, 10.

Yachiyo Engineering Co., L. 1998: The Study on Wateshed Management and Flood Control for the Four Major Viti Levu Rivers in the Republic of the FIji Islands: Final Report Summary. Japan International Cooperation Agency and Fiji Ministry of Agriculture, Fisheries and Forests.

Yeo, S., Blong, R.J. and McAneney, K.J. 2007: Flooding in Fiji: findings from a 100-year historical series. Hydrological Sciences 52, 12.

Yeo, S.W. 1998: Controls on Flood Damages, Ba River Valley, Fiji. School of Earth Science: Macquarie University, 280. 